Portland State University

PDXScholar

\title{
Case Study: How an East European Student Learns to Compose in English
}

Ruth Steinfeld Katon

Portland State University

Follow this and additional works at: https://pdxscholar.library.pdx.edu/open_access_etds

Part of the Bilingual, Multilingual, and Multicultural Education Commons Let us know how access to this document benefits you.

\section{Recommended Citation}

Katon, Ruth Steinfeld, "Case Study: How an East European Student Learns to Compose in English" (1994). Dissertations and Theses. Paper 4770.

https://doi.org/10.15760/etd.6654

This Thesis is brought to you for free and open access. It has been accepted for inclusion in Dissertations and Theses by an authorized administrator of PDXScholar. Please contact us if we can make this document more accessible: pdxscholar@pdx.edu. 
THESIS APPROVAL

The abstract and thesis of Ruth Steinfeld Katon for the Master of Arts in TESOL were presented August 10,1994, and accepted by the thesis committee and the department.

COMMITTEE APPROVALS:

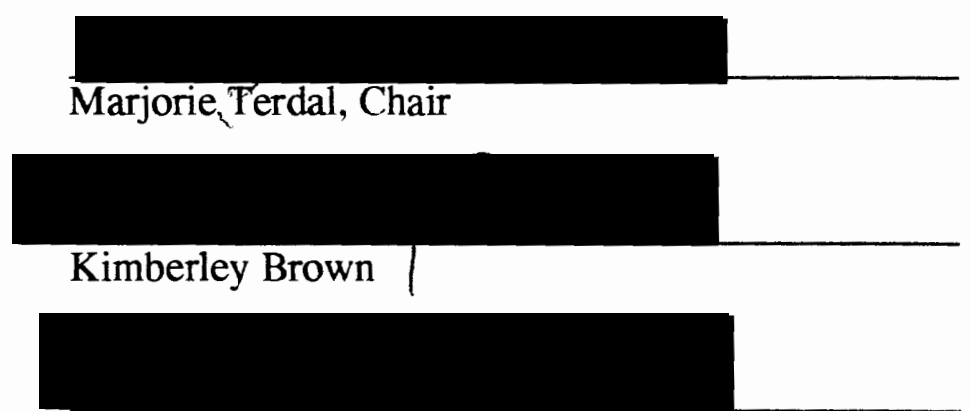

Duncan Carter

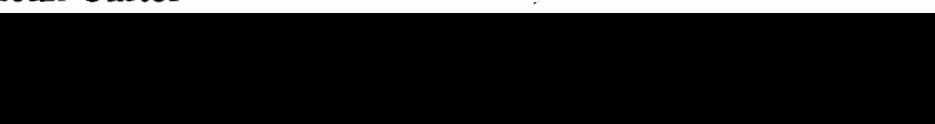

Elaine Limbaugh

Representative of the Office of Graduate Studies

DEPARTMENT APPROVALS:

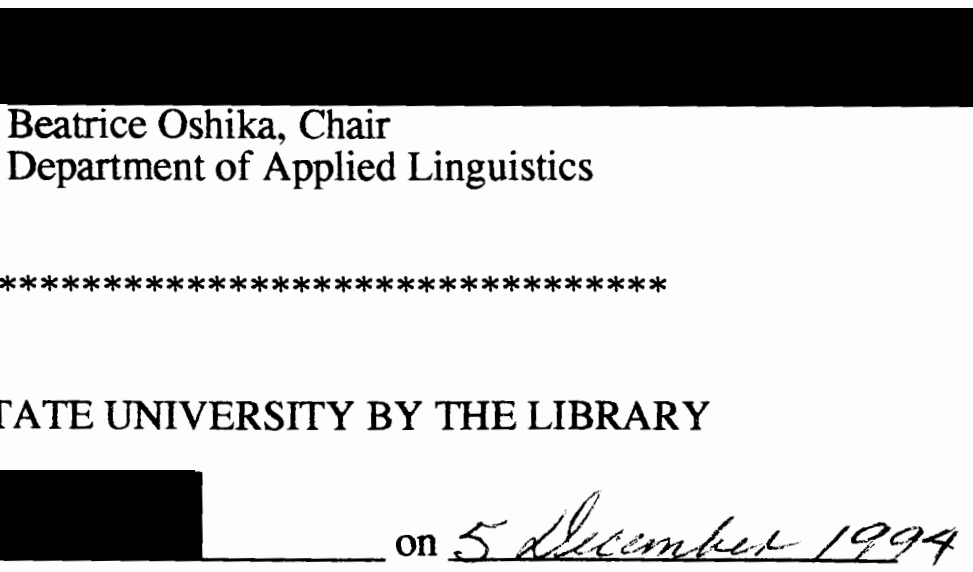

ACCEPTED FOR PORTLAND STATE UNIVERSITY BY THE LIBRARY

by on 5 xhemket 1994 


\begin{abstract}
An abstract of the thesis of Ruth Steinfeld Katon for the Master of Arts in TESOL presented August 10, 1994.
\end{abstract}

Title: Case Study: How An East European Student Learns to Compose in English.

Since the political climate in the former Soviet bloc has shifted, there is an influx of East Europeans to the United States. As these refugees enter the U.S. educational system in greater numbers, teachers must adapt to the special needs of this population. The intent of this study is to focus on the composing skills of a Polish student who enrolled in an English for Non-Native Residents (ENNR) program at an urban university. The investigation examines the contextual framework that supports the subject's literacy experiences by means of a longitudinal case study format. Several ethnographic and experimental techniques are used to explore three areas of interest: cultural context, the learning situation, and the composing processes. Multiple sources of data are used to investigate culture and learning, and a single elicitation technique is applied to the study of the writing process.

Study of the cultural context suggests that the subject's early education and literacy experiences in Poland strongly influenced her development as a writer of English. Investigation of the classroom context at the university revealed both her preferences and frustrations with teaching and learning experiences. 
The primary focus of this study is exploration of writing process by means of a think-aloud protocol. The subject was asked to speak aloud while composing an essay on a narrative topic. She was instructed to say everything that came to mind while writing, and the session was videotaped for later analysis. A coding system was developed to help identify various components of the writing process, such as planning, commenting, rereading and pauses. Writing strategies, repetitions, fillers, revisions, verbal rehearsing, and quantity of words were identified according to frequency and location within the protocol.

The results of the protocol analysis suggest that composing is not a neat and tidy process, but a complex configuration of multiple strategies. In the early stages simple patterns such as comments, planning, and fillers help the subject get started. A cycle of patterns, which seem automatic and deeply embedded, occurs throughout. These pattems emerge as Writing-Rehearsing-Pausing events. Each of these categories contains within a multitude of behaviors, such as pausing to think, rereading, and trying out new ideas. The data reveal numerous efforts at surface editing, yet the final product contains an average of 2.8 errors per sentence. The findings suggest that a writer's strategies and goals may shift during a controlled writing situation, and that inital steps may differ from those needed to attain closure. They suggest that attempts at surface revisions may not, in fact, improve the final product. 


\title{
CASE STUDY:
}

\section{HOW AN EAST EUROPEAN STUDENT LEARNS TO COMPOSE IN ENGLISH}

\author{
by \\ RUTH STEINFELD KATON
}

A thesis submitted in partial fulfilment of the requirements for the degree of

\section{MASTER OF ARTS}

in

TESOL

Portland State University

1994 


\section{DEDICATION}

To my husband, Ron, who provided the inspiration and the love that guided this project through to completion, I dedicate this thesis. 


\section{ACKNOWLEDGEMENTS}

My sincerest thanks goes to my subject, "Enya," who rewarded me with her trust and friendship, while providing the data that made this project possible. I also extend my appreciation to the friends and family members who supported me along the way. Additional credit goes to my thesis committee members, Kimberley Brown, Duncan Carter, and Elaine Limbaugh, for their encouragement and suggestions. I owe a special debt of gratitude to my thesis advisor, Marjorie Terdal, who guided and motivated me with patience and wisdom, towards this goal. Special thanks to Laura McKinney for her invaluable computer assistance during the final editing stages. Finally, and most importantly, this project could not have been realized without the steadfast moral support of my husband, Ron. 


\section{TABLE OF CONTENTS}

LIST OF TABLES

LIST OF FIGURES …................................................................................................

CHAPTER PAGE

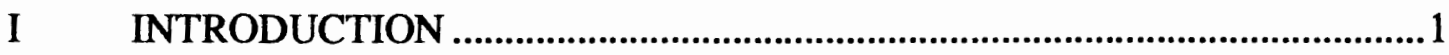

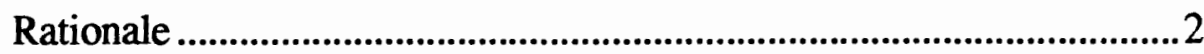

Guiding Questions .................................................................................

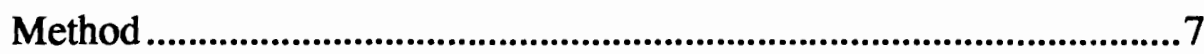

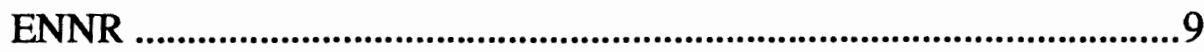

Subject Selection ...............................................................................11

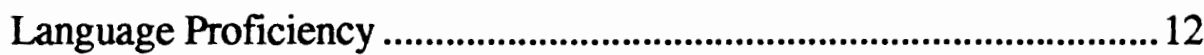

Timeline for Data Collection ................................................................13

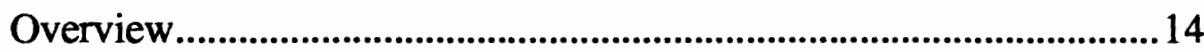

Writing Process Research .................................................................14

II WRITING PROCESS RESEARCH IN ESL .............................................15

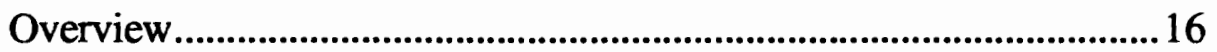

Studies of the Composing Process..........................................................18

Cognitive Science and Composing Process..........................................19

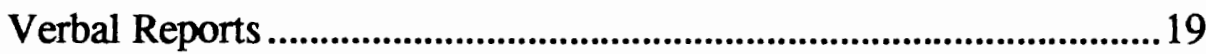

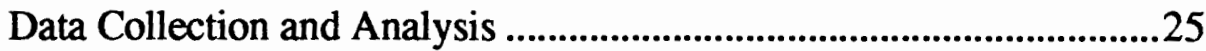

Composing Processes Model .................................................................30

Cognitive Processes Model.......................................................................31 
Toward a Model of Composing in L2 _.................................................

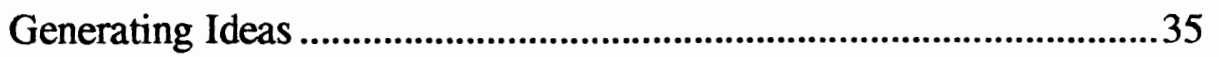

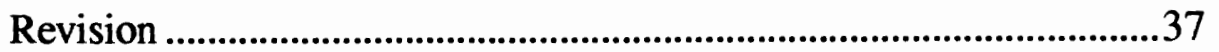

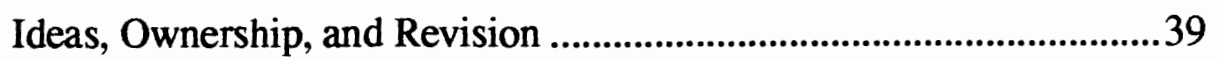

ESL Composition Research Summary ...............................................41

L1 Use in L2 Composing.................................................................41

Transfer of L1 to L2 Writing Skills.......................................................42

What is Known About Composing in ESL?...........................................43

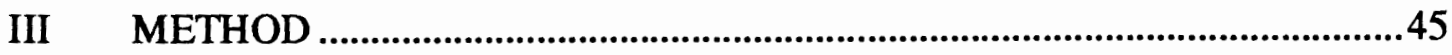

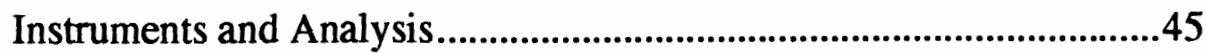

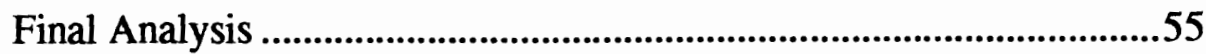

IV CULTURAL CONTEXT - EDUCATION AND LITERACY .......................57

Polish Politics and Education ..............................................................58

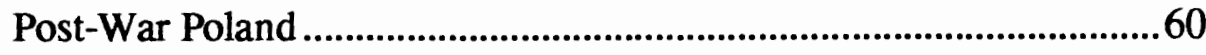

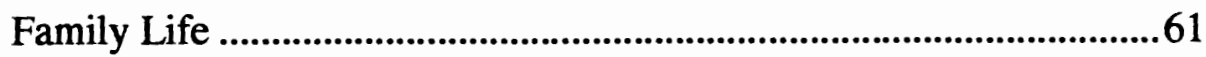

First Language Interview ...............................................................62

Polish vs. English Writing Instruction ....................................................63

Printed Materials Survey ........................................................................70

48 Hour Writing Diary ..............................................................................72

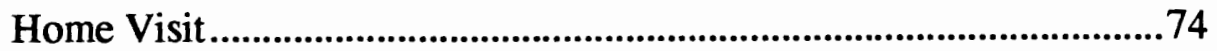

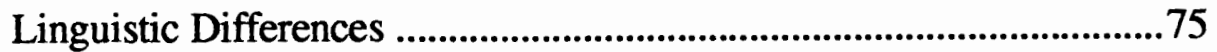

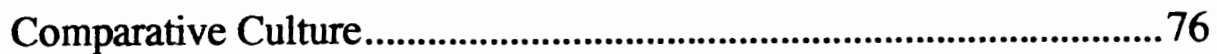

Discussion of Culture ..........................................................................77 
V THE LEARNING SITUATION-

CONTEMPORANEOUS ACADEMIC LITERACY …..................................8

Classroom Observations - Limitations and Advantages .......................80

Classroom Observations- Winter Term .............................................82

Classroom Observations - Spring Term ...........................................83

Observations at the Word Processor.........................................................84

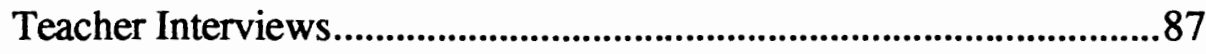

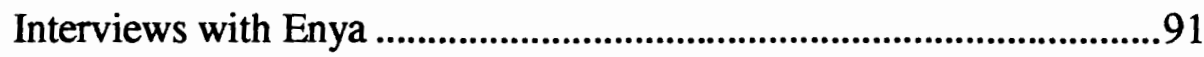

Holistic Evaluations of Student Essays .............................................93

Discussion of Holistic Evaluations ......................................................96

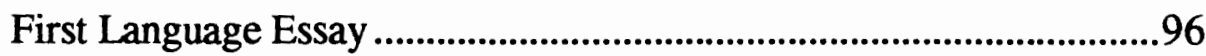

Questionnaire About First Language Composing .................................98

Language Learning Strategies ...........................................................99

Case Study of Yourself as a Writer ..................................................102

"Case Study" Self Profile.................................................................106

VI THINK-ALOUD PROTOCOL-

A LOOK INTO ENYA'S WRITING PROCESS ..........................................108

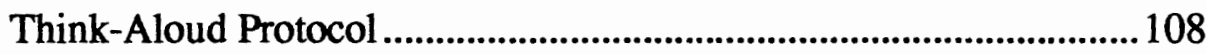

What and When...But Not Why ...........................................................109

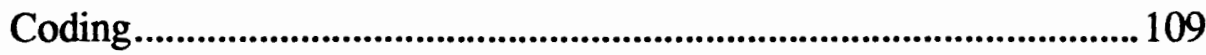

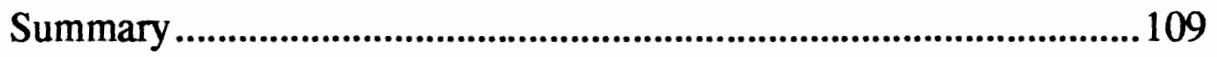

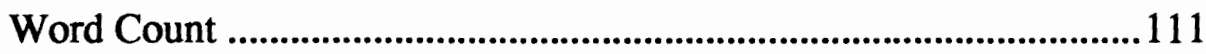

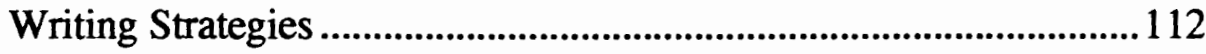

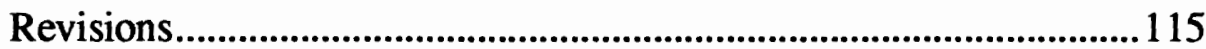

Verbal Rehearsing ...............................................................................117 


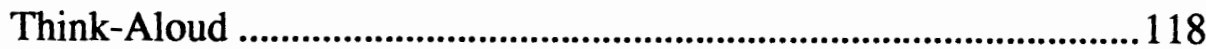

Towards an Integrated Perspective ....................................................120

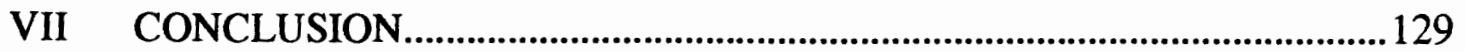

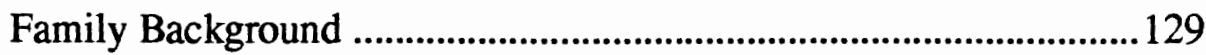

Adult Personal History ......................................................................130

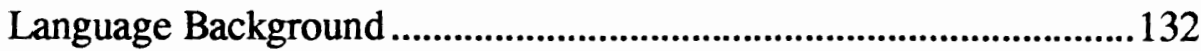

Intellectual Background ....................................................................133

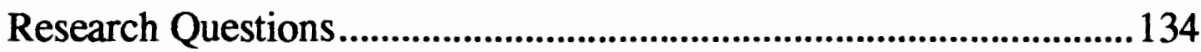

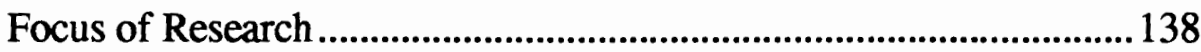

Areas for Further Study .................................................................139

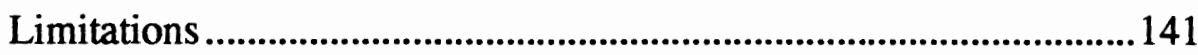

Suggestions for Teaching ................................................................. 143

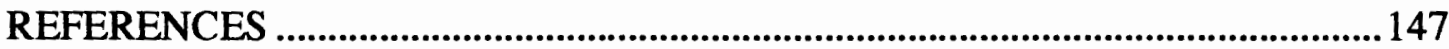

APPENDICES

A PERSONAL INFORMATION............................................. 153

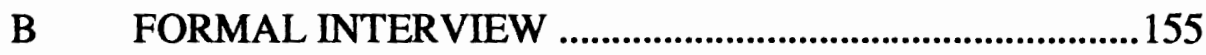

C SAMPLE - 48 HOUR DIARY .............................................158

D HOLISTIC EVALUATIONS .............................................. 161

E SAMPLE ENNR ESSAYS.................................................166

F FIRST LANGUAGE ESSAY ..............................................177

G CASE STUDY OF YOURSELF AS A WRITER ...................180

H ORIGINAL AND REPLICATED ESSAYS ..........................186

I TRANSCRIPTION OF AUDIO PORTION OF

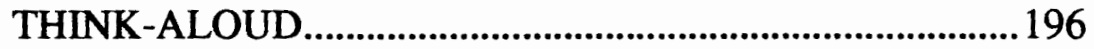


J TRANSCRIPTION OF FINAL PRODUCT ….......................205

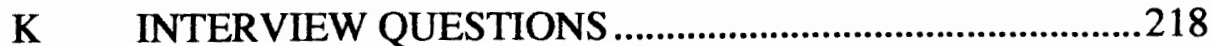




\section{LIST OF TABLES}

TABLE

PAGE

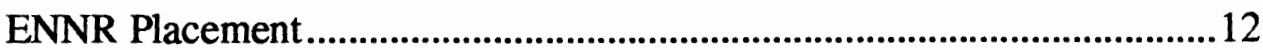

II Enya's Language Proficiency Scores ....................................................13

III Printed Materials Survey ....................................................................

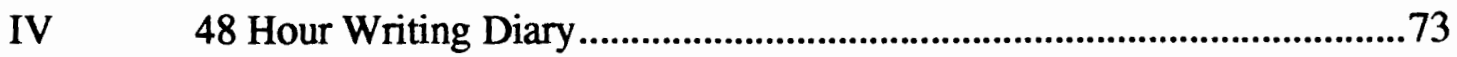

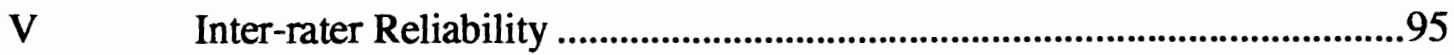

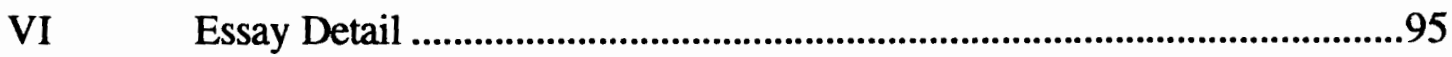

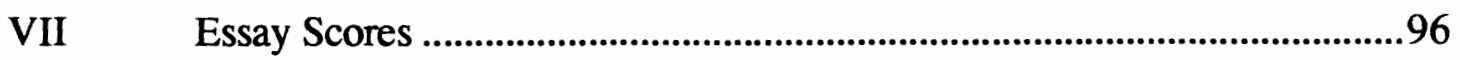

VIII Enya's Strategy Inventory for Language Leaming (SILL) Profile ............100

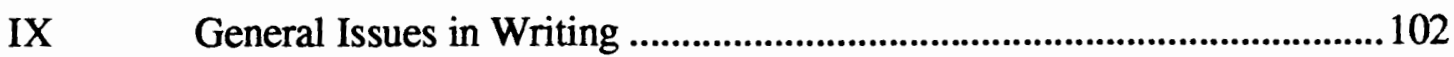

$\mathrm{X} \quad$ Summary of Think-Aloud Data .........................................................110

XI Word Count .................................................................................112

XII Writing Strategies ..........................................................................112

XIII Revision Within Sentences .............................................................116

XIV Revision Between Sentences ........................................................116

XV Verbal Rehearsing ..............................................................................118

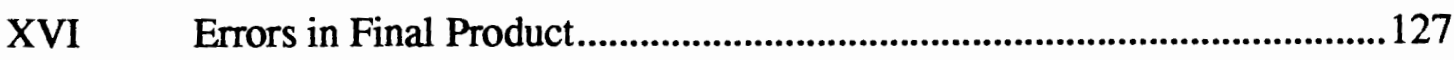

XVII Think-Aloud Comparison of Writing Process in 3 Studies .......................128

XVIII Enya's Estimated vs. Actual Writing Process ...........................................135 


\section{LIST OF FIGURES}

\section{FIGURE}

PAGE

1. Here to There Research Methodology ….......................................................

2. Frequency and Timing of Think-Aloud Events..........................................124 


\section{CHAPTER I \\ INTRODUCTION}

The intention of this thesis is to examine how a particular Eastern European student learns to compose in English. My interest in the topic developed after working as a practicum student, and later as a teaching assistant in a university program for non-native speakers of English. During that time, I was teaching a writing class in which $42 \%$ of the students were non-Southeast Asians. One of these individuals was a 34-year-old Polish woman whose multiple roles included working wife, mother and student.

At the urban university in the Pacific Northwest where this study takes place, a steady stream of Soviet and Eastern Europeans has joined the Southeast Asian population. These groups are studying side by side in the English for Non-Native Residents (ENNR) program. The demographics in ENNR are undergoing a slight shift with the influx of this new group of immigrants, and consequently, Eastern Europeans are likely to have a strong impact on the ENNR program in the future. What is the nature of Eastern European students, and how will they affect what is taught and learned in ENNR? In the past, much attention has focused on the needs, values, and cultural background of Southeast Asian students. Until recently, academic research about the ENNR program focused exclusively on this group. Assessment of statewide immigration patterns suggests that in the future a substantial number of Soviet and Eastern European students will enroll in the ENNR program. The purpose of this study is to describe and understand this newcomer to the university, the Eastern European student. 


\section{RATIONALE}

Prior to $1978,100 \%$ of this state's immigrant population was Southeast Asian. During the following decade, other ethnic groups began to arrive from the former Soviet Union, the Eastern Bloc and other regions of strife. By 1988, immigration of non-Southeast Asian groups, boosted by a large influx of Soviet émigrés, equaled the Southeast Asian population. As of 1992, statewide non-Southeast Asian immigration accounted for $63 \%$ of new arrivals, with Soviets comprising 54\%, Eastern Europeans, $4 \%$, and others, $5 \%$. Southeast Asian groups accounted for only 37\% (Kanal, 1993).

Although the political climate is changing in Eastern Europe and the former Soviet Union, relaxation of emigration restrictions makes it likely that people will continue to leave. It is likely that their destination of choice will be the United States, since U.S. refugee policy supports the reuniting of families. The trend towards resettlement in the region in which this study takes place is indicated by statewide and local figures. From 1988-1994, the state admitted 5,814 refugees from former Soviet countries (The Oregonian, June 26, 1994). As of January, 1993, about 4,000 Soviet immigrants had settled in the metropolitan area (Willamette Week, 1993).

As a group, Southeast Asians tend to be political refugees, fleeing for their lives from violence and corruption. In contrast, Soviet and Eastern European arrivals in recent years are seeking asylum for religious and economic reasons, and not because their lives are in immediate danger. Eastern Europeans differ from the Southeast Asian population in other respects as well. Their western cultural background is more similar to United States culture than that of the Southeast Asians. Racially, they fit in with mainstream America. Their formal educations have not been disrupted by cycles of war and violence, and they achieved universal literacy under 
Communism. Their studies in philosophy, literature, religion, and technology share certain commonalities with education in their adopted country. Even their native languages, with few exceptions, relate more closely to English. As part of the former Soviet Union, many Eastern Europeans were required to study Russian in addition to their native language, making knowledge of a second language an integral part of their schooling. Many are already experienced language learners when they begin to study English. Noting marked differences between eastern European and Southeast Asian students in ENNR, I became curious to find out if certain advantages existed for European students in an academic environment. Since the explicit goal of ENNR is to improve the literacy skills of non-native speakers of English, this report selects a single aspect of academic literacy, the study of writing.

At the university where this study takes place, until now, few research projects in Teaching English to Speakers of Other Languages (TESOL) have focused specifically on Soviet or Eastern European students. Therefore, I decided to concentrate my inquiry on a student representing one of these ethnic groups, a Polish woman. This thesis presents a case study of an individual, and explores three areas relevant to ENNR. It investigates the following aspects of her life: cultural context, the academic learning situation, and the composing process. The cornerstone of my investigation of composing was videotaping and transcribing a think-aloud protocol, which was then analyzed and evaluated. It focuses specifically on how the Polish subject learns to compose in English, by investigating the contextual fabric supporting her literacy experiences. 


\section{THEORETICAL BACKGROUND}

The framework for this research evolves from theories in two areas, ethnography and the writing processes. The study of culture is the cornerstone of ethnography. The role of culture in explaining how instruction and learning are interrelated was highlighted by Vygotsky (1978). In his view, language is a tool which shapes and is shaped by culture.

The rationale for applying ethnographic techniques to second language $\left(\mathrm{L}_{2}\right)$ research is based on a model of language learning through interaction. This theory hypothesizes that language learning is language socialization more than language acquisition (Watson-Gegeo, 1988). Therefore, a researcher's attention should focus on the "other things" that are learned and taught along with language form and structure.

A widely accepted definition of ethnography is one that places it squarely within the domain of $L_{2}$ inquiry. This perspective, supported by Van Lier (1988) and others, places special emphasis on the learning of communication within a particular speech community. It focuses on "what" is learned, "how" it is learned, and "where" (in what context) it is learned (Van Lier, 1988). Functional aspects of written communication vary between groups. For recently arrived immigrants, writing is very important in a practical sense. In survival skills programs, first, they use writing to fill out forms and applications. Next, they learn to write résumés and letters to help them find jobs. Later, the types, functions, and uses of writing vary according to the particular group culture (Heath, 1983). University students, for example, use writing to take notes in their classes, to relay information, to take examinations, and to fulfill academic requirements. 
Along with ethnography, theories of composing help to structure this research project. In the 1970's the view of writing as a linear process was reassessed, and supplanted by a new concept of writing as an act of discovery. Investigators such as Pianko (1979), Sommers (1980), Perl (1979), and Schumacher et al (1984), in first language ( $\left.\mathrm{L}_{1}\right)$ studies, and Raimes (1985), Brooks (1985), and Zamel (1987,) in $\mathrm{L}_{2}$, charted new directions for the teaching of writing. Key studies of the composing process are discussed in detail in Chapter II.

\section{GUIDING QUESTIONS}

The main purpose of this research is to examine and describe how one Eastern European student learns to compose in English. The subunits explore three aspects of the subject's literacy experiences, including cultural context, the learning situation, and the composing process. Some guiding questions will help to systematize the study.

\section{Cultural Context}

This section of the study explores the subject's past and focuses on Polish culture, family background, and early literacy experiences. It is based on the proposition that culture and language learning are closely related, and that the values, attitudes and beliefs of a native culture influence one's perceptions towards an adopted culture. What are the attitudes of Polish culture towards literacy, and how do these attitudes influence the subject's development as a writer of English? What value did her family place on education? What kind of formal education did she have in her native country? How can knowledge of her first language background help an ENNR instructor to provide effective teaching and learning for this student? 


\section{Learning Situation}

This section examines the subject's recent academic career as a student of English, and focuses on some of the teaching and learning events which have transpired in the university setting. It is based on the proposition that learning takes place in the context of the classroom environment, and that learning and communication are interconnected. The types of interaction which occur in the classroom and university setting affect the content of what is learned. How does the subject assess herself as a student of writing, and how do experienced instructors evaluate her skills? What kinds of interaction occur in the classroom, and how do they affect what is learned? Is the subject a proficient writer in $\mathrm{L}_{1}$, and how does that skill compare with her proficiency in English? How proficient is she as a writer of English? Does she compose differently at the word processor than when using pen and ink? What are her leaming strategies? How can a writing instructor use information about the subject's academic strengths and weaknesses to help plan for future writing instruction?

\section{Composing Process}

This section explores the actual composing processes which take place while writing. It is based on the proposition that observation and analysis of real-time writing yield objective data about the thought processes and patterns which occur during composing. Writing is conceptualized as a complex activity consisting of both observable and non-observable behaviors. Observable behaviors can be recorded, counted and analyzed, and include activities such as transcribing, reading, pausing, 
editing and revising. Non-observable behaviors include planning, thinking and generating ideas.

In order to externalize the unobservable aspects of composing, an experimental technique called "think-aloud" (Perl, 1979) is used. Think-aloud is a form of verbal report in which the subject is instructed to say everything that comes to mind while she writes. The assumption is that oral composing reflects a sequence of thoughts, and that these thoughts represent underlying cognitive processes. The researcher interprets the verbalizations as transitions or connectors between what is thought and what is set down on paper. The next step is to identify the patterns that occur during writing. What basic writing patterns does the student use? Does she employ prewriting, planning, rereading, revising and/or reflection? To what extent does she use these strategies, and how effectively?

How can observation of a single student help add to the body of knowledge about writing in general and about second (or third) language composing in particular? Are the experiences of this learner consistent with findings of other studies in the field? Is oral composing a good research tool, and does it have potential as an effective instructional technique as well?

\section{METHOD}

This report uses a case study approach which focuses on an individual learner. The framework for the research is a single case study design, and the rationale for using this format is that it offers the opportunity to explore a unique situation, or the revelatory case. Furthermore, case study design was selected because it is flexible, and can be adapted to suit the purposes of the research. Case study structure offers an action plan for getting from "here" to "there" (Yin, 1984). 
HERE(Initial set of questions)

\section{$\uparrow \uparrow \uparrow$}

(Set of major steps, including collection \& analysis of relevant data)
-THERE

(Set of conclusions

or answers to these questions)

Figure 1. Research methodology.

According to D. Johnson (1992), case studies share four features. First, they are generally qualitative, but may involve some quantification. Second, they are primarily naturalistic, but often use procedures to elicit specific data. Third, they are basically descriptive, yet may transcend description by making contextual or cultural interpretations. Fourth, they are often longitudinal, but may be time-limited.

The guiding questions in this type of study become refined as the research progresses. The key is to focus holistically on the individual learner, someone both dynamic and complex. The subject's view, and not the researcher's, determines the boundaries of the system. The challenge is to explore and understand the entire context, yet to draw out only those features which relate to the purposes of the study, in this case, learning to compose in a second (or third) language.

The data for this case study are both natural and elicited. Naturalistic observations were done in the classroom and home environment. Elicitation techniques were used in observations at the word processor, and during structured and unstructured interviews. Verbal reports of the subject's own thinking were collected to find out more about her composing processes, learning strategies, and writing profile. A think-aloud protocol, discussed above, was the backbone of exploration of the 
writing process. Many written materials were collected, including surveys, school writing, home writing, notes, letters and multiple drafts of essays.

According to Van Lier (1988, p.57), "To my knowledge there is as yet no reported case of a successful integration of experimental and ethnographic work, though it is clearly important to explore this possibility." This investigator takes on Van Lier's challenge by using ethnography and quasi-experimental techniques to explore the writing background of the case study subject. Van Lier further explains, "For the classroom teacher such combined research can be very beneficial, since it ensures that contextual variables, and the actual work that is done in the classroom are taken into due consideration" (1988, p.59). Moreover, it provides the opportunity to generate hypotheses in multiple areas of study, and perhaps discover congruence between them.

\section{ENNR}

The ENNR program at the university where the study took place is a threeterm sequence which functions as a support program for non-native residents whose Verbal Scholastic Aptitude Test scores and Test of Standard Written English (TSWE) scores fall below those required for regular admission to the university. Non-native resident students who score below 350 on the Verbal SATs or below 35 on the TSWE are encouraged to take ENNR. Placement within ENNR is determined by the student's score on the Michigan Test of English Language Proficiency, a retired non-secure version that is not to be confused with the Michigan Assessment battery. Students with scores from 49 to 64 are placed in Intermediate-1. Those whose scores range from 65 to 75 are placed in Intermediate-2. Students who score between 76 and 80 are assigned to Advanced Intermediate level. 
As a political refugee from a Communist country, Enya (a pseudonym, as are all names in this study) was a permanent United States resident. Permanent resident status was the basis of her eligibility to enroll in ENNR classes. Since Enya was not a recent graduate of an American high school, she was exempt from taking the SAT, and other criteria determined her placement in the program.

As a graduate student in Spring 1989, the investigator did a practicum in the English for Non-Native Residents (ENNR) program at the northwestern university where this project took place. The position required two hours of teaching per week under the supervision of a more experienced instructor who taught the same students for four hours per week. The textbook used for this Intermediate-2 level was The Random House Writing Course for ESL Students (A. Tucker \& J. Costello, 1985). In Fall 1989, the researcher worked as an ENNR Teaching Assistant in Intermediate 1. The required text was A Writer's Workbook : An Interactive Writing Text For ESL Students (Smoke, T., 1987).

The ENNR program was instituted in Fall 1984. During the ten year existence of the ENNR program, the student population has been overwhelmingly Southeast Asian. These are university freshman, who as children, were uprooted from their homes in war-torn countries such as Vietnam, Cambodia, and Laos. Their families sought political asylum in the United States, and the children grew up and graduated from local public high schools.

The phenomenon of East Europeans participating in the ENNR program is relatively recent. In recent years a few Czechoslovakian and Romanian students enrolled. In 1988, the subject's husband, Marek, was the only Polish student in ENNR. One year later, in Fall 1989, there were two sections of ENNR Intermediate-1. In the 
investigator's class there were two East Europeans, one of whom was the subject, Enya. In the other section there was one East European.

\section{SUBJECT SELECTION}

The subject was selected because she was not representative of the typical ENNR population. She was different from the average ENNR student in many ways, and her uniqueness created an aura of interest. She was a thirty-four year old married mother of two, in classes where most students were recent high school graduates. Her cultural background was East European, whereas most of the students were of Southeast Asian origin. This researcher and two other ENNR instructors were impressed with her rapid progress as a writing student.

Enya entered the ENNR program in Fall 1988, but was immediately forced to drop out when her son became ill. She re-enrolled in beginning level during Fall 1989 and successfully completed ENNR in Spring 1990. This was her first admission to a university in the United States, and her first experience with formal English instruction. The researcher was her instructor in Intermediate-1, the first of the three course sequence.

Enya, a native of Poland, was not new to the study of foreign language. Growing up in a nation dominated by the Soviet Union, she began studying Russian as a required course in fifth grade, and studied it through twelfth grade. She studied two additional years at college level, for a total of ten years of formal training in Russian. In 1984 she moved to Germany with her husband and young son. During that time she learned German in community-based language classes, but insists that she never liked it, nor spoke it well. 
During the first year she lived in the United States, she worked nights as a janitor and spent her days as a homemaker and mother of two young children. In Fall 1989, when her children entered school and daycare, she taught Russian part time for a private language school. Spring term, as an admitted student, she qualified for workstudy and took a job at the university library. She spent the summer of 1990 working as a Russian and Polish interpreter at the International Refugee Center of Oregon (IRCO). At that time, IRCO was receiving many Soviet émigré clients, and Enya was hired because of her fluency in Russian.

\section{LANGUAGE PROFICIENCY AND LANGUAGE PROFICIENCY SCORES}

In August, 1988, Enya was tested for placement within the ENNR program. Two standardized tests and a writing sample help determine which of the three ENNR levels a student is required to take, Lower Intermediate (I-1), Intermediate (I-2), or Advanced. The examinations given prior to entry are the Comprehensive English Language Test for Speakers of English as a Second Language (CELT), and the Michigan Test of English Language Proficiency. Students are assigned to one of three levels on the basis of the Michigan as Table I illustrates:

\section{TABLE I}

\section{ENNR PLACEMENT}

\begin{tabular}{|l|c|}
\hline ENNR Level & Michigan Score \\
\hline Lower Intermediate (I-1) & $49--64$ \\
\hline Intermediate (I-2) & $65--75$ \\
\hline Advanced & $75--80$ \\
\hline
\end{tabular}

However, a student's performance on the writing sample is taken into consideration. During the time of this study, students whose CELT scores fall below 
90 were required to take a 2 hour/week non-credit lab in listening comprehension and note taking practice. Enya's scores on the language proficiency examinations are indicated in Table II as follows:

TABLE II

\section{ENYA'S LANGUAGE PROFICIENCY SCORES}

\begin{tabular}{|l|l|}
\hline Instrument & Rating \\
\hline Michigan & 65 \\
\hline Writing & M-(Medium Low) \\
\hline CELT & 78 \\
\hline
\end{tabular}

At that time, Enya intended to enroll at the university in Fall 1988. However, the illness of one of her children interrupted her plans and postponed admission for one year. She entered the program in Fall 1989, and since her Michigan score was borderline, and her writing assessment was medium-low, she was placed in ENNR Intermediate-1. Although her CELT score indicated eligibility for the supplementary lab in listening comprehension, she did not enroll in that course due to scheduling conflicts.

\section{TIMELINE FOR DATA COLLECTION}

Data collection occurred over a six-month period, from January to July, 1990. During Fall, 1991, the subject separated from her husband and transferred to the University of Hawaii at Hilo, where she studied for one academic year. Long distance follow up telephone interviews were conducted during Winter and Spring 1992, when the subject was residing in Hawaii with her children. Rating of a first language essay and holistic evaluations of three English compositions took place in Spring 1992. 


\section{OVERVIEW}

The purpose of the case study is to take an in-depth look at an individual's writing and to reconcile it with current theories of cognitive, psycho-social and sociocultural aspects of language acquisition. The perspective of this study is twofold. It examines the subject's development as a writer through a dual lens. The macro lens looks at the subject in totality, from an historical, psycho-social and cultural perspective. It examines many things happening all at once, spanning memories and years. In the words of anthropologist Edward Hall (1969), it operates in "polychronic time. " On the other hand, the micro lens focuses on the here and now, the immediacy of the moment, the day-to-day writing experiences and events in her life. It operates in "monochronic time" (M-time).

\section{WRITING PROCESS RESEARCH}

In the present study, the instrument selected to function as a micro lens is the think-aloud protocol. It focuses intently on the event of composing in the present. In this respect, it differs from introspective techniques, which rely on the subject's sometimes faulty recall of past events. Instead, the thoughts that occur during writing are quickly transposed into words, and the patential problem of time lapse is eliminated. The effect is to bring the researcher closer to the actual mental processes that occur during composing. There has been debate among researchers about the best way to access the complex cognitive processes a writer uses. There has also been debate, in the history of composing research, about the nature of writing, and the best methods for teaching writing. These topics are discussed in the following chapter, a review of research into the field of writing. 


\section{CHAPTER II \\ WRITING PROCESS RESEARCH IN ESL}

Comprehension of the nature of composing in a second language $\left(\mathrm{L}_{2}\right)$ begins with an understanding of first language $\left(L_{1}\right)$ research. There are many similarities between first and second language composing that justify a close look at the theory and practice that inform $L_{1}$ writing pedagogy. The basic features of writingplanning, looking back in order to move forward, making changes, and discovering meaning - are themes common to both disciplines (Zamel, 1983; Raimes, 1987).

Process oriented $\mathrm{L}_{1}$ pedagogy has permeated $\mathrm{L}_{2}$ classrooms. Second language researchers such as Lay (1982), Zamel (1983), and Jones (1985) assert that many of the same strategies employed by native learners are also present in the composing processes of $\mathrm{L}_{2}$ learners. Jones (1985) argues that many instructional techniques for enhancing $L_{1}$ writing are also effective in helping $L_{2}$ learners. Urzua (1987), in her assessment of process oriented pedagogy, indicates that the process strategies taught in $\mathrm{L}_{1}$ classrooms are applicable as well in $\mathrm{L}_{2}$ classrooms.

What goes into the process of writing in a first or second language? What are the cognitive processes, language learning strategies, learner variables and social factors that affect one's ability to compose? These are relatively recent questions, since thirty years ago researchers were less interested in investigating the learner, than the writing he or she produced. Focusing on the learner is a modern development as may be seen in a brief overview of composition pedagogy and research during the last thirty years. 


\section{OVERVIEW}

Until the late 1960's the focus of composition research was on the end result. Typical research of the day described written products and tested various experimental treatments to see which would yield a superior outcome (Freedman, 1987). Curriculum reflected research by offering suggestions for activities that would produce particular sorts of writing. Writing in English was based on the classical model, and the goal of instruction was prescriptive. Focus was on accuracy and correctness, systematically taught.

\section{Behaviorism and Error Production}

In the early 1970 's research called into question prevailing theories of language learning. Until then, teachers, guided by the predominant behaviorist concept of habit formation, encouraged students to avoid errors at all costs. Second language acquisition theory, influenced by the contrastive analysis hypothesis (CAH), attributed errors to first language interference (Silva, 1990). Two versions of the contrastive analysis hypothesis arose, the weak and the strong. The weak version applied contrastive analysis after errors were produced to help teachers understand the differences between the native and target languages in the learning situation. The strong version argued that contrastive analysis could be used to predict errors prior to production (Brown, 1987). A study by Whitman and Jackson (1972) produced persuasive evidence against the strong $\mathrm{CAH}$ version. Researchers estimated the comparative difficulty of grammar test items, and then examined 2500 students. When the test results were compared with the predictions, the researchers found that contrastive analysis failed to predict language interference. 


\section{Prescriptivism and Rhetoric}

In addition to challenging theories of error production, research began to question traditional instructional practices. A 1970 study by Meade and Ellis investigated topic sentences to test whether the prescriptive advice that good paragraphs contain good topic sentences, was in effect applied by professional writers. Their findings challenged the idea that skilled writers adhered to standard textbook guidelines. When researchers began to discover contradictions between what writers actually do and what textbooks say they ought to do, they began looking for a more comprehensive framework (Bridwell \& Beach, 1984).

\section{Towards a Process Approach}

The framework that began to take shape in the 1970's reflected a paradigm shift in composition theory. Attention now shifted from the written product to the process of composing. In 1971, Emig published a landmark study entitled "The Composing Processes of Twelfth Graders" in which she used a case study approach to explore the behavior of writers. Her research, revolutionary in design and provocative in its implications, led the way for new theoretical perspectives. She opened the way for future research by pioneering think-aloud protocol study, and by using multiple sources of data.

In composition research the protocol analysis method has provided an effective window on the composing process. Composing aloud is a way to examine the cognitive processes that take place during writing. A more complete discussion of the theory behind think-aloud composing follows in the sections on Verbal Reports and Cognitive Science. 
Emig audiotaped eight above average high school students as they composed aloud. She gathered additional data from notes which she took while observing the composing sessions, from post writing interviews, and from the students' preliminary notes, outlines and finished products. Contrary to the conventional pedagogical wisdom of the day, her findings indicated that advanced students did little planning and revising on school sponsored topics. She was the first investigator to use the term "recursive" to describe writing processes. Emig's rigor and approach promoted a "science consciousness," which has sustained composition research through the present (Krapels, 1990).

\section{STUDIES OF THE COMPOSING PROCESS}

Since Emig, many have studied writing processes. A study by Pianko (1979) replicated Emig's methodology, but with different types of subjects. Emig's subjects were advanced students, but Pianko 's were a cross-section of "traditional" or "remedial" college students. Like Emig, she found that most writers spend a very brief time prewriting, and that most planning is done during, not prior to, composing. She also supported Emig's contention that writing behaviors occur in linear stages: prewriting, planning, composing (pausing and rescanning), stopping, and contemplating the finished product. Subsequent research was to challenge the linear stage model of composing.

Pianko's study broke new ground in distinguishing between more and less proficient writers. She found that skilled writers had the ability to reflect more on what had been written. Many subsequent studies differentiated between expert and novice writers. In first language studies $\left(L_{1}\right)$ the following investigators (Flower, 1979; Perl, 1979; Sommers, 1980; Schumacher et al, 1984) also made this distinction. In second 
language studies $\left(\mathrm{L}_{2}\right)$ numerous researchers (Brooks, 1985; Abraham \& Vann, 1987; Raimes, 1987; Zamel, 1983) differentiate experts from novices. Implications of the findings of expert/novice studies will be discussed later in this chapter.

\section{COGNITIVE SCIENCE AND COMPOSING PROCESSES}

The field of cognitive science contributed widely to composition research. The cognitivists asked: Why do we learn what we learn? Is learning a function of repetition, comprehension, or linking new material to old? What are the organizing, or metacognitive, principles of the mind?

Even in the era of behaviorism, evidence was accumulating that the mind was not an empty black box. Rather, it was filled with cognitive devices of some kind or another. What these devices did to the input accounted for the output. Information processing theory shows the relationship between input and output, and how incoming information moves from one process to the next. Even though cognitive scientists cannot look directly into the black box, they can use several methods to infer what operations are taking place. One of these methods is the verbal report.

\section{VERBAL REPORTS: PRO AND CON}

A basic tool of cognitive science is an introspective research technique known as the verbal report. The verbal report is a process tracing device to find out what the subject is thinking and what patterns are revealed in his or her composing. Cohen (1987) identifies three categories of verbal report: self-report, self-observation report, and self-revealment. Discussions of verbal report in this paper are limited to selfrevealment methods, specifically, using think-aloud protocol as a research technique. 
What are the advantages and disadvantages to the think-aloud technique? The enthusiasts' position on protocol analysis is summarized by Hunt (1982):

Protocol analysis is very different from the introspective technique used unsuccessfully early in the century. For one thing, subjects don't look back and comment on the thoughts that have passed through their minds; instead they simply turn those thoughts into words as quickly as possible. This brings researchers in touch with - or only one remove from- the actual events... the subjects are conscious of; what remains unspoken can often be inferred. By analyzing the content of the protocol, step by step, researchers can see patterns that either confirm or disconfirm a hypothesis... or that lead them to construct one. (p. 78)

Yet questions remain. How different from other techniques is protocol analysis? How closely related to the verbalized thoughts are the underlying processes? How do investigators scientifically analyze the protocols? How can think-aloud data be used to test or build hypotheses? What effect does a particular topic have on the task? How does a researcher instruct a subject in the technique? What is the justification for using think-aloud with second language learners who are not proficient speakers?

The debate over verbal report data revolves around several issues. Among these concerns are: 1 . absence of a naturalistic experimental environment, 2. accessibility of hidden mental processes, 3 . integrity and completeness of tracing processes, and 4. scientific method in collecting and analyzing data (Ericsson \& Simon, 1980; Hayes \& Flower, 1983; Cohen, 1987).

\section{Naturalness}

A limitation, according to Bereiter and Scardamalia (1983), is that the experimental situation is unnatural. They liken it to a naturalist who confines study of the behavior of apes to observations at the zoo. Do we really know what a writer 
thinks under these artificial laboratory conditions? Ericsson and Simon counter this argument by saying that as long as the task is being conducted in the usual way, the processes remain fundamentally intact (1980). In collection of a verbal protocol, the subject is not trying to please the investigator, as in certain other research situations.

Protocols are typically collected in a laboratory setting. Sometimes the thinkaloud is facilitated by audio taping. In recent times videotaping is becoming more widespread, although videotaping tends to make some people uncomfortable. D. Johnson (1992) recommends preparing the subject by explaining the purpose carefully and by recording practice tapes over a period of time. This, she suggests, would mitigate the discomfort.

\section{Hidden Mental Processes}

People are not conscious of their cognitive processes. They are never conscious of certain processes, such as retrieving something read from long-term memory. There are other processes which may be conscious at the outset, and later become automatized. An example is a beginning writer's conscious effort to specify an audience, contrasted with an experienced writer's ability to do so automatically (Hayes \& Flower, 1983).

Cohen (1987) again raises the question of accessibility of unconscious learning to mental probes. In so doing, he presents two sides of the picture. Much language learning, he asserts, takes place on the unconscious level. Therefore, the best that verbal reports can do is reveal learners' post hoc use of what they have learned. They do not describe "how the systems responsible for interlanguage performance become internalized" (p. 88). The issue is whether or not verbal report data offer more than opportunities for guessing and inferencing based on the learner's product. 
Cohen counters the argument that internal thinking processes are inaccessible, with the assertion that they are not necessarily inaccessible. Ericsson and Simon (1987) support this contention with their finding that "verbal report procedures preserve the sequence of states and hence the cognitive processes should not change as a result of the additional instruction to verbalize" (p. 32). Swarts, Flower, and Hayes (1984) concur that basic thinking states remain unchanged in think-aloud data.

\section{$\underline{\text { 3. Integrity and Completeness }}$}

Do think-aloud protocols give an honest depiction of learning processes? Does the act of reporting cognitive processes, in fact, distort them? The findings of Ericsson and Simon suggest otherwise. Think-aloud protocols have been unjustly criticized because they were confused with other types of verbal report, such as retrospective reports. Retrospective reports have, in fact, been shown to distort data (Hayes \& Flower, 1983).

In a series of studies on verbal reports using think-aloud data, Ericsson and Simon (1980) explored three different situations. In the first, they found that when subjects perform a task in which the solutions are already in verbal form, the act of talking aloud has no effect on task performance. In the second situation, they asked subjects to verbally encode a task (like buttoning a button) which is usually nonverbal. They found that task performance was slowed, but not fundamentally altered in any way. In the third situation the experimenters superimposed an artificial task on a normal one. (While solving a division problem, notice every odd number.) They found that the imposition of a task not normally attended to did, in fact, disrupt task performance. Their findings support think-aloud techniques as long as the task is 
performed in the usual way. The expectation is that collecting a protocol will slow down, but not change the thinking processes.

Are think-aloud protocols complete? Hayes and Flower (1983) contend that although think-aloud data are not complete, they are "characteristically more complete than most of the other methods with which they are compared" (p. 217). Ericsson and Simon caution that think-aloud protocols should not be taken as a true-or-false depiction of the writing process, but as data which need support from additional data in making inferences. Hayes and Flower (1983) agree that some cases benefit from mixing methods. Ultimately, it is the investigator's use of the data that determines its value.

\section{Scientific Nature:}

Cohen (1987) defines "self-revelation" as "think-aloud stream of consciousness disclosure of thought processes while the information is being attended to. The data are basically unedited and unanalyzed" (p. 84). He cautions investigators that subjects may, however, be tempted to indulge in analysis. A think-aloud protocol is descriptive of neither general nor specific language behaviors, rather it shows how learners use what they have learned.

Some concerns about using the think-aloud protocol have been expressed by Bereiter and Scardamalia (1983) in their discussion of writing research. They warn researchers against doing "mind reading" rather than observing. They also advise that researchers focus on the inquiry itself, rather than on the method of data collection. They remind the investigator to seek out "lawfulness" in the data. 
Bereiter and Scardamalia articulate the problems of applying theory too rigidly. No theoretical construct can completely account for the mysterious layers beneath conscious thought. According to the authors,

"process inquiry describes the flow of attention during composing, but it does not reveal why attention shifts when it does and where it does. It indicates processes of discrimination, evaluation, search and recognition, but it does not describe the actual operation of these processes. In effect, thinking aloud protocols display the products of these cognitive activities rather than the cognitive activity itself." (p. 174)

Advantages to think-aloud techniques are that they identify, replicate, and provide rich and voluminous data. The data are retrievable and can be used in a variety of ways for a variety of purposes. It is important for the researcher to analyze the data systematically, to keep clear goals in mind, and to carefully determine the boundaries of the study. D. Johnson (1992) suggests that a high quality analysis performs four functions: 1) identifies important variables, issues or themes, 2) discovers how these pattern and interrelate in the bounded system, 3) explains how these interrelationships influence the phenomena under study, and 4) offers fresh, new insights (p. 90).

Disadvantages are that verbal report data do not provide direct observations of cognitive processes. The verbal report data reflect a sequence of generated thoughts, and it is these thoughts which reflect underlying mental processes. The evidence is a step removed from the goal.

Although strong evidence supports the contention that composing aloud is similar to composing silently, investigators cannot assume that the processes are identical. More evidence is needed, for example, to determine whether composing collaboratively, composing in another language, or composing on different topics significantly alters the cognitive processes. Keeping in mind that think-aloud is a useful, but not all-encompassing tool, guidelines for collecting one are presented. 


\section{DATA COLLECTION AND ANALYSIS}

To collect a think-aloud the investigator instructs, trains and sometimes models the procedure. The subject is requested to say everything that comes to mind while writing; to think, plan, make changes and read out loud. The subject is told not to analyze or try to explain, simply to talk aloud to him or herself while writing. An audio or videotape records the process. The finished product is later analyzed in a systematic way as a means of gaining access to the cognitive processes involved in composing. Cohen (1987) cautions that subjects need instruction in order to avoid analyzing their thoughts as they talk aloud.

At the time Emig and Pianko collected think-aloud protocols, systems for quantifying the data had not yet been developed. The task of designing a meaningful, replicable coding system fell to Sondra Perl (1979). Perl was dissatisfied with the narrative style of earlier studies which failed to ascertain "the frequency, relative importance and place of specific writing behaviors within an individual's composing process" (Perl, 1979, p.318). One of Perl's significant contributions to the field of composition research was her coding analysis scheme for think-aloud protocols. Her objectives were five-fold: 1) to develop a standardized, replicable format, 2) to organize writing behaviors into specific categories, 3) to create a concise format, 4) to develop a structure which related parts of the process to the whole, and 5) to reveal diachronic aspects of composing, i.e. the unfolding sequence of movements in time.

The system contained two components, the code, and the continuum. The purpose of the code was to chart observable behaviors, and the function of the continuum was to connect behaviors with time markers. The coding operation was performed on the student's finished product, and was accomplished by listening to the 
sound of the pen as it moved across the page while the student wrote and talked. Writing was assumed to be taking place when the sound of the pen was heard. Sometimes talking and writing occurred simultaneously, sometimes only talking occurred, and sometimes there was complete silence.

Perl's labeling system provided a replicable way to score writing behaviors. Her sixteen categories of writing behaviors can be grouped in two ways, the metacognitive and the specific. The first seven categories are metacognitive: 1) general planning, 2) local planning, 3) global planning, 4) commenting, 5) interpreting, 6) assessing, and 7) questioning. The last nine categories code specific behaviors: 8) talking leading to writing, 9) talking and writing at the same time, 10) repeating, 11) reading related to the topic, 12) reading related to one's own written product, 13) writing silently, 14) writing aloud, 15) editing, and 16) periods of silence (Perl, 1979, p. 320-321).

The second tool which Perl developed was the continuum. This was a time line separated by ten digit intervals, each representing one minute. Each interval is keyed to a counter on a tape recorder so that a behavior can be linked with a time interval. This makes it possible to determine both the frequency and the duration of each behavior. With the counter operating as a time marker, each behavior is coded and entered on the continuum.

By using subscripts, Perl indicated which draft the student was working on at the time. The operation of talking while writing is placed within square brackets, [ ]. Horizontal brackets above the sentence are numbered to show which sentence was being written. The length of the horizontal bracket indicates the amount of time being spent in the writing of each sentence. 
Reading the chart, which she called the composing style sheet, meant following the sequence along the continuum. It was possible from reading the time line to see which behaviors occurred and in what sequence. Another aspect of the continuum was a scheme to use three types of print, bold, medium and light for entering comments.

The following data were elucidated by this scheme:

1. the amount of time spent during prewriting

2. the strategies used during prewriting

3. the amount of time spent writing each sentence

4. the behaviors that occur while each sentence is being written

5. when sentences are written in groups or "chunks" (fluent writing)

6. when sentences are written in isolation (choppy or sporadic writing)

7. the amount of time spent between sentences

8. the behaviors that occur between sentences

9. when editing occurs (during the writing of sentences, between sentences, and in the time between drafts)

10. the frequency of editing behavior

11. the nature of the editing operations

12. where and in what frequency pauses or periods of silence occur in the process. (Perl, 1979, p. 322)

Development of the think-aloud coding analysis system, opened the way for many future studies. An indicator of the prevalence of protocol analysis in ESL writing research, is the fact that Silva's (1989) review of research covered twenty-two studies, over half of which (12) used protocol analysis. Perl suggested that composing 
aloud might be a good diagnostic, as well as a research tool. A similar conclusion was reached by Raimes (1985).

Building upon Perl's foundation, Swarts, Flower and Hayes offered advice to beginning investigators. They presented five suggestions for novice coders (1984):

1. Look for thinking processes implicitly, but not explicitly in the text.

2. Be aware that details of wording or syntax can be misleading. For example, a writer who says, "I think I will try to..." using future tense, or "I wanted to" in the past tense, is doing much the same thing. The only difference is the time chosen to report the behavior.

3. Avoid the temptation to double-code items. Often a comment seems to encompass more than one behavior at a time. Realize that double coding can be an easy way out, and make pragmatic judgments.

4. Understand that coding can capture only part of the essence of the protocol, and that an attempt to itemize, classify and measure bits of text is reductionistic. A good way to try to figure out what the writer was doing is to establish inter-rater reliability (80-95\%). For this purpose, two raters produce sets of scores, and a correlation is calculated between them (Brown, 1988).

5. Understand that there is no "correct" way to code a protocol. Each coder or group of coders establishes its own "grammar" based on its unique goals and assumptions.

Swarts, Flower and Hayes contend that because protocol analysis is a versatile tool, it can be used in four different types of research: 
1. Exploratory studies: This type of study asks the questions, "What is happening? When? How often? When does trouble occur, and where?" Emig's research is an example of this type of study.

2. Problem-solving studies: These studies give structure to a problem by trying to define a taxonomy of basic elements of the writing "problem." For example, Flower and Hayes (1980) conceptualize the writing assignment as a two-part rhetorical problem to be solved. Part 1 is the rhetorical situation, and Part 2 is the writer. In Part 1, a taxonomy is developed in which the rhetorical situation is defined in terms of two elements, assignment and audience. In Part 2 the writer's own goals are defined in relationship to reader, self, meaning and text. Another type of study sets up a hypothesis and tests it against a protocol. For example, the authors tested a roleplaying hypothesis to discover whether writers used this method frequently to achieve audience response.

3. Comparative studies include examination of differences between writers. Areas of investigation include: expert/novice studies, $\mathrm{L}_{1}$ and $\mathrm{L}_{2}$ studies, age studies, and gender studies.

4. Writing processes model studies apply models of the composing process such as Perl's (1979) examination of individual basic (novice, unskilled, student) writers. Using a model such as Perl's, or Flower and Hayes' cognitive model of mental processes, creates a theoretical framework for composing research. 


\section{COMPOSING PROCESSES MODEL}

Cognitive science laid the groundwork for several models of composing, including: Perl's (1979) "composing processes," Flower and Hayes' (1981) "cognitive processes," Daiute's (1984) "psycholinguistic model," and Bridwell's (1980)

"dissonance model." How does each of these models contribute to an understanding of composing?

Perl asserted that the nature of writing was not straightforward and linear. She identified features of the writing process, their frequency and duration. She concluded that composing patterns are deeply embedded, consistent and recursive. She found that students did minimal "prewriting" and had very little sense of where they were headed when they began. However, strategies quickly came into play once students began to write, and those strategies helped the writers develop and clarify ideas as they transcribed.

Perl described the "recursive" nature of writing as a "shuttling back and forth" from the words on the page to their intended meaning. A movement forward would be followed by a backward movement during which the student reread, edited or digested what was written in order to discover whether what was transcribed corresponded with the intention. The activity of reaching back was accompanied by a "sensing forward" towards some unarticulated goal. This two-fold dynamic, called "retrospective structuring," had an elucidating effect. A new picture of the writing process emerged. Even though writing appears linear on a page, it was newly conceived as a cyclical activity; one which involved alternating patterns of transcribing, discovering, and synthesizing. 
Writing, Perl learned, involved both construction and discovery. It was in the act of building a text that the writer discovered more fully what he or she meant to say. Editing was a behavior which began soon after writing started. Students' editing concerns were either lexical (spelling, word choice, context of words), syntactical (grammar, punctuation, sentence structure), or rhetorical (organization, coherence, audience).

Errors, Perl explained, occurred because of rule confusion, a situation in which rules were misapplied or in which the student relied on intuition. Another aspect of error production was called "selective perception." In this situation students reread their papers from internal cues, without relying on the words on the page to convey meaning. What they thought was what they thought they saw on the page. A writer's egocentric mental state, in which the audience was taken for granted, also accounted for errors. Egocentric writing ignored the necessity for explicit referents, connecting ideas or relating concepts.

Several implications for teaching arose from Perl's findings. She suggested that teachers intervene at key points in the writing process to help students disentangle themselves. She also saw the need for the teaching of editing skills in order to encourage fluency. Moreover, she found that an individual's writing patterns were somewhat altered when writing in different topic modes, such as subjective or content based.

\section{COGNITIVE PROCESSES MODEL}

Researchers who spearheaded the investigation of mentalistic processes in composing were informed by cognitive psychology. Flower and Hayes (1981) 
designed the cognitive processes model of composing. They created a taxonomy of the four basic characteristics of the writing process, which indicated that:

1. Writing consists of distinct processes which do not occur in linear sequence, but as distinguishable patterns which the writer activates while composing. These distinct processes operate within a framework of three basic interacting elements. The interacting elements are the task environment, the writer's long-term memory, and the writing processes. The task environment includes everything external to the writer, the assignment, the audience and the eventual text. The long-term memory is the writer's storehouse of knowledge about topic, audience, conventions and rhetoric. The writer's ability depends on his or her facility to draw what is needed from long-term memory.

The writing processes are the primary thinking processes that operate during composing.

a) Planning is generating content, organizing it, and setting up goals and procedures for writing.

b) Translating is the act of expressing the content of planning in written English.

c) Reviewing is the act of evaluating either what has been written or what has been planned. A Monitor maintains an executive function over the writing processes, directing the writer when to make a shift between processes.

2. Writing processes are highly embedded, but not confined to a fixed sequence. They can operate in any order to meet the demands of the task.

3. Writing is goal directed, involving both global and local plans. Goals provide logic and coherence to the unpredictable process of writing. 
4. Writing stimulates the discovery of new goals, yet it is not constrained by the writer's original goals.

The strength of the cognitive processes model is that it accounts for a general description of a large number of cases. It does not explain individual strategies within the model. The need to examine individual strategies goes beyond the need to identify individual differences. Rather, it propels research into the exploration of learner strategies, of discovering patterns different types of students employ under different circumstances (Freedman, 1987).

\section{Daiute's Psycholinguistic Model}

Daiute's psycholinguistic model of writing builds on information processing theory which identifies short-term memory constraints on writers (Daiute, 1984; Hayes \& Flower, 1980). Many activities occur simultaneously in short-term memory during writing. Among these are: generating ideas, accessing lexical items, planning structures, and translating semantic and phonological items into orthographic ones. Short-term memory can comfortably hold from five to nine units such as digits or words. After the units disappear, their semantic meaning is stored in long-term memory. Daiute (1984) contends that language processing is affected by short-term memory limits. A perceptual clause about six words in length, is equivalent to a basic short-term memory unit. The words fade from memory and the meaning is stored in long-term memory. This process is called semantic recoding.

Daiute's model accounts for errors in the following way. Writers, like speakers, form sentences clause by clause. In producing the sequence the writer monitors the previous clause to complete the sentence correctly. If the short-term memory is overloaded, the monitor may be suspended. This can lead to error production. She 
contends that experienced writers avoid syntactical errors because they have a storehouse of complex sentence patterns available in their long-term memory. They access these automatically when they write.

Daiute's findings have important implications for teaching writing. If writing proceeds on a word-by-word basis, it may make it difficult for writers to organize syntactic structures. Error onset is less likely if students are taught to automatize complex pattern structures. Providing practice exercises on sentence combining, and examining longer sentences for errors, may be helpful to students.

\section{Dissonance Model}

Bridwell (1980), Sommers (1980), and Berkenkotter (1983) argue for a dissonance model of composing, The dissonance model is based on the concept that revision is the reconciling of text with intent. Berkenkotter tape recorded a professional writer, Donald Murray, as he composed aloud over 62 days. She learned that when substantive revision was needed, he "collapsed" planning and revising into a new activity, which she labeled "reconceiving." When writers sense a conflict between what they want to say and what the page reveals, they make changes in an attempt to resolve this conflict. The writer's other option is to shift his or her goals. Bridwell claims that the traditional outline-draft-edit model of writing forces students into a single, time limited episode of final drafting, which discourages extensive revision.

\section{TOWARD A MODEL OF COMPOSING IN L2.}

What is the developing model for writing in a second language? Since the 1980 's, influenced by the research in $L_{1}$ composing, $L_{2}$ writing research has been 
process oriented. Composite research depicts the writer as one engaged in a cyclical process of creatively building a text, and learning at the same time. The writer not only transcribes preformed ideas, but discovers new ideas along the way. Processoriented pedagogy has emerged from these findings, and so far it has produced positive effects in $\mathrm{L}_{2}$ classrooms (Spack, 1984; Raimes, 1985; Jones, 1985; Urzua, 1987). The process approach "stresses generating ideas, writing drafts, producing feedback, and revising" (Raimes, 1985). The following sections examine two of the features of the writing process, and relate them to $L_{1}$ and $L_{2}$ research.

\section{GENERATING IDEAS}

The source of content for $\mathrm{L}_{2}$ learners is often $\mathrm{L}_{1}$ (Edelsky, 1982; Johnson,1985; Silva 1989). According to Jones and Tetroe (1987), $L_{1}$ use has several functions. It keeps the composing processes flowing, it helps in local planning, and it helps in setting abstract rhetorical goals.

Monitor overuse often impedes the flow of ideas and shifts the writer's attention away from developing a controlling idea, or "sense" of where he or she is heading (Jones, 1985). The work of Ericsson and Simon (1980) and Daiute on shortterm memory limitations supports Jones' findings. Jones (1985) suggested that poor instructional techniques may contribute to overuse of the monitor. If a writer has been taught rigid rules and inflexible planning techniques, he or she is often stifled in the attempt to compose (Rose 1980). Flower and Hayes (1980), on the other hand, suggest that stymied writers may need more rules and plans. They may benefit in instruction on heuristics: identifying and solving problems, experimenting, and evaluating possible solutions. Language learners may require both more and fewer rules at the same time. They may need to reconceptualize some rigid rhetorical rules such as : "a 
main idea," or "a topic sentence." Shaughnessy warns that students "are not always certain of how a writer recognizes a main idea when he has one or how he sets about finding one if he doesn't" (1977, p. 215). The writer may just sit there worrying and block any further ideas from forming. Students may need help in forming a data bank from which to draw ideas. Many types of data can form a base from which to draw information (Shaughnessy, 1977). These can be content based or otherwise. To encourage fluency and power in writing, a technique called "freewriting" was developed by Elbow (1973). In $\mathrm{L}_{2}$ pedagogy, freewriting entered the classroom by way of journal keeping. Students were encouraged to write as much as they could without censorship. The journal has been a frequent source of material for writing topics in language classes (Krapels, 1990). Other invention strategies have been embraced. Spack (1984, p. 654) classifies them according to groups which may be useful for different types of tasks: "empirical modes (interviews, visits, observations), rational modes (classical topics, questions, problem solving formulas) and intuitive modes (journals, meditation, analogy and Elbow's free writing)."

Raimes (1983) argues that "choice of topic "should be the teacher's most responsible activity" (1983, p. 266). It affects many aspects of writing, including syntactical structures, cohesive elements and fluency (Reid, 1990). In a comparative study of different topic types, Reid concluded that certain topics elicit more fluency than others. Brooks (1985) found that when unskilled ESL students were asked to choose their own topic, their writing was more proficient than when given an assigned topic. Along similar lines, Hildenbrand (1985) compared an ESL college student's writing in two modes, expressive and school-centered. Her findings indicated that there was a disjunction between the teacher's orientation and the student's own ideas 
and presuppositions. She recommends that teachers examine both their own and their students' perceptions about a writing assignment.

\section{REVISION}

A major focus of composition research has been revision. Brooks (1985), studying unskilled ESL college writers, argues that for ESL learners, revision is the main component of the composing process. What are the concerns of students as they make changes?

Sommers (1980) led the way for investigations of revising and editing in her longitudinal study of twenty novice student writers and twenty expert writers. Her subjects wrote three essays, one expressive, one explanatory and one persuasive. They submitted two drafts of each essay for a total of nine written products per writer. Each writer was interviewed three times, and asked to suggest revisions on an anonymous essay. Sommers counted and categorized the changes made. Her taxonomy identified four revision operations: deletion, substitution, addition and reordering. Furthermore, she identified four levels of change, which included: word, phrase, sentence or theme. One coding system related frequency of revision to both level and operation. A second coding system recorded a "scale of concerns" for each writer, identifying operations in each draft as primary, secondary or tertiary.

Sommers found that expert writers create meaning in their engagement with writing, in their struggle to negotiate between text and intent. Their perspective is that of the "big picture," which includes strategies for reordering lines of thinking, evaluating purposes, and concern with audience. Strategies for revision help writers balance competing demands on their attention. Thus, writers can learn to concentrate on several objectives at once by developing strategies to sort out their various 
concerns during revision. The implication for teaching is to encourage students to attend to global concerns while writing, and to help them to develop strategies for revising and editing.

Sommers reported differences in the revising patterns of student and experienced writers. Student writers perceived revision as a "mop up" activity, a way to clean up after their initial efforts. Another contrast concerned the levels of changes. Her findings indicated that experienced writers make changes at all levels, while student writers do not make substantive changes. They confine revision episodes to surface changes on the word or phrase level. She also stated that student writers are "bound" by the rules they've been taught, a contention supported by Rose (1980). Student writers make lexical, but not semantic changes. They may be able to solve the immediate problems, but they are blind to textual problems. Sommers claims they are unable to "re-view" their work.

Do skilled and unskilled ESL learners revise differently? Brooks (1985) reports that less proficient writers are less fluent, and focus more on correctness. Like Sommers' student writers, Brooks' unskilled ESL leamers made only surface type revisions. Raimes' (1985) conclusions in her study of unskilled ESL writers differed from Brooks'. Raimes found that her subjects wrote a lot, and were not preoccupied with error at the expense of ideas. More research is needed before this discussion can be resolved.

Revisions do not necessarily enhance the writing of less skilled students, either in their native language (NL) (Perl, 1979) or in $\mathrm{L}_{2}$ (Brooks, 1985). Less proficient writers leave a trail of unresolved errors. Perl explained that they rely more on intuition because they are unable to make informed decisions while editing. Moreover, 
their "error hunting" activities prevent them from being flexible about writing and revising (Perl, 1979; Rose, 1980; Jones, 1985).

\section{IDEAS, OWNERSHIP, AND REVISION: A PERSPECTIVE}

The following is an attempt to integrate what is known about generating ideas, ownership of text and revision activities. The field of composition research has established that short-term memory limitations constrain the writing process. The amount of data which can be "juggled" simultaneously is limited. If there are further constraining factors, such as graphological impediments (i.e. coping with a new orthographic system), or applying fixed grammatical rules, the struggle may become even harder. It seems appropriate to assert, as many researchers have previously stated, that writing is both anxiety producing and painful.

Evidence from the field of cognitive science strongly suggests that many items which originate in short-term memory are eventually automatized for storage in longterm memory. The long-term memory is a data bank for storage of information. Time, experience, and practice with certain facts, skills, and information promote the likelihood those items will be stored in the unconscious, long-term memory. Transfer of these items is facilitated by the individual's own hard work. The personal investment of energy and time which are required in order to automatize an item makes it meaningful. These items, when they are stored as bits of information that coalesce or integrate, may be called "thoughts," or "ideas." Because they emanate from an unconscious source, it may be inferred that they are meaningful, and reflect "ownership."

How do ideas which evolve from the unconscious differ from those on the conscious level? How do they relate to writing and revising? The contents of the ideas 
which have been retrieved from the unconscious are more meaningful to the writer. Ideas that come from short-term memory reflect surface concerns. A thought such as, "I need to buy milk, so I must go to the store" is an example of a surface idea. On the other hand, solving a crossword puzzle, or figuring out why your car won't start, are global ideas, and the writer will likely have much to say about them. It is in the process of grappling with, and formulating ideas that a writer discovers meaning. The meaningfulness of the text implies ownership. The literature strongly suggests that ownership of text, or the student's commitment to the writing task, enhances the written product. A writer who is committed to the task is more likely to care about writing well. Concern with writing well directs the writer to return to the text again and again to try to get his or her meaning across. The literature supports the contention that more proficient writers occupy themselves with global, not local concerns.

To summarize, when long-term memory is the source of ideas for writing, then the formulation of those ideas encourages ownership of the text. In turn, ownership of text directs the writer to revise globally. These concepts argue strongly for a process approach to the teaching of writing.

The broad goal of a process orientation, at its best, is to help students automatize basic skills to free them for larger concerns. In teaching ESL writers the challenge is to deal with students and their needs on many levels: linguistic, affective, heuristic, and social. This calls for instruction on the linguistic level to help them with grammatical, syntactical and lexical items, yet without binding them by rigid rules which stifle creativity. It also implies dealing with students on the affective level; instilling confidence in them that writing is something they can do. In a process approach, peer conferencing, writing several drafts, and much encouragement and positive feedback are needed. Students need instruction on the heuristic level as well. 
They need opportunities for practice to help them internalize important elements of rhetoric, and to employ different genres in a comprehensible way. On a social level, they need teachers who do their best to make them feel comfortable, understanding all the while that, "the writer writing is not at home" (Mandel, 1980).

\section{ESL COMPOSITION RESEARCH: SUMMARY}

Much of what is known about composition has been learned from $L_{1}$ research (Zamel, 1982, 1983; Raimes, 1985; Krapels, 1990). Most L $\mathrm{L}_{2}$ research has been observational, and used female subjects, most of whom were either Chinese or Spanish speakers. Most studies involved a small number of subjects, two-thirds of whom were advanced ESL learners. Samples were not randomly selected, but were acquainted with the researcher. Researchers often chose to study present or former students (Silva, 1989).

Silva found that among issues studied were:

1. Writing Process (recursion, variation among $\mathrm{L}_{2}$ writers, transcribing, and revising)

2. $\mathrm{L}_{1}$ Use in $\mathrm{L}_{2}$ Composing

3. Monitoring

4. Transfer of $L_{1}$ Skills to $L_{2}$ Writing (Silva, 1989)

Since Writing Process and Monitoring have been discussed in previous sections of this paper, the following discussion is limited to items 2 and 4 above.

\section{$\mathrm{L}_{1}$ USE IN L 2 COMPOSING}

There are some positive aspects of using $L_{1}$ in $L_{2}$ writing. Several authors cite the role of $L_{1}$ as a source of content (Edelsky, 1982; C. Johnson, 1985; Silva, 1989). 
In a study of 26 primary grade children, Edelsky found that knowledge of $L_{1}$ writing is the foundation upon which $\mathrm{L}_{2}$ writing is built. She contended that $\mathrm{L}_{1}$ did not interfere, and suggested that $L_{1}$ composing processes might transfer to $L_{2}$ (1982). Lay (1982) taped adult speakers of Chinese as they composed and found that they used $L_{1}$ knowledge in their $\mathrm{L}_{2}$ composing processes. When there were more language switches the writing was of better quality than when there were fewer. She also found that topics relating to home and family elicited more NL switches than topics that concerned life in the United States, a finding corroborated by C. Johnson (1985) studying a group of Japanese and Spanish speakers. A study by Jones and Tetroe (1987) of Spanish speaking writers supported Lay's (1982) suggestion that certain $\mathrm{L}_{1}$ features transfer to $L_{2}$. Jones and Tetroe also indicate that students use $L_{1}$ to help with certain aspects of planning, a finding supported by Johnson.

There are, on the other hand, some limiting features to $L_{1}$ use. Jones and Tetroe (1987) found that extensive $L_{1}$ use was counterproductive for advanced $L_{2}$ students. Johnson indicated that when students felt confident in their $\mathrm{L}_{2}$ writing ability, use of $L_{1}$ decreased. The research suggests that use of $L_{1}$ in $L_{2}$ writing is appropriate up to a point. It probably helps beginning students more than advanced.

\section{TRANSFER OF $\mathrm{L}_{1}$ TO $\mathrm{L}_{2}$ WRITING SKILLS}

Strong evidence links transfer of writing skills from $L_{1}$ to $L_{2}$ with respect to such features as audience, planning patterns, and models. Jones and Tetroe (1987) assign $L_{1}$ strategies a central role in $L_{2}$ learning. They found that subjects who were experienced $\mathrm{L}_{1}$ writers transferred their competencies to $\mathrm{L}_{2}$. Conversely, they discovered that subjects who were inexperienced $L_{1}$ writers were equally unsuccessful 
in L2. Brooks (1985) came to a similar conclusion, and noted that lack of Cognitive Academic Learning Proficiency (CALP) adversely affected a student's ability to write.

\section{WHAT IS KNOWN ABOUT COMPOSING IN ESL?}

Much is known about the similarities between $L_{1}$ and $L_{2}$ writers. Raimes $(1985,1987)$ searched for the differences, but the evidence is weak. Raimes' research suggested that ESL writers are more committed to their tasks, write more, and are less preoccupied by local errors than Perl's (1979) basic writers. Others in the field, notably Brooks (1985), have reached opposite conclusions.

In other areas there is less controversy. The body of research seems to support the contention that there is a positive correlation between overall language proficiency (as determined by placement tests such as the Michigan Test of English Language Proficiency) and ability to write in English. There is strong evidence that good learning strategies transfer from $L_{1}$ and enhance the quality of writing in $L_{2}$.

Great variation exists among individual ESL students, in their backgrounds, perceptions and attitudes. Although good writers engage in the same cyclical patterns of planning, retrospective structuring, pausing, rereading and revising, each student, NL or $\mathrm{L}_{2}$, is unique in approach. Strategies differ widely among students of all types.

How can research help teachers understand students as individuals and address their needs? A research approach which looks at the individual through a prism may be called for. Such a tool exists, and is gaining in popularity as a design for research. The case study approach offers possibilities for the study of writing because it is flexible enough to incorporate many different research techniques, and is open enough to include many sources of data. One effective technique which fits well with case study design is think-aloud protocol analysis. In Silva's (1989) survey of recent 
writing research in ESL, over half the studies incorporated composing-aloud data. He urges researchers to expand its application even more broadly. One of the advantages is that protocol data can be used in many different ways according to the goals of the research. Since case studies limit themselves to small numbers of students, it is not advisable to generalize from the data. Rather, it is preferable to pool the data from many case studies for the purpose of generating hypotheses. The body of ESL research is growing rapidly, and the data are accumulating at a quick pace. 


\section{CHAPTER III}

\section{METHOD}

This research is based on single case study design, combining qualitative and quantitative measures. The rationale is that case study format offers the investigator the opportunity to explore a unique situation, a "revelatory case." There are two possible case study designs, "holistic" and "embedded." The objectives of this research match the embedded structure, because it, by definition, explores subunits within the larger question.

The main focus of this study is to examine how a particular East European ENNR student learns to write in English. Subunits of the analysis fall into three categories. The first group investigates cultural context, exploring the subject's educational and literacy backgrounds (See Chapter IV). The second group explores the subject's learning situation in a contemporaneous academic setting (See Chapter V). The third and final subunits analyze the subject's composing processes by means of a think-aloud protocol (See Chapter VI).

\section{INSTRUMENTS AND ANALYSIS}

The instruments used in this case study can be categorized into two types, those that "ask" and those that "watch." Instruments which "ask" include questionnaires, surveys and interviews. Those that are designed to "watch" include classroom and computer observations, field notes, and the study of documents. A quasi-experimental "watching" instrument, critical to the report on writing processes, is a videotaped and coded think-aloud protocol. 
The following sections will discuss the instruments and units of analysis employed in this case study research. The methods applied to study of cultural context are discussed first, followed by methods applied to the learning situation, and ending with a description of methods used to investigate the composing process.

\section{Instruments and Analysis of Cultural Context}

It was determined that a profile of cultural context would be constructed for the purpose of exploring the subject's background. For a detailed account of the findings relating to culture, see Chapter IV. The strategy is based on a plan to employ multiple units of analysis. Two types of cultural context are explored, historical and contemporary. The profile is constructed on two levels. On the macro-level, the goal is to identify sociocultural patterns, and explore broad issues such as politics, economics and religion. The instruments used to implement this goal include numerous extensive interviews with the subject, samples of her essays about culture, a documented visit to her home, and interviews with two natives of Poland in addition to the subject. The interviews were both formal and informal. Field notes were transcribed either during or as immediate follow-up to the interview. Background reading about education in Poland, as well as student essays about Polish language and culture, comprise additional sources. A sample questionnaire may be seen in Appendix A.

First Language is a formal twenty question instrument designed to elicit information about the subject's training in Polish. It includes fourteen objective questions about her literacy history (1-14), three subjective questions involving selfassessment ((15-17), and three questions about present literacy experiences (18-20). (Appendix B). 
On a micro-level, contemporaneous context is explored in an attempt to build a "writing profile." Writing events which occur in the context of home, school and family are recorded through collection of documents. For the purpose of assessing literacy in the subject's home, she was asked to complete a Printed Materials Survey, which documents the category, language, and number of reading materials at hand. It quantifies printed materials in nine categories: novels, poetry, textbooks, art books, other non-fiction, children's books, religious books, magazines and newspapers. The materials are listed according to the numbers in each of five languages: English, Russian, Polish, Czech, and German. (See Chapter IV).

Writing done at home and elsewhere was explored by means of an instrument called a 48 Hour Writing Diary. This is a record of writing activities maintained by the subject over a two day period. In the 48 Hour Writing Diary, she recorded the nature, duration, and language of every writing activity which occurred. All types of writing events were to be noted, including school related, personal, business, or casual writing. These include such everyday activities as writing checks, addressing envelopes, taking class notes, essay writing, study notes, and telephone messages. A sample of the diary is included in Appendix C.

\section{Instruments and Analysis of the Learning Situation}

Steps were taken to determine the subject's present-day context of learning. A detailed account of the findings may be seen in Chapter V. The plan was to gather information about the formal learning situation in relationship to the subject.

Observations. The classroom environment as a literacy community was a source of data about teaching, learning, and social organization. Data about the classroom environment were collected by means of four on-site observations, two 
during winter term, and two during spring term. The researcher assumed the role of non-participant observer, and field notes were taken on-site.

Two observations took place in the computer laboratory while the subject composed. The purpose was to collect real time data about the composing process. The sessions were held at the request of the researcher, and the objectives were explained. The procedure was to sit beside the subject and observe as she wrote, noting changes and deletions as she worked. The investigator assumed the role of nonparticipant observer in order to allow the subject to function in a normal way to whatever extent possible. Potential difficulties surrounding researcher involvement are discussed in Chapter VII in the section about limitations.

Interviews. In order to assess the subject's academic performance and interaction in the classroom setting, an open-ended personal interview with each of her ENNR instructors was conducted. Questions addressed the following topics: course requirements, social and academic adjustment, attitudes, motivation, strengths and weaknesses in language, and effects of cultural background. Notes were taken during the hour-long interviews, and responses of the interviewees were later compared and analyzed for similarities and differences in perspective.

The subject, as key informant about the learning situation, was interviewed for one-hour intervals in informal, open-ended format. Five interviews took place while the subject was studying in ENNR. The number and duration of the interviews was set arbitrarily, with the purpose of establishing a longitudinal body of evidence covering two terms of enrollment. Field notes were compiled after the meetings, in order to help build a sense of trust between the investigator and the informant. Data regarding the subject's attitudes towards the learning environment, and her likes and dislikes about ENNR were subsequently evaluated. 
Writing Samples. Writing samples were collected, representing work the subject submitted during each of her three terms in ENNR. Although these final drafts did not reveal the composing process per se, they helped to build a writing profile. The procedure was to examine writing samples over a period of time, and to determine if one year of academic training in ENNR helped to improve the subject's skills. It also offered a broad comparison between her skills as a writer in her first language, and her ability to write in English.

Four ESL instructors, ranging from two to twelve years teaching experience in ESL, rated the compositions. The instrument used was a ten-point holistic evaluation scale adapted from Reid and O'Brien (1981). The rationale for choosing a holistic evaluation scale was that it more closely matched a rating system used by the first language evaluator as described below. Scoring ranges from zero to ten, which corresponds with rankings from Poor to Excellent. The lowest possible grade is zero, and the best is ten. Four categories are rated, including English Structure, Content, Organization and Overall Writing Proficiency. The raters were trained as a group by the researcher. They read copies of the Reid and O'Brien handout, which assigns criteria for evaluating each of the first three categories according to: Excellent, Good, Average, Fair and Poor. Overall Writing Proficiency is a composite judgment.

Each rater had three scoring sheets, one for each composition. The raters were directed to write their names on each sheet. The working part of the paper consisted of a table with the evaluation scale across the top, and the writing categories on the left. The numbers 1-9 were listed under the bottom row of boxes.

Evaluators were instructed to assign a numerical value and record it in the appropriate box. A copy of the Reid and O'Brien guidelines and scoring sheet may be seen in Appendix D. 
The raters read each composition and entered their judgments on the scoring sheet. The compositions are included in Appendix E. Each rater's average score per composition was computed, and then a composite score for each composition was calculated. The range of scores for each essay was determined. Skills in structure, organization, and content were examined separately, and average scores for each were recorded. Inter-rater reliability was calculated by dividing the lowest rating by the highest rating in each essay. Further details on establishing inter-rater reliability are presented in Chapter V.

In addition to submitting writing samples in English, the subject was asked to compose a short essay in Polish, on a topic of her choice. This assignment provided a limited basis for comparison between her writing in English and her writing in her first language. A first language rater evaluated the composition on a holistic rating scale based on content, organization, linguistic complexity and grammatical correctness. To encourage objectivity, a first language rater who had never met the subject was selected. Kristi, a native speaker of Polish, was instructed to evaluate the essay holistically on a four point scale of Excellent, Good, Fair or Poor. Then, in an openended, guided interview she offered her opinions about the subject's first language essay. A copy of the first language essay may be found in Appendix F. Additional documents were collected for review, including classroom generated items such as notebooks and dialogue journals.

Self-Profile as a Writer. The subject was requested to complete two forms which were designed as self-assessment instruments. The purpose was to cross-check the subject's self-evaluation with information from other sources, in order to determine areas of agreement or disagreement. The first self-report, a highly structured, easily scored, and objectively analyzed survey, is the Strategy Inventory for Language 
Learning (SILL): Version for Speakers of Other Languages Learning English ( $R$. Oxford, 1990). According to Oxford (1990), the SILL has been thoroughly fieldtested, and its reliability and validity have been established. This study uses SILL Version 7.0, which is adapted to the particular needs of language learners, and contains fewer items and simpler language than Version 5.1. The survey consists of 80 items, and takes approximately 30 minutes to complete. The SILL is based on a 5 point scale, indicating frequency of occurrence, from "never true of me" to "almost always true of me." Ratings are assigned to six categories of strategy, Parts A-F. For specification of the types of strategy, and for the findings, see Chapter V. An overall average is calculated to demonstrate how often the subject uses learning strategies in general, and averages are taken for each of the six groups to indicate which of them she uses most often. See Table VIII.

The second self-assessment instrument is Case Study of Yourself as a Writer. adapted from Trimbur. This assignment enables the subject to explore two areas, her personal writing history, and her present writing patterns. It elicits information by addressing general categories of writing background and process. There are eleven issues about writing, summarized as follows: moments, stages, kinds, in-school vs. out-of-school, audience, physical, process, intervention, response and feedback, problems, and myths. See Table IX. A copy of the assignment and a sample response may be seen in Appendix G.

\section{Instrument and Analysis of Composing Process}

The instrument used to study real-time writing process is a think-aloud technique. Think-aloud is a special kind of verbal self report which elicits disclosure of mental processes as they unfold. Cohen (1987) defines such concurrent stream of 
consciousness techniques as "self-revelation." Further discussion of think-aloud procedure and findings is found in Chapter VI.

A protocol is collected in a laboratory setting by asking the subject to compose aloud on a specified topic in front of a video camera. One advantage of a video recording is that it provides natural data. In addition, it offers a convenient source of analysis, and can be viewed many times, and from many perspectives. Since video taping sometimes makes people, especially shy people, uncomfortable, D. Johnson (1992) suggests that the purpose of the taping session be carefully explained, and that practice sessions be held for warm-ups. Raimes (1985) demonstrated how to talk while composing, and recommended that her students practice at home.

In the present study, the subject was introduced to think-aloud in the laboratory setting. As preparation, she listened to a five-minute demonstration audiotape, previously recorded for training purposes by the investigator. The researcher explained that the demonstration tape was made during the writing of a first draft of a composition called, "How I Found a Job." The subject listened to examples of planning out loud, searching for appropriate vocabulary, rereading, making changes, and spelling. The subject studied a copy of the sample composition for evidence of changes, such as crossed out words and misspellings. After listening to the tape and viewing the training document, the subject observed the researcher during a follow-up demonstration of how to verbalize everything that comes to mind while composing. The taping session began when the subject indicated that she understood the directions.

The present study assigned the subject a narrative topic identical to the one used by Raimes, "Tell about something unexpected that happened to you." The subject was instructed to talk as she wrote, and to think, plan and make changes out loud. The 
degree of structure and intervention was low. There were no time constraints, and the subject determined her own stopping point. The investigator assumed the role of nonparticipant observer, and refrained from intruding. The videotaped data were collected concurrently with task performance, and provided an oral, written, and visual record for later analysis. The goal of a think-aloud is to check the relationship between what learners are saying and what they are doing (Jones, 1982; Tetroe \& Jones, 1982).

The videotape was held for coding and data analysis which took place at a later date. The audio portion of the tape was transcribed and coded according to a system loosely adapted from Raimes. The following sections describe the procedures for transcription, coding, and analysis.

Replicating the Essay. The first step in retrieving the data was to view the video for a holistic impression. Attention now turned to the handwritten manuscript and what the writer actually did. Next, steps were taken to preserve and protect the written text in its original form. To maintain the integrity of the primary document, a typewritten copy was made, which approximated it as closely as possible. This copy became a working document which was marked by the investigator. It recorded the subject's writing as closely as possible, revealing events such as misspellings, additions, deletions, and punctuation. The original and replicated essays may be seen in Appendix H.

The next procedure was to establish a time frame in order to find out not only what happened, but when it happened. To accomplish this goal, the method was to watch the video again, to break it down into one-minute intervals by means of a stop watch, and to indicate the time segments on the sheet.

Transcribing the Video. Attention now shifted from what the writer did, to what she said. The next step was to create a new document which corresponded to the 
video. The objective was to transcribe every spoken word the subject said during the session, including pauses and fillers. This was a complex and time-consuming procedure, accomplished with the help of a stopwatch and VCR counter. In the video transcription correct English spelling is used, although individual letters, parts of words, and syllables are included when they indicate speech. The transcribed videotape may be seen in Appendix I. With the transcription in hand, the video was viewed for a third time, to indicate the points at which speaking and writing overlapped. This correspondence is coded by underlining, as seen in Appendix J.

Coding. At this point, there were two working documents, and decisions were made about how coding would proceed. Since this was an exploratory study, the body of data per se generated ideas about what direction to take. Numerous components of the composing process were examined, including: prewriting, planning, commenting, rereading, writing strategies, and revisions. The time spent in pre-writing activities, and in task completion is noted and recorded in Chapter VI. Working from the transcription, the nature of the composing process was further investigated. Comparison between the total number of words in the original essay, and the number in the final product was calculated.

One area of interest in the think-aloud is that of silence. Once again, the stop watch was used, this time to calculate the length of pauses and hesitations. Only silences of two seconds or longer were recorded. Findings about pauses and fillers are found in Chapter VI.

The sources of data retrieval were the videotape and the transcribed documents. Data such as pauses, rereadings, minute-by-minute segments, and overlap of speaking and writing were retrieved directly from the video. Having done so, additional time-related data were retrievable from the transcriptions. The total time 
spent in writing was calculated, then analyzed according to type and frequency of strategies used during the first half and second half of the videotaped session. Writing strategies were identified and coded, and caution was taken to avoid double coding.

Revisions were categorized according to four types of change, additions, deletions, substitutions and movement. They were analyzed further to determine whether they were revisions of mechanics, grammar, word choice (lexical), organization or content. The location of revisions either within, or between, sentences was determined.

When a particular behavior, such as verbal rehearsing, appeared frequently, it became a focus of attention. For example, numerous examples of trying out new words and ideas were discovered. This disclosure directed the investigator to tally and analyze those items which suggested that the subject was using the strategy identified as verbal rehearsing.

\section{FINAL ANALYSIS}

The objective of this research is to bring together data collected in the three main areas of the study, cultural context, the learning situation, and the think-aloud protocol. The next section of this study examines each of these topics independently. It is organized so that each of the three following chapters presents both findings and results. In Chapter IV, the primary focus is on the subject's background and culture, whereas Chapter V investigates the classroom context in an academic setting. Chapter VI contains data about composing processes, by means of collection and analysis of the think-aloud protocol. Each chapter attempts to draw inferences about the nature of the composing process in general, and how it relates specifically to the subject of this 
case study. Based on the findings of this research, and on the implications of the literature in the field, recommendations for teaching are presented in Chapter VII. 


\section{CHAPTER IV \\ CULTURAL CONTEXT: EDUCATION AND LITERACY}

A passage from Lost In Translation, an autobiography (Hoffman, 1989) of a Polish refugee who emigrates to North America, describes the dilemma inherent in acquiring a new language:

Polish is no longer the one, true language...Polish insights cannot be regained in their purity; there's something I know in English too. The wholeness of childhood truths is intermingled with the divisiveness of adult doubt. When I speak Polish now, it is infiltrated, permeated, and inflected by the English in my head. Each language modifies the other, crossbreeds with it, fertilizes it. Each language makes the other relative. Like everybody, I am the sum of my languages... (p.273)

A hidden agenda in language leaming that is often overlooked, but influences the success or failure of second (or third) language acquisition, is culture learning (Damen, 1987). The cultural patterns, concepts, beliefs, and perceptions implicit in any linguistic system comprise the "cultural baggage" that are toted along. What is it like to become bilingual, and therefore, at least partly, bicultural?

This chapter asks, "How does a student develop cultural competence along with linguistic competence?" It begins with the subject's native culture, seeking to establish the social setting in Poland. Applying cross-cultural perspectives, it explores themes in political, educational, and family background, in an attempt to uncover variations between her native and adoptive cultures. 


\section{POLISH POLITICS AND EDUCATION}

Enya received her formal education at the elementary, secondary, and lower division college levels in her native country, the Polish People's Republic. The following section presents a brief history and overview of the Polish educational system and statistics which reflect the state of education during her student years, 1964-78.

From the 17th to the 20th century, Poland was invaded and occupied by foreign powers. During many years of occupation, 1795-1918, foreign powers destroyed education, and closed most of the Polish universities. When independence was finally gained in 1918, Polish education began to be restored. During the War, the Polish people suffered terrible losses under Nazi domination. Their country was devastated, and millions of Poles died as a result of massacres, starvation and imprisonment. As news of the horrors of the concentration camps was uncovered, attempts were made to overcome guilt and recrimination, along with efforts to physically rebuild a nation (Knowles, 1978).

The post-war era established the People's Republic of Poland, and with the assistance of the former Soviet Union, the nation's educational system was completely reorganized. The Communist leadership dominated the post-war elections, and followed Russian style policies. Under the Communists, Poland shifted from an agricultural to a rapidly industrialized economy.

One of the goals of the newly industrialized nation was to achieve universal literacy. The restructuring of education was one of the easiest and most effective postwar accomplishments. It was achieved, in part, because an underground educational system had miraculously thrived during the war. As the Communists continued to 
further the expansion of schooling, they ushered in a national system which succeeded in bringing literacy to all Poles. Higher education became more widely available under the restructuring. According to The International Encyclopedia of Higher Education (Knowles, 1978), from 1944-74 there were 687,400 graduates. Of these, $48.7 \%$ graduated between 1966-73. Women's' access to the university also improved, with the proportion of women students rising from $29.8 \%$ (1945-50) to $40.2 \%$ (1966-70), to $46.5 \%$ (1973).

A strong educational system, based on the rigorous classical model of European education, prevailed. The model of education was rote learning, and the teacher-centered classroom. Creativity and innovation were not encouraged (Kuhlman, 1992). Along with teaching the basics, the schools were required to instruct in both political indoctrination and the Russian language. Many students ridiculed these subjects, and did not take them seriously.

The political agenda of the day largely suppressed intellectual freedom, especially in academic areas such as history, political science, and government (Kuhlman, 1992). The study of foreign language mandated that all students begin learning Russian in fifth grade, and for those who attended high school, it was studied through twelfth grade. By the time the subject of this study, Enya, graduated from secondary school, she had studied eight years of Russian as a second language. It was taught by traditional methods, and spoken only in the schools. According to Marek, her husband, there was a great deal of resistance to learning Russian, and it was treated lightly. He described his Russian teachers as "tough, imposing, and dogmatic."

The repressive atmosphere which characterized the Communist-dominated system had a strong personal impact on Enya in her formative years. In the second 
draft of an essay she wrote in Spring 1990, she described the following humiliating situations:

As a student in middle school in my country, I remember being horrified by my P.O. (Military Indoctrination for Youth) teacher. Once 1 had to stand in front of the whole school and was verbally punished by the teacher because of my poor grades in this subject. It made me feel anxious. The entire political system of Poland made me anxious. Having to visit any of the government offices made me really uneasy. When my mother decided to retire because of her serious health problems she asked me to talk in her name with the State Office for Old Citizens. The careless and hostile atmosphere made me feel there very nervous.

The structure of the educational system includes infant schools, primary schools, secondary schools, and higher studies. Children aged 7-16 attend an eightgrade primary school, and upon graduating, they may apply for secondary education. Three principal forms of secondary schools exist: college preparatory, technical, and vocational. A diploma from a four-year grammar school (lycea) may admit a student to a program of post-grammar school courses called "policealne studia zawodowe." This type of training offers a two-year degree, and is similar to programs at community colleges in the United States. Enya took her post-secondary education at such a "studia" for two years in preparation for teaching kindergarten through fourth grade. However, she did not fulfill the practice teaching requirement, and so did not receive her two-year degree.

\section{POST-WAR POLAND}

Growing up in post-war Poland offered little in the way of a safe haven, security, or innocence. The legacy of the war ushered in an inflexible Communist regime, replacing the old way of life with new forms of discontent. Communism offered structure, but not security, to non-partisans. There was pressure to conform to 
the totalitarian system, yet there were strong undercurrents promoting resistance. Polish Catholicism, the majority religion, for example, was in direct opposition to the atheistic tenets of Marxist philosophy. Underground publishing houses prospered after 1956, accompanied by a new appetite for Western authors such as Steinbeck, Faulkner, and Hemingway (Kuhlman, 1992). A nation which had suffered centuries of occupation and division prior to the war, reluctantly changed masters as an aftermath. For many Poles, Communist domination was just another in a long series of political humiliations.

What kind of people did the Communists find? Who were the Poles? Prior to World War II, sizable minorities such as Ukrainians and Jews inhabited Poland, and the nation was primarily agrarian. Following the War, only a scant minority population remained, and Poland was largely homogeneous. Perhaps as a result of this long history of subjugation, the Polish people distrust indoctrination and authority. They have a fierce streak of independence, and a tendency to defy rules imposed from above by those in power. This is a cultural trait shared by the woman who is the focus of this study.

\section{FAMILY LIFE}

Enya is a product of Post-War Poland. Born in Krakow in 1954, she is the only child of a Polish couple who had fared badly under the Nazis. Her mother and father were older than average when she was born, and she describes them as devoted, yet anxious parents. Her mother was fearful, and her father was disappointed. A prolific artist, he did not pursue a career as a watercolorist, but made his living as an electrician. Although very intelligent, her father did not have much formal education, and did not pressure his daughter to achieve academically. 
Enya's parents participated neither in organized religion nor politics. They were not practicing Catholics, and religion was not a significant factor in Enya's life. Neither did they believe in the Communist system, a fact which caused a rift in her family. Her father, an ardent anti-Communist, has a brother who was a party official. As a result of their irreconcilable political differences, the two brothers have avoided contact with each other for over twenty years. As an adult, Enya has continued to resist both formal religion, and doctrinaire political thinking.

Besides her parents, her closest relative is an aunt who led an extraordinary life. During the War, she had hidden a Jewish man, and later married him. They were the first family members to emigrate from Poland, moving first to Brazil, and later settling permanently in Israel.

\section{FIRST LANGUAGE INTERVIEW}

The goal of the first language interview was to obtain a history of Enya's literacy background in her native language, and to explore her present use of Polish in reading and writing. The interview took place by telephone in Spring 1992, and notes were taken during the conversation. A copy of the interview may be found in Appendix B.

Before Enya started first grade in 1961, she was required to take an entrance exam. She was admitted, and took reading and writing instruction at age 7 in first grade. At the beginning stages, she received help from teachers, but not from her parents. Methods of instruction included teaching the alphabet, and the copying and writing of sentences.

Primary school consisted of first through eighth grades. Class size was 25-30 students, and the primary source of reading and writing materials was the textbook. 
Until fifth grade, Enya did not do much outside reading, but after that she began to read novels and stories, and also wrote stories at home. During high school she lost interest in reading, and her reading and writing grades were "not good." Her formal schooling ended with two years at the "studia" as noted above. In 1979, as part of her teacher training program she taught children with Down's syndrome. The following year, when she was expecting her first child, she worked at a public library.

Enya says she does not like to read or write Polish because she has lost contact with her culture. It is easier for her to read English now, and she has not done any reading in Polish for three years. The only writing she currently does in Polish is letter writing. At present she writes primarily in English, mostly formal academic papers, of 6,10 , or 12 pages in length. To the question, "How do you rate yourself as a writer in Polish?", Enya responded as follows: spelling, organization and creativity are good, but punctuation is fair. During the conversation Enya elaborated on the rhetorical differences in organization between writing in English and Polish. "English organization is very difficult," she explained. "English is very clear, and it forces you to analyze and give examples. Polish is more poetic. You put down feelings and dreams, you wander around and come back. There is no analysis." In Chapter V, under the heading, "First Language Essay," Kristi characterizes Enya's organizational pattern as circular, wandering and unclear.

Enya rated her reading skills in Polish on the same four-point scale. She evaluated her speed as fair, and comprehension as excellent.

\section{POLISH vs. ENGLISH WRITING INSTRUCTION}

This section presents both the Polish and American views of academic writing in Poland. The Polish perspective is based on interviews with the subject, her husband, 
Marek, and with Kristi, the First Language rater. The American perspective is represented by information gleaned from two academic papers. The first author, Carter, is an exchange Professor who taught writing at Warsaw University in Spring, 1984 (Carter, 1986). The second author, Kuhlman, taught English at the Jagiellonian Institute in Krakow from 1986-1987, and visited there again in 1989 (Kuhlman, 1992). Interviews with three natives of Poland, including Enya, were conducted independently, and views of one informant were not disclosed to any other informant. Although four sources constitute an admittedly small sample, the opinions expressed were similar, as revealed in the following discussion. Marek was a student in ENNR during the academic year 1988-1989. A taped interview with him was conducted in May, 1992. A list of interview questions may be seen in Appendix K. The Polish point of view is supplemented by information gathered from an interview with Kristi in February, 1992. Notes were recorded during the conversation.

The informants were in agreement on three characteristics of Polish writing instruction: emphasis on grammar and spelling, use of literary models, and poetic, flowery style. In contrast, academic writing in English emphasizes organization and content, information, and linear discourse.

\section{Organization}

The four sources expressed similar opinions regarding organization of compositions. During an interview, Enya elaborated on the differences in organization between writing in English and Polish. "English is very difficult," she explained. "English... forces you to analyze and give examples. The organization (in Polish) was less important for my teachers. It seems to me a big mistake. I do think the organization of composition is (as) important (as) spelling and grammar." 
Along similar lines, Marek stated, "Polish students learn to write with an introduction, a development, and a conclusion." Polish teachers, he explained, concentrate on the mode of thinking, not the organization.

Carter asserts that Polish university students write in classical essay style, based on the humanitarian orientation taught in secondary school. According to Carter, the introduction asks an important question, like "What did the writer think about what he wrote. " The development (body) investigates and evaluates it from various perspectives. The conclusion announces the thesis.

Kristi explained that often students were given a title, then made a plan for it. She elaborated as follows, "In Polish we were not so concerned with organization. Do I like it? Why?"

\section{Content}

Marek addressed the importance of facts and the quantity of supporting points that English instructors require. He reports that in English, information and the amount of information drawn from the reading material, are considered more valuable than the students' own opinions and thoughts.

Carter found that in the persuasive mode of essay writing, Polish students rarely used recent historical facts to support their ideas. They preferred relying on internal proofs, such as definition, circumstance, and relationship. He explains the Polish avoidance of factual and statistical material in terms of students' negative reaction to government propaganda. Carter argues that:

Their reluctance to accept TRUTH from external sources, especially political sources, results in part from the Polish government's use of propaganda methods. Because their government misused statistics to distort the economic picture during the 1950's, the students almost never quote a statistician 
in their essay. In fact, to quote a percentage... to a Polish student is to court instant skepticism (p.8).

Furthermore, Carter contends that students avoid citing recent historical events as a source of evidence because of the government's propensity for rewriting the history books. "Yesterday's hero," he explains, "may become tomorrow's persona non grata" (p.8).

Kuhlman explains how the prevailing attitudes towards authority affect students' writing. She proposes that in an atmosphere of repression, teachers were not trained to encourage the type of inquiry and modes of thinking that might challenge the system. Instead, they relied on safer teaching techniques, emphasizing spelling, grammar, punctuation, and other specific skills. Consequently, she found students were unwilling to try out new ideas, or to take risks in their compositions. Students did not feel psychologically free to express themselves, and were reluctant to write persuasively.

\section{Grammar and Spelling}

The three sources quoted in this section deal with somewhat different aspects of composition writing. However, they are in agreement on the high degree of emphasis placed on local errors in evaluating student writing.

The following is a statement by Enya, exactly as written:

In my first language I was taught how to spell how to use the grammar and also how to write compositions, but the most importent thing it was the grammar and spelling. The students were trying to satisfy requermants of the educational program but not many of us could do it $100 \%$. I remember that in High School for "0" misteaks in spelling or grammar we could get "A" for one misteak "B" for 2- "C," for 4-" $D^{n}$ and for 5 or more " $\mathrm{F}$." I remember getting often " $\mathrm{D}$ " or " $\mathrm{C}$ " because of my problem with punktuation. 
Carter contends that Polish faculty base their teaching techniques on grammar and idiom drills, with little writing beyond the sentence level. Kuhlman asserts that only grammar, spelling, and handwriting were corrected in primary grades. All other aspects were ignored.

Evaluations were based on traditional homework and grades, and were equivocal at best. In discussing the grading system, Marek stated that a double grade was assigned, one for grammar, the other for "thought." One of Kuhlman's students said a typical teacher response might be, "Contents-very good, composition poor." Another of her students commented that teachers paid attention to grammar and spelling, and failed to note the content.

\section{Poetic and Flowery Style}

Three informants described Polish preference for figurative language, imagination, and emotional expressiveness in student writing. In comparing Polish writing with English, Enya stated, "Polish is more poetic. You put down feelings and dreams, you wander around and come back. There is no analysis."

Marek contrasted thinking and writing in Polish with that of English. He stated, "My (Polish) way of thinking is different. In my way of thinking I can be abstract, I can give certain impressions about feelings or emotions." Along similar lines, Kristi asserted, "Polish teachers like a more flowery style... not so clear." 


\section{Use of Literary Models}

Enya made no comments regarding the influence of literary models. However, since the four remaining sources are in agreement on this topic, their views are included as data. In an unedited account, according to Marek:

The impact of the literature you were reading (in class) showed in your writing. Every lecture we had a week of discussion about literature, French, German, English, Polish... some in translation of course. After a week you answered questions from the lecture; 'Why did this hero act like that or this'?

Sometimes we were answering questions about the literature.

Kristi explained that short essay questions usually focused on the literature assigned for the week. At the end of the week a longer essay was due, with an assigned topic that was also based on the readings.

Carter reports that the Polish faculty are frequently expert in British and American literature, and that literary criticism is a predominant component in the teaching of writing as a foreign language. The approach is essentially product oriented. Students examine features of published text, then "write a paragraph or short essay that attempts to imitate the published text ${ }^{n}(p .4)$.

According to Kuhlman, primary grade students were often forced to copy a summary and write dictations. At the upper primary levels, the most popular form of classroom composition was the "rozprawka," a type of argumentation. In this mode, a thesis is assigned, students give reasons pro and con, and draw a conclusion. In Chapter V, an account of Enya's First Language Essay suggests the $L_{1}$ influence of the "rozprawka" on her writing. 


\section{Linear Discourse}

Enya characterizes English discourse as very "clear," and defines Polish writing as "wandering" and "coming back." In Chapter V, Kristi, the First Language rater, uses almost identical words, "wandering" and "unclear" to describe Enya's own composing style in Polish. She finds, in critiquing the subject's Polish language essay, that the conclusion is disconnected from the earlier development of her topic. Kristi's comments on unsystematic language and ambiguous style correspond with frustrations noted by Carter.

Carter applies the theory of contrastive analysis to Polish and U.S. modes of composing. While residing in Poland, he was retained as final editor for two journals, one philosophy, and one literary. He recounts his amazement at the rhetoric as follows:

Never never have I read such academic prose that circled about a subtle definitional point... without coming to a clear and concrete conclusion. No journal in the western democracies would ever consider accepting such involuted work that quite lacks in a linear systematic method and concrete proofs. (p. 6)

He further explains, that in contrast to English writing, which promotes linear discourse, the Slavic system favors:

circumvoluted discourse, organization, and style: namely, turning, coiling, and folding around a central concept. (p.6)

Until secondary school, according to Kuhlman, very few teachers actually taught students how to write. In the advanced levels at the English Institute, however, students received intensive training in essay writing. The perception of one of Kuhlman's students was that only after years at the Institute, did he feel that his writing was becoming more systematic and rational.

In discussing cross-cultural variations in essay writing, Marek reports, 
Here (U.S.) it's more rational way of approaching essays. The structure is more organized. (In Poland) you didn't care if sentences logically respond to it. We weren't obligated to write clearly in a way that there is... a continuation. You could break or reconnect a certain impression-a thought. I feel like (the) impact (in the U.S.) is on information... more information you put from the material... it's more valuable.

\section{PRINTED MATERIALS SURVEY}

A feature of the climate for literacy in Poland is the scarcity of books (Kuhlman, 1992). Part of the problem is the popularity of books since the lifting of censorship. Book publishers simply cannot keep pace with the overwhelming demand, especially for Western authors. Booksellers cannot stock enough of these books, either in English or translated into Polish. Amongst the most highly-prized categories are books for children. The lack of books is also a problem on university campuses, where classes of twenty-five students often share one, or perhaps two texts. These are kept on reserve in the library, and loaned to students for two-hour intervals. This creates a frustrating and tiresome situation, for both students and teachers. It encourages a teacher-centered classroom environment, since teachers feel obligated to lecture on the content of the scarce textbooks.

Enya, a library aide, surrounded by books at the university, is a person who created an environment of printed materials in her home. This section reports the results of an instrument used to assess literacy in the subject's home. The results of the Printed Materials Survey are shown in Table III.

Enya completed the printed materials survey in Spring 1990, before her separation from her husband. She was asked to count all the reading materials in her home. She reported literature in 5 languages: English, Russian, Polish, Czechoslovakian, and German. The categories included: novels, poetry, textbooks, art 
books, other non-fiction, children's books, religious books, magazines, and newspapers.

TABLE III

PRINTED MATERIALS SURVEY

\begin{tabular}{|l|r|r|r|r|r|r|}
\hline Type & Total \# & \#English & \#Russian & \#Polish & \#Czech & \#German \\
\hline & & & & & & \\
\hline Novels & 31 & 5 & 0 & 26 & 0 & 0 \\
\hline Poetry & 4 & 0 & 1 & 3 & 0 & 0 \\
\hline Texts & 19 & 14 & 0 & 5 & 0 & 0 \\
\hline Art & 41 & 7 & 0 & 32 & 1 & 1 \\
\hline Other & 2 & 1 & 0 & 1 & 0 & 0 \\
\hline Non-fiction & & & & & & 12 \\
\hline $\begin{array}{l}\text { Children's } \\
\text { books }\end{array}$ & 224 & 58 & 26 & 124 & 4 & 0 \\
\hline $\begin{array}{l}\text { Religious } \\
\text { books }\end{array}$ & 7 & 4 & 0 & 3 & 0 & 0 \\
\hline Magazines & 116 & 2 & 0 & 102 & 0 & 12 \\
\hline Newspapers & 6 & 0 & 1 & 5 & 0 & 0 \\
\hline & & & & & & \\
\hline TOTALS & 450 & 91 & 28 & 301 & 5 & 25 \\
\hline
\end{tabular}

What follows are some comments and generalizations about the results of the survey. There was a very large quantity of printed materials $(450)$ in her home, which suggests that reading is an important part of her family life. The number and variety indicates a rich cultural background and broad range of interests. It also suggests a sharp contrast to the limited availability of books in Poland. The adopted homeland offers the luxury of an abundant supply of easily attainable reading materials.

The number of languages (5) was impressive. The quantity of Polish materials reported was 301, while the total of English, Czech, German, and Russian materials was 149. Polish language sources accounted for $68 \%$ of the total, and outnumbered English materials, 301 to 91 . English materials were more numerous than Polish only in the categories of textbooks (14 vs. 5) and religious books (4 vs. 3 ). 
Children's books were the only category to span all 5 languages, and when added together there were nearly as many books in second, third and fourth languages (100), as in Polish (124). Nearly 50\% of all printed materials were children's. These numbers suggest that the parents strongly encourage their children's literacy, and that they want the children to preserve their NL background.

Newspapers and magazines were overwhelmingly Polish, nearly $99 \%$. Of 122 materials in this category, only 2 were in English. In a previous section, it was reported that Enya has done no reading in $\mathrm{L}_{1}$ since 1989 . Yet only two years ago, almost every periodical in her home was in Polish, as was $68 \%$ of total reading materials. Perhaps when she began attending university, in 1989, she devoted all her reading time to improving her English, and ignored the Polish language materials in her home. Another speculation might be that her husband read the Polish newspapers and magazines. A third possibility is that the reporting was inaccurate.

\section{HOUR WRITING DIARY}

This section reviews the results of a log of Enya's literacy activities over a two day period in Spring, 1990. For the purpose of this study, Enya made a record of everything she wrote for two days in a "48 Hour Writing Diary." Samples of her writing are included in Appendix C. She kept track of the time spent on each activity, and reported spending about 3.5 hours per day on writing, all but 11.5 minutes related to school work. At the time when she completed this writing diary, she was studying English and Russian at the university. She reported spending 5 hours writing in English, 1 hour 40 minutes in Russian, and $1 / 2$ minute in Polish. The most time spent on a single writing activity was 2 hours work preparing a first draft and notes for an 
essay. During the two-day period, she spent almost half her writing time, 3.5 hours, working on the ENNR assignment. Table IV displays the results.

TABLE IV

48 HOUR WRITING DIARY

\begin{tabular}{|l|r|c|}
\hline Type & Minutes Spent & Language \\
\hline & 10 & \\
\hline 1. Check and address envelope & 10 & English \\
\hline 2. Class notes & 30 & Russian \\
\hline 3. Class notes & 60 & Russian \\
\hline 4. First draft \& notes & 120 & English \\
\hline 5. Notes & 10 & Russian \\
\hline 6. Class notes & 30 & English \\
\hline 7. First draft of essay & 90 & English \\
\hline 8. Notes (English class) & 30 & English \\
\hline 9. Note (about homework) & 1 & English \\
\hline 10. Telephone message & 0.5 & Polish \\
\hline & & \\
\hline Total & & \\
\hline
\end{tabular}

An examination of the discretionary time Enya spent on out-of-class work, reveals a sharp imbalance, favoring English studies over Russian. During the two-day period surveyed, Enya spent about 3 hours and 40 minutes on English activities outside the classroom, and allocated only ten minutes to her Russian notes. Perhaps she was rushing to meet a deadline for her English class, and set Russian studies aside for the duration. Or, perhaps the diary is indicative of how the subject generally prioritizes her homework time. A sample of her vocabulary study may be seen in Appendix C. 


\section{HOME VISIT}

This section presents an overview of a visit to Enya's home in March, 1990. Enya and Marek own their home in an integrated neighborhood in the metropolitan area. At the time of the visit, their two children were attending the Waldorf school, based on anthroposophic philosophy. In conversation, I learned that much thought, expense, and effort went into both the choice of schools, and the logistics of commuting to and from the schools. They take great pride in their son's achievements, and describe him as musically talented, self motivated, and a fast learner.

Both music and art are important elements in their family life. They have a piano at home, which both husband and wife play, and their son is a serious violinist. Art figures strongly in their lives, since Marek, like Enya's father, is an artist.

Enya expressed strong feelings about racial equality, and was pleased that her daughter had the opportunity to play with African-American children in the neighborhood. If she thought her children were becoming prejudiced, she said, she would transfer them to an integrated public school. Marek criticized his Polish countrymen for their bigotry, especially their antisemitism. Both felt that living in the United States gave them unique and welcome opportunities for multiculturalism.

Enya and Marek were gracious, attentive hosts. Their home reflected interest in, more intellectual, humanistic, and artistic concerns than in material possessions. Elements of their European background were expressed by the types of food, manner of serving, and topics of conversation. They prefer folk remedies and holistic treatments to Western medicine They also chose a school for their children which had European roots. 
The family was economically poor, but rich in European culture and intellect. During the visit, conversation centered mainly on music, books, children's education, university classes, and philosophy. The impression Enya and Marek made was of people who "walk their talk" by actively working at promoting integration and fighting prejudice on a daily basis.

\section{LINGUISTIC DIFFERENCES}

This section offers a brief account of one aspect of linguistic differences between the Polish, Russian, and English languages as described by Enya in a twopage essay, Personal Pronouns. The essay, written for ENNR I-2, has been corrected for readability by the researcher. The introduction states:

I am interested in the differences between languages, and I would like to try to share with the reader some of the issues which are interesting for me; but it is quite difficult to do it if one has a limited ability to use the language in which one wants to express it. Anyway, I want to write about it because it is special for me.

She goes on to explain that in Polish and in Russian the personal pronouns form a separate word class with clear-cut boundaries. English, differs, she explains, because it has a three-gender system in singular, but lacks the distinction in the plural. Having only,

one gender system in plural makes our expressions limited somehow, and not as precise as it could be. Especially in English, where the language expressions of other grammatical issues (for example, using a complicated system of past tense to describe just the right time of the action or state of being) are very accurate, it seems quite difficult to understand why the issue of personal pronouns is not complete.

The essay, Personal Pronouns, reveals Enya as an astute student of languages. Her systematic and inquiring mind analyzes the fine points of the languages she 
studies. She understands that languages are unique, and not completely logical. By choosing a topic which she finds interesting and meaningful, she overcomes English language constraints and successfully communicates her ideas.

Further insights about Polish language and culture are revealed in a conversation with Enya. She maintains that Polish culture is "new," only a thousand years old. In fact, it didn't have an alphabet until it adopted the Roman alphabet in the year 1,000. In order to transcribe an oral language, the Polish people had to add many letters, along with curlicues above the letters. "It's a folk culture... people dancing around a fire and telling stories. It's oral, not a written tradition," Enya explains.

\section{COMPARATIVE CULTURE}

Another ENNR essay, this one written during Spring term, is a window on Enya's attitudes towards Polish and American cultures. My Culture and Yours is a four page essay which compares the two societies on three points: religion, politics and language. She appreciates the religious tolerance she finds in the U.S., and contrasts it with her country. Poland, she claims, has a homogeneous population, which is "not very tolerant." She says $\mathbf{9 0 \%}$ are Catholic, and being a non-Catholic minority is often problematic.

Political orientation is a private belief in the U.S., and there is no visible sign of conflict between numerous parties. Poland, in contrast, has two opposing parties, and there is "no place for tolerance" between them. She gives two examples of how her own parents imposed their staunch anti-Communist convictions. Her father, she states, refused to maintain contact with his brother, a Communist official for the government. When she was a child, her parents forbade her to play with children 
whose parents were Communists. In 1981, when she lived in Warsaw, she saw signs on display in stores such as, "Communists not welcome."

Enya appreciates America's tolerance for many different languages. In her neighborhood, people are friendly, even though the languages they speak at home may differ. She describes her amazement when she found out that a shopkeeper in New York's Chinatown spoke no English. Closer to home, she was asked to work as a Russian medical interpreter for an American born logger who was hospitalized after a logging accident. To her amazement, she discovered that he was born and raised in a Russian-speaking community of Old Believers, and because of unique ethnic ties, never needed to learn English.

In Poland, to be a citizen a person must have one Polish parent and speak the language. Forty years of isolation from the West exacerbated the nation's linguistic insularity. Enya explains that foreign students on campus were severely criticized for speaking Polish with a heavy accent. The rationale was, "If they live with us, they should speak like us." She tells how her mother worries that her little granddaughter, growing up abroad, won't speak Polish perfectly, "And what will the neighbors think?"

\section{DISCUSSION OF CULTURE}

Enya recognizes that the United States is no longer a "melting pot" of immigrants hurriedly trying to shed and reject their former lives. She sees the process as slower now, and compares present-day American society to a "vegetarian salad" of separate ingredients. In Spring 1990, she wrote an assessment of her place in her adopted culture:

Arriving, acculturation, assimilation are behind me I believe. I am here, I do accept the culture and I feel part of the society.

But, I want or not I will have forever my Slavic accent and way 
of thinking. I do believe that the very first step to avoid prejudice towards ourselves is to be not prejudice towards others. This is it what I am working on.

Brislin (1981) identifies four processes in long-term adjustment, including: cultural adjustment, identification, cultural competence, and role acculturation. The following sections attempt to describe Enya's immigrant experience in terms of two of these categories.

\section{Cultural Adjustment}

Part of the sense of feeling "at home" in a society, is the "fit" of personality and culture. American culture suits an individual with high achievement motivation, because it provides many opportunities to fulfill those needs.

Empathic people develop communication skills faster than non-empathic people, according to Brislin (1981). Enya demonstrates respect and understanding of the different backgrounds and needs of others. Her ability to relate with other people is fostered by her desire for affiliation. She creates opportunities to meet, interact with, and help others.

Another factor is her strength of personality. Although she is sometimes selfdeprecating, she is a strong-willed, independent individual. She makes difficult choices, is hard-working, and eager to take on new challenges.

Brislin (1981) maintains that group affiliation and completion of task-related goals facilitate cultural adjustment. Enrollment in the university enabled her to develop both group ties and career goals. Equality of opportunity in education was available to Enya in the United States, and she grasped the chance to attend college. The university became a vehicle for acculturation, and opened a door which was ordinarily shut to people over thirty in Poland. 
As a woman, she also appreciated her adoptive culture. "Here I feel free," she remarked. "In Poland you can't be a woman without a man...Here I feel more positive, freer." Despite the odds of poverty, marital separation, motherhood, age and language, she was determined to graduate from college, and eventually earn a graduate degree.

\section{Identification}

I contend that Enya never felt a sense of belonging in Poland. The Poland that was home to Enya was a homogeneous, totalitarian, repressive environment with meager tolerance for diversity either in politics or education. It was essentially a monistic society in which conformity was the norm. In this atmosphere, she felt stifled by the rigidity of the social structure surrounding her. In emigrating to the United States, she discovered new norms for thinking and being which were more compatible with her own. She felt more at home in a pluralistic society. She identified with the democratic values of her adoptive culture, and the freedom to speak openly about her opinions. She recognized that prejudice was a factor in U.S. society, and yet appreciated opportunities to personally strive towards eradicating stereotypes from her life. Because of the congruence between her personal values and the values she encountered in the United States, she was able to embrace her new homeland, and to acculturate quickly.

This chapter showed some connections between how Enya became bicultural, as she became bilingual (or multilingual). The following chapter shifts the context from cross-cultural learning to academic training in a classroom setting. The classroom develops a culture of its own, since it functions as a specialized ad hoc group, coming together for a specific time and purpose (Damen, 1987). Chapter V discusses the nature of learning in the classroom community. 


\section{CHAPTER V}

THE LEARNING SITUATION: CONTEMPORANEOUS ACADEMIC LITERACY

The results which are presented in the following sections were gathered from numerous sources, and focus on Enya's studies of English in an academic context. Information about the classroom context is presented below. The formal learning situation was studied by means of classroom observations, teacher interviews, student interviews, and observations at the word processor. Data concerning Enya's writing ability were examined with the assistance of English language raters who evaluated three student essays and by a first language rater who examined an essay in Polish. A learning strategies task, "Strategy Inventory for Language Learning" (Oxford, 1990) was completed by the subject, and presents a profile of her preferred learning style. The subject researched herself as a writer in a self-report, "Case Study of Yourself As a Writer," adapted from Trimbur. A copy is located in Appendix G.

\section{CLASSROOM OBSERVATIONS: LIMITATIONS AND ADVANTAGES}

It is necessary to identify the limitations of classroom observations as a research instrument. The first problem is that of objectivity. The most significant feature of classroom observations is that objectivity cannot be claimed, and that objectivity in a scientific sense is irrelevant (Van Lier, 1988). Since every description is based on certain values and theories, it is therefore subjective.

A second problem is lack of completeness. The data represent bits and pieces of the context, rather than the total picture (Heath, 1983). The researcher selects 
particular events for description, and omits others. As a result, the context receives partial rather than comprehensive treatment.

If classroom observation is a flawed instrument, what justification is there for employing it in educational research? The classroom is a literacy community, based on a particular culture. Certain principles of social organization underlie the behavior and interactions within the classroom setting. In case study research, it is useful to examine the subject in relationship to the classroom environment. How does the classroom differ from other pieces of the culture? What, in particular, promotes or impedes the subject's language learning? Does she understand and follow the rules of the game? What is her role in class? Is she an active or passive learner? How does she participate and interact with instructors and peers? Are there changes in her classroom behavior over a period of six months or more?

The following guidelines, based on Van Lier (1988), may be helpful when the decision is made to study the classroom context:

1. Relate pieces of the classroom culture to components of the larger culture.

2. Record data as a tool for mediating between subjectivity and detachment.

3. Identify the values and the theories of language learning that color perceptions of what is going on.

4. Interpret observation and description through agreement with other participants and sources of data.

The next two sections present condensed accounts of what occurred during several visits I made to Enya's English classes. They highlight sociocultural aspects of language learning, including academic and social roles and expectations. 


\section{CLASSROOM OBSERVATIONS: WINTER TERM}

ENNR classes were two hours long. Two classroom observations took place in ENNR Intermediate-2 during February, 1990. The researcher, assuming the role of non-participant observer, sat in the back of the room during both sessions and took notes. Eleven students and the teacher were present during the first observation. The students sat in rows at movable desks. Enya arrived thirty five minutes late for class. She worked with Van, a twenty-nine-year-old Vietnamese male student. The tasks were the completion of a cloze passage, and discrete point exercises based on the reading.

The second observation was completed ten days later. This time there were eleven students and two observers besides the researcher. The instructor asked "Who hasn't done the reading for today?" and Enya said she hadn't. She explained that she had been absent for a week because she was sick with pneumonia.

For thirty minutes students worked alone or in pairs on a vocabulary exercise. Enya chose to work with Van. They seemed to have fun working together, although they failed to complete the task correctly. The last half hour of class was devoted to a lively discussion of a reading assignment. Enya did not laugh at some immature remarks that were made by younger classmates.

Winter term observations revealed that Enya was sometimes late, had many absences, and chose to work with older peers rather than with younger students. As a more mature student, she was not amused by the same comments as the recent high school graduates. She seemed to participate more actively and comfortably when the task was class discussion than when specific lexical items were the objective. 


\section{CLASSROOM OBSERVATIONS: SPRING TERM}

The third and fourth observations took place during Spring term in Advanced ENNR, with a different instructor. When the third observation began, eleven students were present. On this occasion three students walked in late, but Enya was on time. As in the previous class, seating was in rows at movable desks. The observer sat across the room from the subject, and once again assumed the role of non-participant observer. Enya sat diagonally behind her friend Van. The class began with a quiz on a reading assignment.

The quiz and follow-up activity lasted for 20 minutes. During the quiz, Enya's frequent erasures suggested that she was having difficulty. The second classroom activity was devoted to small group discussion based on the reading. Enya was both an active participant and an active listener. The last 20 minutes of class focused on sharing ideas about the reading. Now the class was engaged in whole group discussion. The following excerpt shows Enya's unedited, sensitive, empathic comments on Maxine Hong Kingston's "Misery of Silence":

She was forced to talk. She had to talk...such a terrible feeling. Suffering. The Chinese girl is symbol of newcomers to the United States... her personality, her inner life. Because she doesn't talk the black (paint) is the barrier. Now as an author she hopes to break the barrier. She was hoping her ability would improve.

My impressions were that Enya displayed enthusiasm, fluency and clarity in her response to the reading. She communicated mature ideas, and took an involved and active role in the discussion. Any evidence of Enya's frustration with English appeared during the writing, rather than speaking activities. 
The fourth and final classroom observation took place two weeks later. Class began late with nine students present, and Enya was even tardier. The stated objective of the lesson was to correct stylistic errors in a given sentence.

During the lesson on style, Enya seemed to lack confidence in her knowledge of rules. She offered several incorrect responses which were ignored. Yet, she was persistent, and kept trying until one of her responses was acceptable. Over the span of two terms, Enya's ability to work with the younger students seemed to improve. Her attendance also improved during the second term. Four patterns which seemed to persist over time were frustration with discrete point exercises, preference for classroom discussion on a higher thinking level, spotty preparation, and tardiness.

\section{OBSERVATIONS AT THE WORD PROCESSOR}

The purpose of observing the subject at work on the computer was to have direct access to the writing process. Watching Enya at the computer provided a glimpse of what, when, and how she made changes as she composed. During Enya's first term in ENNR the students were introduced to the computer lab and received formal training in using the Apple Ile. Each week one class hour was devoted to writing and/or revising at the computer. By February 1990, when the first observation took place, the subject was familiar with basic word processing procedures.

The first session at the computer lasted a half hour. During this observation, Enya was working on a first draft of "My Memories of Snow," an assigned topic for ENNR Intermediate-2. Between 11:15 and 11:30 she typed slowly, using the "hunt and peck" method. She expressed need for a dictionary, and requested help from the researcher. She frequently paused to edit between lines 1 and 7 , and reread from the beginning after line 8 . She paused again to reread the entire text after line 11. After the 
seventh line she repeated that she missed not having a dictionary, and again asked for help. At 11:37, before starting a new paragraph she asked for help with spelling, and spent the next two minutes attempting to correct her misspellings. However, she ignored several, for example, "reflektions" and "frosen." She paused after these misspellings, as though she sensed something wrong, but attended to lexical concerns instead.

The second computer observation took place in March and was twenty minutes long. Enya was typing a second draft from a handwritten first draft of a composition called "Personal Pronouns." She asked the researcher several questions during this session. She inquired about plurals, and made multiple spelling changes in a single word. Struggles with word forms and spelling persisted, including problems with "using," "emphasize" and "describe." After numerous misspellings, Enya sat back and shook her head from side to side.

When she resumed, she did not look at her first draft at all. She self-corrected an error, and her words flowed without error or pause for several sentences until she wrote, "nit komplete." Again, she was able to self correct. At 12:20 she said, "I am really stressed out because of time, and I cannot think clearly," and the session ended.

Enya's goals differed during each of the two word processing observations. During the first session, in February, 1990, she was composing her first draft. Nearly all of her time during the second session was aimed at transcribing and polishing a second draft from a handwritten draft. The results of the first session at the computer consequently suggested more process operations than the second. The patterns which emerged during composing were: type-pause-revise-reread. Revisions were done only at the word level, and involved either vocabulary or mechanical concerns. There was no attempt to revise on content or organization levels. At the computer, Enya 
seemed to lack independent vocabulary skills, expressing need for a dictionary and seeking help from the researcher. An effective compensatory strategy was to substitute a word she knew, "feet" for a word she could not remember, probably, "shoes."

Enya frequently paused after a spelling error to revise, but performed an operation unrelated to the error, by changing or adding a word. For example, in the first essay, after a pause following the misspelled "frosen," she added "lakes." The fact that she changed correct usage, "reflektions on," to "reflektions of," suggests that her knowledge or rules was incomplete. While engaged in editing, she missed several mechanical errors.

During the second session, it was only when she stopped transcribing from her first draft that she attained some fluency. While copying from her handwritten draft, she was preoccupied with errors. The strategy that seemed to work best for her was to forego editing completely.

According to Krashen (1987), conscious learning may operate as an editor, or Monitor, when three conditions prevail. These requirements are time, focus on form, and knowledge of rules. Two observations at the subject's side while she composed at the computer suggest that Enya repeatedly misapplied the Monitor. Although she made frequent attempts to use her conscious knowledge of rules in editing, she lacked the necessary knowledge to apply the rules correctly. She seemed to sense that something was wrong, but was unsure of what it was. At the computer, she behaved like Krashen's (1987) Monitor overusers, whose preoccupation with mechanical concerns disrupts their fluency. Although Enya had mastered the basic skills of word processing, she did not seem comfortable with it. Her attitude towards computers was succinctly expressed in a "Case Study" document discussed below, in which she wrote, "I like handwriting; I hate computers." 
Studies by Collier (1983) and Benesch (1986) attempt to describe how the composing processes are affected by computer technology. Both studies found that methods of revision did not differ significantly between traditional modes of composing and composing at the word processor. Benesch found that individuals varied according to how they interacted with the computer. Stylistic preferences determined whether the student used the computer to generate ideas, to edit, or to simply master the technology.

Computers will continue to have a significant impact on the future of writing and of writing instruction. New technologies will facilitate activities such as interactive and collaborative writing and editing on big screen computers (Freedman, 1987). Further research is needed on how learning styles, learning strategies, and proficiency levels are affected by computer interaction.

\section{TEACHER INTERVIEWS}

An interview between the researcher and Enya's ENNR Intermediate-2 teacher took place near campus in March, 1990, while she was enrolled in his class. A personal interview with her Advanced ENNR instructor took place in June, 1990, and a telephone interview was conducted in May, 1992.

The results of the interviews with both instructors were similar in most respects. Each contributed a slightly different perspective, but their assessments dovetailed to a large extent. 


\section{Composite Teacher Interview}

According to her instructors, Enya was a serious, mature student, and ranked in the top third of the class. They speculated that she would have preferred a more serious environment than what she found in ENNR. In class, she and another student, Marya, liked to chat in Russian, and the instructor sometimes had to ask them to refrain. Enya and Marya kept mostly to themselves, but Marya blended in better. Enya sometimes chose to work with Van, but was more aloof with the younger students. She was a risk taker, but somewhat less so than Marya. In comparison to Marya, she was less assertive and more vulnerable. She participated to a high degree in all activities, whole group, small group and pair work. Overall, she was very motivated.

Enya was often late, and frequently came to class tired because of her responsibilities. The instructors were aware that she was having problems with her husband and with her children's frequent illnesses. Her own health was problematic, especially during a siege of pneumonia which resulted in several absences. (During Winter term she was absent 7 times, which amounted to missing $20 \%$ of the course. In contrast, during Spring term she was only absent 2 or 3 times.) Enya was exceptionally diligent about keeping in touch, and was the only student who turned in a medical excuse for an absence. She succeeded in handing in all her assignments, although they were often late.

Several behavioral contrasts were reported by the two instructors. For example, during Winter term she missed the deadline on 4 out of 11 assignments. She also turned in handwritten drafts when typewritten ones were expected, but the teacher accepted them out of sensitivity to her family obligations. In contrast, she was 
punctual with all her work during Spring term, and there was no indication of handwritten drafts or frequent absences.

In composing, Enya has great sensitivity and good ideas, but is constrained by her inability to express herself in written English. Her oral skills are strong, and she is a good communicator. The only limiting factor is her writing, not her speaking. She is a good critical thinker, perceptive, and has unique analytical skills.

At the time she was enrolled in ENNR, her expressed goal was to earn an MA in Slavic languages. The instructors predicted that until her cognitive skills were integrated with other linguistic competencies, she would have difficulties. They reported that she was limited by serious word order and word structure problems, and wrote incoherent sentences. One of the instructors conjectured that she may have been translating from Polish. The other instructor remarked that Enya was "held captive by minimal language." The second instructor explained that:

In an essay about visiting her aunt's house, she wrote about wonderful things: smells, toys in the attic, the kitchen as her favorite place... all held back by language. I would say that Enya is intelligent, well educated, and has great insight into Slavic languages. However, in many ways her English is an impediment to her. It's just an afterthought, there's no importance to learning language; she's more interested in ideas and concepts than in lexical concerns.

The teachers maintained that Enya was very opinionated and had set ideas. She often displayed intolerance towards other people's opinions and/or suggestions. During writing conferences she often balked at the teacher's suggestions. In the opinion of one instructor, "This was evidence of her strong will." She also had problems detaching herself from her work. 
When queried on the effect of Polish culture, the teachers suggested that European background helped facilitate adjustment. One effect of being European is graphically illustrated in the following anecdote.

During a class discussion of prejudice, I asked which students had felt the effects of discrimination in the United States. With the exception of Enya and Marya, every student had suffered from prejudice. The Europeans are white and their accents have no pejorative connotations; in fact the way they speak may make them more appealing and interesting to native speakers.

As a student, Enya seemed to be intrinsically motivated. One instructor commented:

I felt like she was learning something. She is the kind of person who doesn't care about grades, she just wants to leam. In the beginning, she makes a judgment about a class. If she decides it's good, she is conscientious; otherwise she takes it easy. We did sections on prejudice and language in the reading packet. She was interested, so she worked hard.

Both instructors agreed that Enya would be a positive addition to any future class. They commented that she is sensitive, and more vulnerable than her friend Marya. To help motivate her, the teacher should present ideas that are challenging to think about; ideas about stimulating subjects which she finds interesting. Two subjects she enjoys discussing are politics and human behavior.

In one teacher's opinion:

The nature of her ideas and creativity is very strong. Her grammatical structure is very weak, and mechanics are lacking. Grammatical errors create a wall. If professors see a poorly written paper, I mean grammatically poor, they write it off. There seems to be less tolerance in English departments than in other academic areas.

When asked to give advice for conferencing with Enya, the instructor replied:

I would ask her about presentation of ideas: Are they clear? Is development adequate? I suggested that writing comes alive through details. I circled grammatical problems such as verb tense, and I'd encourage her to figure it out for herself. She could come back for help if she needed to. 
When the instructors were asked to evaluate Enya's skills, they rated her "excellent" on creativity, and "good" on organization. In the areas of spelling, punctuation, and grammar, they ranked her fair. Her final grade was B for each of the three terms of ENNR.

\section{INTERVIEWS WITH ENYA}

The subject's views about the learning situation at the university, and about her academic goals were revealed in five interviews which took place between February and May, 1990. Each interview was informal and open ended.

Information gathered from the subject interviews forms the basis of the following generalizations. Enya's views of the learning situation suggest two broad categories; Preferences and Frustrations. The section on preferences includes both likes and dislikes.

A) Preferences:

1. Enya prefers a demanding teacher with high expectations. She is critical about the books she is assigned, and favors "interesting" readings. She liked Langan (1988) because the text provided structure, but she did not favor Raimes (1987) because she found the format confusing. She felt negative about a teacher who failed to set high standards, and expressed reluctance to share the work she did in that class with the researcher. Her harsh opinion of the work she did during Winter term may be unjustified. The following section will reveal that one of the essays she wrote for this class was judged superior to essays she wrote either in Fall or Spring terms, by four experienced ESL composition raters.

2. Homework is important to her, because it helps her to gain independence. However, as the interviews reveal, she sometimes came to class unprepared. She was 
late turning in 4 out of 11 assignments (Winter), took a "0" on one quiz, and walked out during another (Spring).

3. She would prefer not to have grades, and suggests that she would work harder if she didn't have to worry about getting C's. She wrote that she studies effectively "only this what I have interest in. I do not think the grades stimulate my learning process. I think they often slow down the process." Bad grades could stand between her and her goal of getting admitted to graduate school, so she feels pressure to do well.

4. Classroom activities which she likes include discussing interesting readings (Fall, Spring), and grammar (Fall). She would have wanted to take an additional grammar class, but could not fit it into her schedule. She dislikes vocabulary work (Winter) and walked out during a vocabulary quiz (Spring).

5. She has strong preferences and likes reading authors whose opinions she shares. In Russian Literature she would have preferred reading the dissidents. She also has strong opinions about her writing, and expressed dissatisfaction with what she wrote during Winter term, but was pleased with her progress during Spring term. Her set ideas about her work may account for her tendency to "balk" at feedback during conferences.

6. She preferred structure, and felt good about the Langan (1988) book because it "tells you what to do." This text prescribes using a detailed outline format for essay writing. It gives step by step guidelines for every aspect of planning, organizing, and executing a standard English essay. In an interview with her husband, the researcher heard the following description. He said, "Enya has a systematic mind; she likes order. That's why she likes grammar." She expressed a similar attitude in her own words; "Every house needs a structure before you build the rest." Yet, she was aware of the 
limitations of the Langan text, and said "It's good for now." Yet, she couldn't see herself writing in that restrictive format forever.

B) Frustrations:

1. Physical environment is important to Enya, and she was frustrated at not having an adequate study area. She made an attempt to improve the situation by renting a place, but it did not work out for her. She longed for the generosity of her friends in Poland, which enabled her to study freely in their homes.

2. Illness caused her to miss $20 \%$ of her Winter ENNR course, and two classes at the beginning of Spring term. Her children were frequently ill, and her own health was often a cause of absence. She was often late, and sometimes tired because of her family, work, and academic responsibilities.

3. Her frustration with herself as a writer of English was expressed when she remarked that it would take "twenty years to get comfortable writing in English."

4. She is vulnerable about feedback and also about prejudice, although she herself stereotyped Orientals as "polite" but "close-knit."

5. She was frustrated by limitations imposed by computer lab regulations.

\section{HOLISTIC EVALUATIONS OF STUDENT ESSAYS}

In June, 1992 four experienced ESL composition raters met at the researcher's home in order to evaluate three essays written by Enya while she was a student in ENNR. One essay from each term was selected in order to examine her progress over a nine month duration, and a letter code of "A," "B," and " $\mathrm{C}$ " was assigned. Copies of the essays are included in Appendix E. Two of the compositions, "B" and " $\mathrm{C}$ " were Comparison/ Contrast type. The third, essay "B" was a narrative. For the sake of 
uniformity, a final draft of each composition was chosen for evaluation. The essay labeled "A" was composed during Winter term, essay "B" was composed during Fall term, and essay "C" was composed during Spring term. Each essay was typed and double spaced. Essay "A" was 2 pages long, and contained 582 words, essay "B" was 2.25 pages long, and contained 634 words, and essay " $\mathrm{C}$ " was 4.25 pages long, and contained 1,092 words. The longest essay $\left(" \mathrm{C}^{\prime \prime}\right)$ was nearly twice as long as the shortest (B). The raters were instructed to score the essays on a 10 point scale as described in the Method section of this paper. Agreement was close on both " $\mathrm{A}$ " and "C." On essay "A," the scores ranged from 8.6 to 9.1 for a variation of 0.50 . The range of scores was highest on essay "B," ranging from 5.1 to 8.2 for a variation of 3.10. One particular rater scored essay "B" very low across the board, which may account for the discrepancy. On essay " $\mathrm{C}$," the range was between 8.4 and 9.2 for a variation of 0.80 .

Inter-rater reliability was calculated by dividing the lowest rating by the highest rating in each essay. For essay "A," the lowest was 8.6, highest 8.2, with a 94.5\% reliability. For essay "B," the lowest was 5.1, highest 8.2 , with a reliability of $62 \%$. For essay " $\mathrm{C}$ " the lowest was 8.4 , highest 9.2 for a reliability of $91 \%$. The average inter-rater reliability was $82.5 \%$.

Inter-rater reliability for each essay is shown in Table V. 
TABLE V

INTER-RATER RELIABILITY

\begin{tabular}{|c|c|c|}
\hline Code & $\begin{array}{c}\text { Range of } \\
\text { Scores }\end{array}$ & Reliability \\
\hline "A" & $8.6--9.125$ & $94.5 \%$ \\
\hline "B" & $5.1--8.2$ & $62 \%$ \\
\hline "C" & $8.4--9.175$ & $91 \%$ \\
\hline
\end{tabular}

The title, date, letter code, average score, and word count for each essay are shown in Table VI.

\section{TABLE VI}

ESSAY DETAIL

\begin{tabular}{|l|l|l|l|l|}
\hline Title & Term & Letter Code & $\begin{array}{l}\text { Average } \\
\text { Score }\end{array}$ & $\begin{array}{l}\text { Word } \\
\text { Count }\end{array}$ \\
\hline Visiting My Aunt's House & Winter & "A" & 8.91 & 582 \\
\hline Kaffehuis Or Broadway Bistro & Fall & "B" & 6.66 & 634 \\
\hline My Culture and Yours & Spring & "C" & 8.73 & 1092 \\
\hline
\end{tabular}

The evaluators examined each essay in three discrete categories, English Language, Content, and Organization. In order to determine whether the subject showed strengths or weaknesses in any of these writing areas, they were examined across the board for all raters and all three essays. Table VII shows average scores for each category on a 10 point scale. 
TABLE VII

ESSAY SCORING

\begin{tabular}{|l|c|}
\hline Area & $\begin{array}{l}\text { Average } \\
\text { Score }\end{array}$ \\
\hline English Language & 8.00 \\
\hline Content & 8.25 \\
\hline Organization & 7.93 \\
\hline
\end{tabular}

\section{DISCUSSION OF HOLISTIC EVALUATIONS}

Several generalizations about the holistic evaluations can be noted. The results show only minute differences in the ratings of Enya's skill in the three categories: English Language, Content, and Organization. Improvements in quality were suggested over the duration of the academic year, with essay "B," the Fall term assignment, rated 6.6, over 2 points lower than the two subsequent assignments. All the raters ranked the compositions in the Average, Good, or Excellent range, with none at the lower end of the 10 point scale (Poor or Fair). Quantity improved, with approximately $90 \%$ increase in essay length between Winter and Spring terms. The dramatic increase in length may be accounted for by the requirements set by the instructor for the Spring assignment. The raters preferred the narrative essay by a narrow 0.2 margin over the Comparison/ Contrast composition written for Advanced ENNR.

\section{FIRST LANGUAGE ESSAY}

Enya composed an essay in Polish in response to an assignment given by the researcher. She was asked to compose a one to two page composition in her native 
language on a topic of her choosing. The essay, written in July 1990, is a two page rough draft, handwritten in pencil. See Appendix F. Kristi, a native speaker of Polish, was asked to rate the essay. According to Kristi, the translation of the title is, "My Second Meeting With Brunen Schultzen." The essay is based on the late Polish writer, whose political perceptions Enya admired.

Kristi was asked to evaluate the essay impressionistically according to style, clarity, vocabulary, organization, and content. The categories of organization and clarity were problematic for the reader. Kristi described her reaction to the essay as follows:

It is very difficult... she is going somewhere, and coming back with her writing. She drops an idea and picks it up later. She picks up an idea, tries to develop it, and throws it away. Like when you are tired all the ideas of the day are just mixing together. It's unclear. The essay as a whole is understandable, but it falls apart in small sections. She is telling about everything, but nothing. She doesn't develop it very well. The conclusion isn't connected with anything in the paper. Her conclusion says that the writer is very important to her because he describes East European Jewish culture. But that doesn't appear any where else in the paper.

Kristi gave the composition an overall rating of Fair on a scale of Poor, Fair, Good, or Excellent. Her justification for the grade was that the essay "doesn't meet the requirements for a teacher." Vocabulary was rated Good. Regarding style, Kristi commented, "Not very good within a sentence. This is very typical of Polish writing...to use very long sentences. And when writing very long sentences she misuses grammar. Also she has unrealistic language."

Kristi is a science major, and not an experienced composition rater, yet her impression of Enya's Polish language essay adds data to the profile of the subject as a writer. The results of the evaluation of a first language essay suggested that Enya is not highly skilled as a writer of Polish. However, in spite of the fact that the rater 
found problems with organization and clarity, she was able to understand the gist of the composition. She suggested that it did not meet the standards for an academic paper, and that it revealed problems in style and grammar.

Kristi commented that the conclusion of the paper seemed unrelated to previous content, as though it was "stuck on" as an afterthought. However, data obtained from several first language sources, including Enya, her husband Marek, and Professor Carter (1986), suggest that conclusions which resemble an "afterthought," are typical of Eastern European rhetorical style. By the time Kristi was asked to evaluate the essay, she may have been so familiar with English rhetorical patterns, that she applied English standards to an essay written in Polish.

In the final sections of this chapter, the results of three self-assessment instruments are discussed. Enya submitted a written response to each. The first was completed in 1990, and the second and third were mailed to the researcher during Summer, 1992. Enya reported that she liked doing the profiles.

\section{QUESTIONNAIRE ABOUT FIRST LANGUAGE COMPOSING}

During Winter, 1990, Enya provided written responses to the following questions:

1. How do you get ideas in your first language?

2. What were you taught in school?

Her reactions to the questions are as follows:

1. In my first language I get ideas the same way as it is for me in English, just faster.

2. In my first language I was taught how to spell how to use the grammar and also how to write compositions, but the most importent thing it was the grammar and spelling. The teachers had a leading role towards the students. They were the 
authority. The students were trying to satisfy requermants of the educational program but not many of us could do it $100 \%$. I remember that in High School for " 0 " mistakes in spelling or grammar we could get "A" for one mistake " $B$ " for 2 - " $C$ " for $4-" D^{n}$ and for 5 or more "F." I remember getting often D's or $C$ 's because of my problem with punctuation. The organization of the composition was less important for my teachers. It seem to me a big mistake. I do think the organization of composition is as important as spelling and grammar in school. I was taught how to use grammar and spelling.

\section{LANGUAGE LEARNING STRATEGIES}

Enya completed the Strategy Inventory for Language Learning (SILL):

Version for Speakers of Other Languages Learning English (Oxford, 1990). The inventory consists of six parts, (A-F). Each part covers a different type of strategy. The student reads each statement and decides how true it is for him or her according to a five point scale ranging from 1 (never or almost never true of me) to 5 (Always or almost always true of me). Enya's profile is shown in Table VIII. 
TABLE VIII

ENYA'S STRATEGY INVENTORY FOR LANGUAGE LEARNING (SILL) PROFILE

\begin{tabular}{|l|l|c|}
\hline Part & Categories of Strategies & $\begin{array}{l}\text { Average on This } \\
\text { Part }\end{array}$ \\
\hline & & \\
\hline A. & Remembering more effectively & 2.88 \\
\hline B. & Using all your mental processes & 3.42 \\
\hline C. & $\begin{array}{l}\text { Compensating for missing } \\
\text { knowledge }\end{array}$ & 4.5 \\
\hline D. & $\begin{array}{l}\text { Organizing and evaluating your } \\
\text { learning }\end{array}$ & 3.66 \\
\hline E. & Managing your emotions & 2.66 \\
\hline F. & Learning with others & 3.83 \\
\hline & & \\
\hline OVERALL & & $\underline{3.46}$ \\
AVERAGE & & \\
\hline
\end{tabular}

The profile that emerges is that of an active learner who effectively utilizes all the strategies at hand. Her dominant strength as a learner is in compensating for incomplete knowledge by guessing, using context clues, and paraphrasing. Another strong area is social interaction, where her main strategies are "asking" about language and learning about U.S. culture. She always, or almost always pays attention to what English speakers are saying. She integrates all her mental processes in two ways, speaking and writing. She almost always starts conversations in English, and does all her writing in English. First language cognates help her learn new words, and she makes written summaries of new information in English.

Enya's weakest category, according to her profile, is in managing her emotions. Yet, she reports that she is able to relax and is not afraid of making a mistake. Her lower scores in this area related to the fact that she does not communicate her feelings about learning English either to a person or a diary. In a follow-up telephone 
conversation we discussed the inventory and Enya explained: "My strategy is mostly talking to people. Polish people are not so interested in reading and writing. In Poland people talk all the time. They visit and talk."

Enya's strengths appear to lie in the oral/aural areas rather than literacy competencies. Her discomfort with certain aspects of writing are revealed in the following anecdote. I was asking about her techniques of revision, and she retorted wittily, "I don't like to revise. I write it and I hand it in. If I polish, I make it Polish." Data from her conversations, her facility with the think-aloud task, observations of her eagerness to participate in class discussions, and her skill in speaking several languages, suggest that of the language categories, she is most adept at speaking and listening.

In her native Poland, Enya had studied beginning English conversation for only three months. Once in the United States, she acquired English naturally, through informal tutoring sessions with a neighbor. The neighbor, Linda, was a junior high school English teacher. Almost every day, she would visit Enya's house and they would talk, sometimes for hours. She never corrected or discouraged Enya from trying. When Enya made a mistake, Linda would repeat it the correct way. Through their conversations, Enya began to believe in herself. Linda spoke naturally and very simply. She created a comfortable atmosphere; she was a friend, an advisor, and a teacher.

Others also came to the house and spoke English. Enya made an effort to converse with her two children in English as well. In 1987, after one year in the United States, she felt confident enough to seek employment and took a job as night janitor at a department store. In Fall 1988, she began taking classes at the university in 
drama and piano. One year later, in 1989, she entered the ENNR program, and had her first experience learning to write in English.

\section{CASE STUDY OF YOURSELF AS A WRITER}

The second self-assessment instrument, was an assignment intended for native speakers of English, adapted from John Trimbur, Boston University. Enya was asked to read the instructions and write her responses as best she could. There was to be no follow-up paper, as in the original assignment. The assignment, as well as a sample of the subject's response may be found in Appendix G.

The purpose of the "Case Study of Yourself As a Writer" was for the subject to do "research" on herself by exploring both her writing history and her present writing patterns. The assignment asked questions about general issues in writing. These are summarized in Table IX.

TABLE IX

GENERAL ISSUES IN WRITING

\begin{tabular}{|l|l|}
\hline 1. Moments & 7. Process \\
\hline 2. Stages & 8. Intervention \\
\hline 3. Kinds & $\begin{array}{l}\text { 9. Response and } \\
\text { Feedback }\end{array}$ \\
\hline 4. In-School vs. Out-of-School Writing & 10. Problems \\
\hline 5. Audience & 11. Myths \\
\hline 6. Physical & \\
\hline
\end{tabular}

Enya began the assignment by numbering the categories $1-11$, and by making brief notations in margins beside 5 of the 11 sections. Her account is described and paraphrased below. Direct quotes are copied exactly as she wrote them. 


\section{\#1 \& 2 Moments and Stages}

Enya combined her responses to the first two questions, but dealt with stages and neglected moments.
1973-77 "Creative":
Her first successful experiences in writing
1984-86 "Emotional": occurred in Polish high school.
1989-91 "Semi-academic, stiff": close friends in Poland. This describes the papers she wrote in Russian for her literature classes. While in Germany, she wrote letters to her
1991-92 "Free, relaxed": She feels more free writing in English (papers for History classes, and letters to close friends in English and Polish).

\section{\#3 Kinds}

When she writes papers she feels "stiff," but writing letters is more "flexible."

\section{\#4 In-School vs. Out-of-School}

Enya's response was similar to \#3, but she elaborated.

In-school writing is for more less personal, why? I am not sure. Maybe I am less myself, still a stranger, alien, less comfortable, less safe, feel often out of place. Letters are more personal, I am more myself, more relaxed, more emotional.

\section{\#5 Audience}

She writes for three audiences, "teachers, people I love, friends." "Teachers penalize me because I don't want disappoint them. So some friends do. But not close friends. Writing to them is a pleasure." She is sensitive and vulnerable to feedback, as she describes: "Yes, I do remember bad experiences more that good once. Because I 
am so called soft conscious, easy get hurt. Had more bad than good experiences (no support at home-non of my parents writes, eccept letters)."

\section{\#6 Physical}

She likes to sit at a table in the living room where she is comfortable and has good light. "Usually I write mid-slow. I like handwriting, hate computers, etc., use pen. I sit not to close to the table so I can put my head on my left hand (which is laying on my leg). As I am writting I move the paper up only with my right hand. Because I don't use help at my left hand while I write the paper usually dances on the table, but I am able to manage to write anyway. The only problem is if the reader can read it." She included a sketch of herself sitting at a table in the position described above.

\section{\#7 Process}

Enya combined part of answer \#7 with \#6. She described her writing patterns: "start, think, write, think, write, reread, correct, write, stop, think, write, reread, change, correct, stop, go away, start again (but not from the beginning, just continue)" ands so on to the end of that particular writing session. To the question about generating words, she responds, "I just sit and write until the paper or letter is finished... I write what ever I remember on subject, what I have been processed in my brain before." In academia there are consequences for writing quickly. She explains, "My school papers are always first draft therefor bad grades too. I do the best on exams, fast answers. No revising, editing. I loose my interest pretty fast in writting. 
Sounds like I am neurotic." She says what gives her "the most trouble is rewritting, revising. Why? I get discouraged easy."

\section{\#8 \& 9 Intervention, Response and Feedback}

Enya's reaction to the issue of intervention overlaps her answer to the questions of response and feedback. She describes how she responds well to positive feedback, and how frightened she is of criticism. Discussing a highly critical instructor, she relates, "I freeze inside with every red mark of his pen." She wants to feel safe in the writing situation. She expresses her feelings, "Yes, I am a child somewhere inside I am, and need warmth and acceptation. No more intervention. No peers involved."

\section{\#10 Problems}

Enya is frustrated because she knows she is intelligent, and has wonderful ideas, but they come out incoherently. Her biggest problem, she says is "how (to ) put my brilliant ideas on paper. I seem to be so intelligent when I think, and it comes on paper is such deformed way, so primitive, sometimes (only) I have read my writtings again (after few days) and hardly could understand what I ment (past tens- of mean)."

Enya asserts that her greatest progress is that she does not care anymore about spelling. "This in the past created (a) block in writting for me... If I had to check one word in the dictionary, than I am not sure at every other one and my writting is over...Yes, all my papers are like that (freewriting). Bad grades. I don't care, I feel free." 


\section{\#11 Myth}

Her neighbor thinks that all writers are interesting people. Since she told him she wants to write a book, he thinks she is interesting.

Enya very successfully accomplished the task, "Case Study of Yourself As a Writer." Her account describes a writer who is avoiding the issue of mechanics. She is frustrated in her attempt to communicate her ideas coherently, and is discouraged by negative feedback. She likes to write without pressure, and especially enjoys writing letters to friends. Her preferred writing strategy is freewriting, putting down everything she knows about a topic. She uses this technique effectively on quickly written short answer questions, which do not demand the difficult tasks of editing or revision.

\section{"CASE STUDY" SELF PROFILE}

Enya is a product of a formal educational system, which was basically alien to her nature as a creative, free spirit. However, in spite of her dissatisfactions, her Polish education provided her with many skills for acquiring English. English became her fourth language, after Polish, Russian, and German. Prior to exposure to English, she had extensive formal training in Polish and Russian. She studied beginning level conversational German while living in Germany, while picking up the language in a natural setting. By 1984, when she arrived in the United States, she was adept at three languages and used her linguistic facility to acquire a fourth.

Picking up English in a naturalistic setting became a challenge, even fun. Because of the necessity for employment, and Enya's enjoyment of language learning, she was an eager, highly motivated learner. She gained confidence, and set herself the 
goal of completing a college degree. When she entered the university in 1988 , she had no formal training in English. At first she took classes which demanded some oral/aural skills, but had no literacy requirements. One year later, she embarked on a path which required reading and writing proficiency, namely ENNR.

In ENNR, she found the readings and discussion stimulating, and liked being challenged. She also enjoyed the creativity she discovered through the freewriting and brainstorming techniques she learned. She had first encountered English by means of a naturalistic environment, and continued to seek out the language in informal ways. Although she said she wanted more grammar and structure, the formal aspects of the language continued to be problematic for her.

She felt most secure when given specific guidelines on how to develop an essay. When required to write multiple drafts of an essay, Enya was able to produce high quality, mature writing. Since shifting career goals from linguistics to history, she is no longer expected to present multiple drafts. Yet, she continues to write as though the first draft she submits were a finished piece. She continues to employ the technique of brainstorming, which enables her to write long essays. However, because she avoids revising, teachers sometimes comment that her writing is disconnected. She continues to be highly sensitive to criticism of her work, and finds it difficult to take suggestion.

Many units of analysis, along with longitudinal features of this case study, have been covered in Chapters V and VI. In contrast, the following chapter deals with a single, isolated experiment, conducted in a laboratory setting, for the purpose of exploring a particular writing event. Whereas the previous chapters covered contextual variables, the following chapter explores the writing process. The elicitation instrument used to examine writing process, is a think-aloud protocol. 


\section{CHAPTER VI}

\section{THINK-ALOUD PROTOCOL: A LOOK INTO ENYA'S WRITING PROCESS}

In June, 1990, Enya was videotaped while composing an essay on the topic, "Something unexpected that happened to me." The topic was selected because it was expected to elicit a straightforward narrative format which would be familiar and therefore comfortable. The assignment was adapted from Raimes (1985), who assigned a similar topic to her students, "Tell about something unexpected that happened to you." The resulting Think-Aloud protocol provided rich data for quantitative analysis and provided insights into Enya's mental processes as she composed. This chapter will explain the results of the investigation and coding of the videotaped session.

\section{THINK-ALOUD PROTOCOL}

Enya followed instructions to talk as she wrote, to say what she thought, to make changes out loud and to read aloud. She was directed not to analyze or explain, but simply to state her thoughts. Cohen (1987) collected think-aloud data on himself and described his struggles to stick with descriptors and avoid self-analysis while thinking aloud. Enya had no such difficulty. She listened to the training tape (see Chapter III for details) and watched a brief demonstration. When the taping began she seemed comfortable with the think-aloud process and carried it through without hesitation. 


\section{WHAT AND WHEN... BUT NOT WHY}

The videotape enabled the investigator to see and hear what Enya did as she composed. A stopwatch helped calculate when she did something and how long it took. It was possible to look at patterns of frequency of occurrence of writing strategies and whether they occurred more frequently early or late. It was also possible to measure the duration of an activity. However, the data do not permit saying why Enya did what she did. Such speculation rests outside the scope of this study, and belongs in the area of cognitive psychology.

\section{CODING}

This study began with the intention of coding the think-aloud protocol according to the scheme utilized by Raimes (1985) and adapted from Perl (1981).

Rather than diagramming the process in a sequential manner as Raimes did, the data was coded in tabular form. This helped to quantify each item and to easily identify patterns of occurrence. Copies of the working documents may be seen in Appendices H-J.

\section{SUMMARY}

The taping session lasted 43.5 minutes, but Enya finished writing at 37 minutes. The final 6.5 minutes were spent rereading and editing. She wrote a total of 19 sentences, but only one sentence, her last, was written fluently. Fluency was defined as a sentence having no more than one silence and/or repetition (Raimes, 1985). A summary of Enya's composing session may be seen in Table X. 
TABLE $X$

SUMMARY OF THINK-ALOUD DATA

\begin{tabular}{|l|l|}
\hline Total Time Spent & $43.5 \mathrm{~min}$ \\
\hline Finished Writing & $37.0 \mathrm{~min}$ \\
\hline Total Sentences & 19 \\
\hline Total Sentences Fluent & 1 \\
\hline Prewriting & $1.5 \mathrm{~min}$ \\
\hline Comments (Total) & 9 \\
\hline A. Mechanical & 2 \\
\hline B. Content & 7 \\
\hline Rereadings & $13(6$ continuous) \\
\hline Returns to Sentence \#1 & 4 (minutes 7, 21, 23,38) \\
\hline \# Times Gap between Sentences $>60$ sec. & 6 \\
\hline Planning & 6 \\
\hline
\end{tabular}

Prewriting describes the activities which help the writer get started. It includes the planning and rehearsing events which precede the writing of the first sentence. The time Enya devoted to prewriting was brief, 1.5 minutes.

Commenting was defined as a remark that expressed a personal reaction or opinion. "I don't know how to finish this sentence," was coded as a comment. Also included in this category were positive or negative assessments such as, "Yeh" or "No, this is not a capital." Enya made 9 comments, 2 concerning mechanics, and 7 about content. All comments occurred during the first half of the session.

Rereadings occurred 13 times. Twice, continuous reading spanned large chunks of time. The first occurred during minutes 19-21. The second took place during the last 6 minutes of the videotape. She returned to reread her first sentence 4 times: minutes $7,21,23$, and 38 . Struggles about how to proceed often precipitated rereading: "And what next," "I don't know how to finish this sentence," and "No" followed by crossing out. 
Gaps longer than 60 seconds between the writing of sentences were examined. There were 6 gaps, ranging in length from 1.5-6.5 minutes.

Planning events articulated a goal or strategy. Episodes coded as "planning" include, "No, I think I should start different," "I was thinking to write," and "Now I'm thinking about starting new part." There was a total of 7 planning events.

\section{WORD COUNT}

Word count was tallied on both the final product and the rough draft. Since the video and written product revealed numerous episodes of crossing out, the decision was made to compare the drafts. The total number of words in the final product was 398 , and the total number in the rough draft was 590 . This indicates that $40 \%$ of the quantity written was retained in the final draft.

In the final draft the word count in the first and second parts of the essay was approximately equal. Enya wrote 202 words during the first half (minutes 1-21) of the session, and 196 during the second half (minutes 22-43). The total number of words written in the rough draft was 590 . Of these, 367 words were written in the first half, and 223 in the second half. A comparison was made to determine whether she retained more of the words written during the first half or second half of the session. She kept $55 \%$ of the words written early, and $88 \%$ of those written later. Word Count information is displayed in Table XI.

The speculation is that during the last half of the writing session Enya's monitoring strategies shifted from deletion of large chunks of discourse to refinements in grammar and or mechanics. Her editing strategy was directed more at form than at content at that point in time. Indeed, she completely stopped writing text from minute 37 to minute 43.5 when she added a brief closing sentence. 
In contrast to Perl's (1979) unskilled native speaker students, and more similar to Raimes' (1985) ESL students, Enya did not seem concerned about the length of the composition. The number of words she produced didn't seem to matter.

TABLE XI

WORD COUNT

\begin{tabular}{|l|c|c|c|}
\hline & $\begin{array}{c}\text { \# Words } \\
\text { (Total) }\end{array}$ & $\begin{array}{c}\text { \# Words } \\
\text { (First Half) }\end{array}$ & $\begin{array}{l}\text { \# Words } \\
\text { (Second Half) }\end{array}$ \\
\hline Final Product & 398 & 202 & 196 \\
\hline Rough Draft & 590 & 367 & 223 \\
\hline & & & \\
\hline \% Final vs. Rough & $\mathbf{6 7 \%}$ & $\mathbf{5 5 \%}$ & $\mathbf{8 8 \%}$ \\
\hline
\end{tabular}

WRITING STRATEGIES

Five categories of writing strategies were tabulated: fillers, silences, spelling events, crossing out and repetitions. The number of events in each category and its occurrence within the first or second half of the session was recorded. The figures may be seen in Table XII.

TABLE XII

WRITING STRATEGIES

\begin{tabular}{|l|c|c|c|c|c|}
\hline Event Type & $\begin{array}{c}\text { First Half } \\
\text { Events }\end{array}$ & $\begin{array}{c}\text { Percent of } \\
\text { Total }\end{array}$ & $\begin{array}{c}\text { Second Half } \\
\text { Events }\end{array}$ & $\begin{array}{c}\text { Percent of } \\
\text { Total }\end{array}$ & Events \\
\hline Fillers & 47 & $72.5 \%$ & 18 & $27.5 \%$ & 65 \\
\hline Silences & 39 & $60.0 \%$ & 26 & $40.0 \%$ & 65 \\
\hline $\begin{array}{l}\text { Spelling } \\
\text { Events }\end{array}$ & 27 & $61.0 \%$ & 17 & $39.0 \%$ & 44 \\
\hline Crossing Out & 7 & $22.5 \%$ & 24 & $77.5 \%$ & 31 \\
\hline Repetitions & 124 & $48.0 \%$ & 135 & $52.0 \%$ & 259 \\
\hline
\end{tabular}


Fillers are articulated non-words which promote continuity without transmitting content. Fillers such as "eh," "er," and "uh," occurred 65 times during the session. It was evident that Enya utilized them 3:1 during the first half compared to the second half. A look at the first 5 minutes reveals that nearly $50 \%$ of the total occurred during that time at a rate of 6 fillers per minute. After five minutes the average drops to 1 per minute. Some speculation is possible. Perhaps Enya used fillers to help her get started, but found different strategies to use later on. Perhaps she became more efficient as she continued to work. Or, perhaps she simply realized that time was running out and stopped hesitating in order to finish quickly.

Silences of less than 2 seconds were not calculated. There were 65 pauses during the session, with $60 \%$ occurring during the first half, and $40 \%$ in the second. There was a total of 179 seconds of silence, with $61 \%$ taking place in the first half and $39 \%$ taking place in the last half.

Pauses were examined in context and coded according to the types of operations surrounding them: repetition, spelling, filler, page turning, gaps between sentences, rereading, crossing out and other. The greatest number of silences, 28 (43\%) occurred within the context of repetition. The following example (Appendix J, minute 37) illustrates 5 pauses within a sequence of repetitions (underlining denotes writing while speaking): " I changed my my unh my unh attitude (.2) towards (.3) I changed my attitude towards the (.3) towards the (.3) towards the life (.2) life." The pattern seems to be: write-rehearse-pause-(.2) write-pause-(.3) -repeat-pause (.3) -repeat-pause (.3) -write-rehearse-pause (.2) -write. This example shows yet another similarity to Raimes' students, who are described as using a word or phrase like a "prod" to uncover needed language. 
The protocol's numerous illustrations of reaching back accompanied by sensing forward approximates Perl's (1979) description of the dynamic she calls "retrospective structuring." The data support the contention that the process of writing is indeed cyclical, and that it involves patterns of transcribing, discovering, and synthesizing.

Spelling events were defined as episodes of either letter-by-letter or syllableby-syllable pronunciation of a word. There was a total of 44 spelling events, with $61 \%$ occurring during the first half, and $39 \%$ during the second.

A timid person who is afraid to make mistakes might choose to use pencil and eraser. Enya's writing and clean up operations were done in pen, so there was no opportunity for erasing. By choosing to write with a pen, Enya had to rely on crossing out rather than erasing as a deletion technique. She crossed out a total of 207 words while composing. Crossing out was achieved in many ways. Single letters, syllables, single words, sentences and whole paragraphs were deleted at a time. Crossing out was done 31 times, with $22.5 \%$ taking place early, and $77.5 \%$ later. The speculation is that more surface editing took place towards the end of the session.

Enya did not seem concerned about submitting a meticulous paper, nor did she choose to hide her "mopping up" operations. What might make her look "good," getting the job done "right," or "more is better" appeared to be unimportant factors. She spent a great deal of time on what she may have thought was important--getting her ideas across.

Repetition was the strategy Enya employed the most. It was defined as an event in which either a word or syllable occurred two or more times within a minute. Enya used repetition 259 times, averaging about 6 per minute. The events occurred almost equally during the first and second parts of the tape. Each repetition was coded. 
For example, "Poland Poland" was coded 1, "financial our financial situation our financial situation" was coded 2 and "postponed was post post postponed" was coded 3. What is evident from the tape, although not in the data, is how labor intensive it was to produce the desired word. The following example illustrates the process: "...because 'document' on its own doesn't make sense-'travel document' may Marek need needs, third person, needs to go to Poland." A pause of 4 seconds follows this sentence.

The complexity of the composing process is suggested by the following example. The sentence which appears as a "product" is actually a sequence of modifications and regroupings. Enya is dexterously juggling several balls in the air at a time. Within seconds, she repeats, spells, uses a filler, makes grammatical adjustments and pauses twice. This time the pauses occur within the sentence. "I was surprised surpi-surpri-surpri-sed surprised to, no by, Marek Marek's deci deci decision d-e (.4) um to take Igor with him (.2)." The pattern here seems to be: writespell-write-revise (edit)-revise (edit)-repeat-repeat-repeat-spell-pause-filler-write. (Appendix J, minute 13)

\section{REVISIONS}

Revisions are changes made within the text. They were examined according to their location either within sentences or between sentences. Revisions within sentences may be seen in Table XIII and revisions between sentences are recorded in Table XIV. Four revision strategies were coded: Additions, Deletions, Substitutions and Movement. When Enya changed text by adding a word, phrase or sentence, it was coded Addition. When she removed words by crossing out it was coded Deletion. When she replaced a word or phrase with another, it was coded Substitution. When 
she changed the position of a word, phrase, sentence or paragraph it was called Movement.

TABLE XIII

REVISION WITHIN SENTENCES

\begin{tabular}{|l|c|c|c|c|c|c|}
\hline & M & G & L & O & C & Total \\
\hline Additions & 4 & 6 & - & - & 7 & 17 \\
\hline Deletions & 8 & 5 & 4 & 3 & 8 & 28 \\
\hline Substitutions & 5 & 4 & 1 & -- & 2 & 12 \\
\hline Movement & -- & -- & 1 & 3 & 1 & 4 \\
\hline Total & 17 & 15 & 6 & 5 & 18 & 61 \\
\hline
\end{tabular}

TABLE XIV

REVISION BETWEEN SENTENCES

\begin{tabular}{|l|c|c|c|c|c|c|}
\hline & M & G & L & O & C & Total \\
\hline Additions & 2 & -- & -- & 1 & 4 & 7 \\
\hline Deletions & 3 & 2 & -- & 15 & 2 & 22 \\
\hline Substitutions & 1 & -- & 2 & -- & -- & 3 \\
\hline Movement & -- & -- & -- & -- & -- & -- \\
\hline Total & 6 & 2 & 2 & 16 & 6 & 32 \\
\hline
\end{tabular}

The composing process was examined according to five categories:

Mechanical, Grammatical, Lexical Choice, Organizational and Content. The first two categories look at form, while the last three investigate content. These categories are based loosely on Chapin (1989).

Mechanical refers to changes in punctuation, capitalization and spelling. Grammatical deals with verb tense, agreement, articles and plurals. Together, these two categories describe surface editing. Lexical choice describes revisions made for meaning and word form. Organization denotes presentation of the material and its 
location within the composition. Content describes changes which clarify, expand or delete ideas.

There is overlap between Table XIII and XIV and Table XII, in that spelling events were coded separately in Table XII, but subsumed under Mechanical in Table XIII and XIV. The predominant form of revision, both within and between sentences was Deletion. In Table XIII almost $50 \%$ of the revision operations were deletions, and Table XIV shows that $66 \%$ were in fact deletions. Movement, as a revision strategy was almost nonexistent.

Table XIII reveals that within sentences Enya focused on Mechanics (M), Grammar $(\mathrm{G})$ and Content $(\mathrm{C})$. Together these categories constitute $83 \%$ of the internal revision strategies, while Lexical $(\mathrm{L})$ and Organizational $(\mathrm{O})$ operations constitute only $17 \%$. Between sentences, as illustrated in Table XIV, she concentrated on Organizational strategies, which made up $50 \%$ of the total. The remaining categories-Mechanical, Grammatical, Lexical and Content- together comprised another $50 \%$.

\section{VERBAL REHEARSING}

Episodes of trying out words and phrases orally were tallied as shown in Table XV. Verbal rehearsing was analyzed according to structure or content. Of 31 episodes of structural rehearsing, word choice was noted in 13 and grammar in 18 instances. There were 14 episodes of content rehearsing, with 10 related to ideas and 4 to brainstorming. The data reveal more than twice as many examples of structural than content related rehearsing. 
TABLE XV

VERBAL REHEARSING

\begin{tabular}{|l|c|l|c|}
\hline & Structure & & Content \\
\hline Word Choice (WC) & 13 & Ideas (I) & 10 \\
\hline Grammar (G) & 18 & Brainstorming (B) & 4 \\
\hline Total & 31 & Total & 14 \\
\hline
\end{tabular}

\section{THINK-ALOUD: AN EXAMPLE}

The period from 6 to 9 minutes demonstrates Enya's struggles to put words on paper. As illustrated below, Enya is thinking aloud, but the only words which remain in the final draft are the last three, "We called Immigration." Written text is denoted by underlining.

1. After writing sentence 3 Enya says, "And what next?" this triggers rereading.

2. She rereads fluently sentences 1-2, "Before May we did not plan to go to Poland because we wanted at first feel more comfortable in U.S. and then eventually go visit our country. Also our financial situation was and is stressed so the plan to go to Poland was postponed."

3. She pauses to edit." I don't know how to write postponed." (changes third letter to "s").

4. She continues reading, while attending to mechanics, "In the middle of MayMay-capital (changes " $\mathrm{m}$ " to " $\mathrm{M}$ ") we got a message from Marek's family that his father is sick of cancer and decided over the night (inserts comma) comma decided (inserts comma) comma that Marek would go to Poland on first week of June, 1990." 
5. She completes rereading and begins to plan, "Now I'm thinking about starting new part."

6. She states an incomplete thought, and attends to grammar, "At first we eh call -no, called... I have problem with past tense."

7. She comments, begins again, rehearses ideas, and pauses. "I never know what to write. At first we called to our friend who probably we-we thought so knows about it. (.3)"

8. She turns the page and writes, "about what we do need kind of document travel document 'Marek' needs to go to Poland."

9. She rehearses ideas, using repetition. "What-what to do eh if you want go to Poland-what kind of documents we need, what kind of visa, what kind of passport, whatever-about what-what do we-do need-what maybe-what kind of document-travel document."

10. She attends to content and grammar. Because 'document' on its own doesn't make sense-travel document...may-Marek need-needs-third person, needs to go to Poland

11. She pauses, comments, rehearses ideas, spells and deletes twice. (.4) Yah. She wasn't home so we just called eh- Immigration and Naturalization (spells)- so actually take it out.

12. She turns back a page and crosses out, "At first we called to our friend who probably, we thought so, knows."

13. She makes a false start, turns to the next page, crosses out and begins writing sentence 4. "We at first- no, no (turns) next to We called (.3) Immigration. 
Enya seemed to take stockpiled verbal materials stored in her mind and put them into action (Stevick, 1989). She needed time to attach words to experience before setting them down on paper. The words she articulated functioned as resources for proactive planning, and retroactive editing. Verbalization seemed to provide a springboard for beginning a new sentence. The example illustrates how rereading, surface editing, deleting and rehearsing ideas activated her linguistic reserves until she was ready to write.

\section{TOWARDS AN INTEGRATED PERSPECTIVE}

Any type of coding is a form-oriented model (Van Lier, 1988), and as such, is limited in its ability to identify boundaries between the start of one thought and the end of another. So it is unable to show what actually happens. A problem occurs when concern for classification overrides concern for overall patterns of action that occur in the setting. The videotaped session, in effect, offers more than a description of a writer's cognitive strategies. If viewed from a social-cognitive perspective, it provides a more comprehensive analysis of the protocol. The following section addresses five questions about Enya's think aloud data:

1. What did she learn?

2. How did she do it?

3. What was the effect of context ?

4. What does the product show?

5. What general conclusions does the protocol suggest? 


\section{What did she learn?}

Current research on writing suggests that writing is a problem-solving activity. As such, it involves a hierarchy of cognitive strategies, beginning with interpreting a task and establishing broad goals for successfully achieving it. Next, subgoals are established for planning what to say and how to say it. The solution occurs on multiple levels.

Several intellectual challenges were posed by collecting a think-aloud protocol. Enya began with an assigned, narrative topic, "Something unexpected that happened to me." There were no constraints on the time allotted for the task. The social context was prescribed and unfamiliar, imposing use of a think-aloud technique. The setting was a unique laboratory arrangement which took place in an office equipped with a video camera. Only the subject and the non-participant investigator were present. Enya was asked to write for a particular audience, a former instructor and confidante. Her materials were an ordinary yellow legal pad and a pen. The purpose of the experiment was explained to her as a way to explore a writer's thinking processes as she composed.

Enya's broad goal as a writer was to communicate an intended message for a reader. Her first task was to interpret the assignment. From the resulting protocol, it seems she figured out and understood "something unexpected" to mean "surprise." Many subgoals appeared. Some were automatic, taking little time or attention, like how to form letters, and how to utilize the rhetorical form of the narrative. Mastery of storytelling and chronological form was an automaticized skill, and presented few problems for her. As she worked out the time frame in the essay, she seemed to be clarifying people's roles and the sequence of events for herself. Other subgoals were 
more challenging and time consuming. Among these were: getting and organizing ideas, word choice, and the mechanics of spelling and punctuation.

Midway through the essay she seemed to be psychologically blocked about the impact of the "surprise." At this point, she reviewed her writing and added factual information. This was followed by discourse-level changes. By the end of the essay she seemed to have worked through the emotional block, and shifted format from simple chronology to exploration of more personal implications of her husband's decision to leave for Europe with their son. At that point, she began to brainstorm aloud using gestures, but ceased writing. Her tone of voice became more intimate as she resumed writing about how the "surprise" would affect her future. Once she satisfactorily discovered and recorded her personal feelings, she abruptly ended the essay.

How did she do it?

Describing the composing process per se, an observer reports and codes evidence of planning, transcribing and revising. The types of writing events, their frequency of occurrence, and location within the protocol, are summarized in Figure 3 below. It reveals that although the same nine operations took place during the first and second half of the videotaped session, the proportion of each shifted. The most constant operation throughout was the amount of repetition, with approximately $50 \%$ taking place during each half. The eight remaining activities varied markedly. During the first half of the session, the predominant operations were commenting (100\%), planning (83\%), fillers ( $72 \%)$, and silences $(60 \%)$, in contrast to lower frequencies of rereading (30\%), deletions (23\%), and additions (17\%). The subject wrote 124 more words during the first half than in the second half of the rough draft. Analysis of the 
second half of the session indicates a high incidence of additions (83\%), deletions (78\%), and rereadings ( $70 \%)$, and lower quantities of fillers (28\%), planning (17\%), and comments $(0 \%)$.

The findings permit speculation about what Enya did while composing. It appears that her strategies and goals shifted during the composing session, and that her initial steps differed from those needed to attain closure. She began with simple operations and advanced towards more complex patterns. The complex patterns enabled her to invent and create new text. During the wrap-up stage, neither any comments nor written text appeared. In the final stages of the protocol, rereading stimulated revision, with high frequencies of additions and deletions occurring during the last five minutes of the session. This suggests a vigorous attempt at error correction, although the data show only one enror-free sentence in the final product. Working from the transcription, the nature of the composing process is further investigated. 


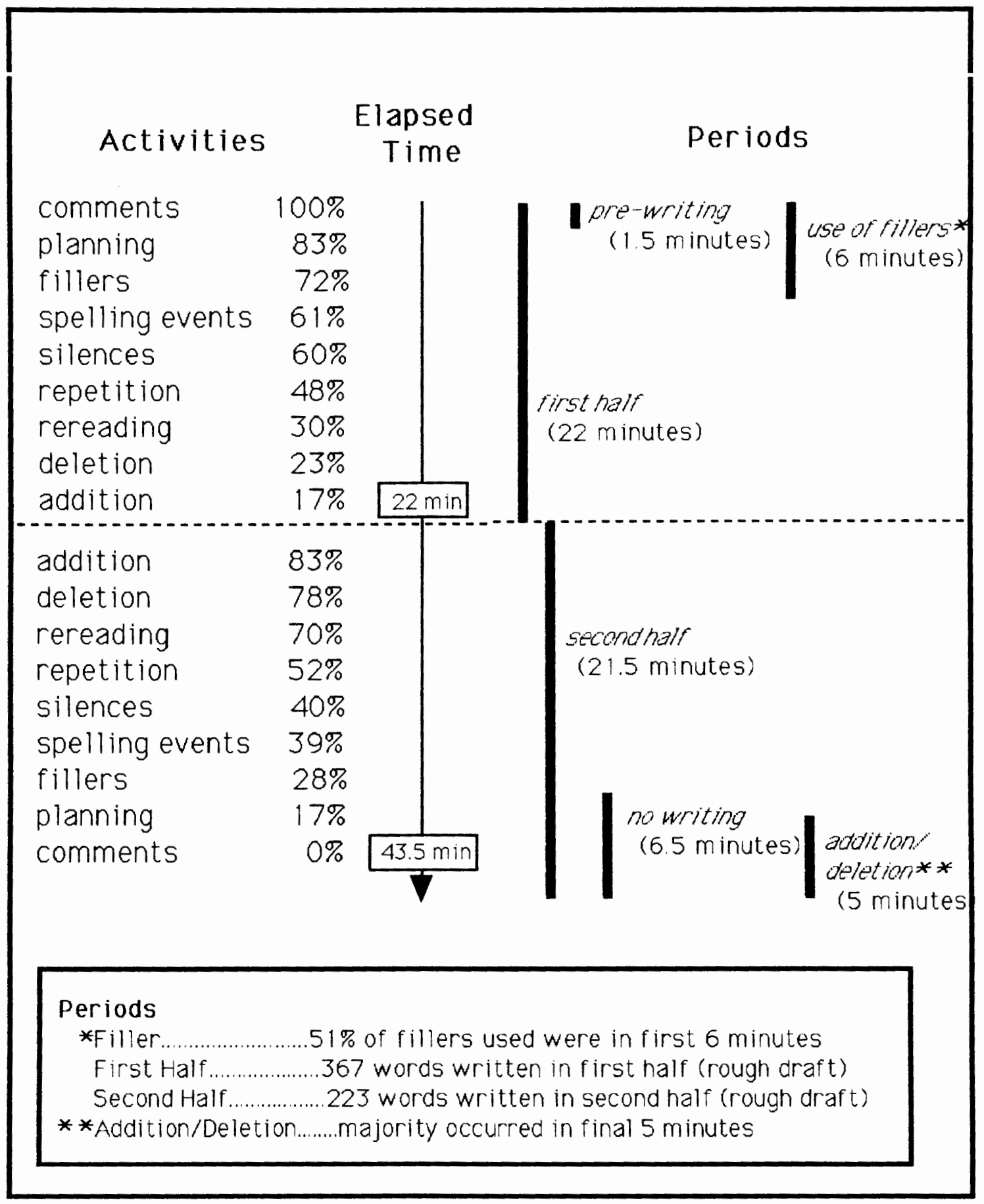

Figure 2. Frequency and Timing of Think-Aloud Events. 
This study does not focus on kinesthetics, but it may be of interest to note some examples of covert prosody which may be observed on the videotape. One can see that Enya's involvement with her task is very physical, and that much movement is visible in the tape. She turns pages frequently, crosses out in big, sweeping motions, shifts positions, nods her head, and tugs at her scarf. Taking a broad overview, a researcher may infer periods of frustration, re-evaluation, insight, and shifts in perspective by examining a think-aloud protocol.

\section{What was the effect of context?}

Enya likes to speak English, and this laboratory setting provided her with an uninterrupted opportunity. She did a great deal of verbal rehearsing in the planning of her essay. The style of her written language is very close to spoken language, and she seems to be relating this account to an audience who knows the main players. She does not take the time to define her characters, because they do not need explaining. In the laboratory setting, she was aware that the researcher was present, and was a listener as well as a reader. Had Enya been alone in the room with the recording equipment, perhaps the composition would have assumed a more literary than conversational tone.

\section{What does the product show?}

Is Enya a novice whose skills are just developing, or an expert writer who has mastered the skills of writing in English? In most respects, Enya's protocol fits the profile of the novice writer. Inexperienced writers produce writer-based prose, which assumes audience familiarity with the topic and characters. Her struggles with 
grammar imply limited knowledge of implicit structure of the language. The linguistic style of her composition is closely linked to spoken English, as opposed to written. The closing of her essay is undeveloped, implying incomplete knowledge of how to write an appropriate conclusion.

On the other hand, several of her skills suggest that she is progressing towards an expert level. She revealed flexibility in changing her plan as she developed her ideas, and showed skill in using cohesive devices and connectives. Her primary revision strategy was to review her writing in order to improve organization and to generate ideas. This was accomplished primarily by deleting large chunks of discourse.

Is Enya's composing process idiosyncratic, or does it reflect her cultural background? Three features of Polish language instruction suggest a cultural influence on her think-aloud essay. First, her formal training in $\mathrm{L}_{1}$ focused primarily on the mechanics of writing. Similarly, the think-aloud reveals the subject's preoccupation with errors. Secondly, Polish writing instruction generally disregarded strategies for development of an essay. The think-aloud is similar in its lack of supporting details. Lastly, the conclusion of Enya's protocol did not seem to flow logically from the previous content. In contrast, it appeared to be "tagged on" in a way that resembled the typical Polish "rozprawka." The writing patterns revealed in the protocol are unique to the subject, yet colored by her Polish educational background.

\section{What general conclusions does the protocol suggest?}

The Monitor, according to Krashen (1987), is a "watchdog" device to edit one's output. Expert writers are optimal monitor users. They do not give so much attention to mechanical concerns that it interferes with fluency. However, they do perceive 
where corrections are needed, and alter their work by consciously attending to appropriate form. Observations of Enya's protocol suggest that she is not an optimal monitor user, but a monitor overuser. Like Perl's (1979) Basic Writers, she gives so much attention to the mechanics of writing, that she sometimes loses her train of thought. Even when engaged in monitoring, she often fails to identify the problem. For example, $16 \%$ of the words in the final product are misspelled. Table XVI displays the quantity and category of mechanical errors retained in the final product. The data suggest that monitoring does not necessarily lead to improved writing (Jones, 1985).

\section{TABLE XVI}

ERRORS IN FINAL PRODUCT

\begin{tabular}{|l|c|}
\hline Type of Error & Number Observed \\
\hline & \\
\hline Spelling & 25 \\
\hline Articles & 11 \\
\hline Prepositions & 7 \\
\hline Word Form & 6 \\
\hline Possessives & 3 \\
\hline Agreement & 2 \\
\hline Negatives & 1 \\
\hline & \\
\hline Total & 58 \\
& (2.8 per sentence) \\
\hline
\end{tabular}

Enya's mastery of the narrative form was automatic, and her plan demanded only simple short-term memory for a chronology of events. During this warming-up period, her revisions occurred primarily at the form and word level. More complex cognitive processes came into play when subjectivity entered the process. At first, confusion and writer's block seemed to occur. Perhaps her plan to illustrate a sequence of events was undergoing internal restructuring on multiple levels. Following several deletions of large chunks of discourse, rereadings and brainstormings, the videotape 
suggests a cognitive shift from a sequential account to a more subjective exploration. She develops these ideas along different lines, but fails in her conclusion to connect her newly discovered attitudes with the "surprise." It is up to the reader to make the connection. In English, the responsibility for tying things together lies with the author, and in that sense she fails to be explicit.

Since this study is based on the research of Raimes (1985), and Perl (1979), I decided to compare Enya's think-aloud protocol with that of Raimes' eight students and Perl's student, Tony. Unlike Tony, Raimes' students were non-native English speakers. Data was not available in all categories. (See Table XVII below). The comparison suggests that Enya's writing profile resembles Raimes' ESL students in areas of planning, number of words per minute, and revising. Enya's profile differs from the others in the amount of time she spent prewriting.

\section{TABLE XVII}

THINK-ALOUD COMPARISON OF WRITING PROCESS IN 3 STUDIES

\begin{tabular}{|l|l|l|l|}
\hline & $\begin{array}{l}\text { Raimes } \\
\text { (8 students) }\end{array}$ & $\begin{array}{l}\text { Perl } \\
\text { (Tony) }\end{array}$ & $\begin{array}{l}\text { Katon } \\
\text { (Enya) }\end{array}$ \\
\hline \# Planning Operations/Session & 5.3 & 32 & 6.0 \\
\hline Words Written Per Min. & 10.0 (mean) & 4.7 & 11 \\
\hline Pre-Writing & $\begin{array}{l}4.7 \text { min } \\
\text { (range 2-11 min) }\end{array}$ & $5.6 \mathrm{~min}$ & $1.5 \mathrm{~min}$ \\
\hline Revising Editing Affecting Content & $55 \%$ & $12.5 \%$ & $48.5 \%$ \\
\hline $\begin{array}{l}\text { Revising/Editing Within Sentences } \\
\text { vs. Between Sentences }\end{array}$ & $57 \%$ & --- & $63 \%$ \\
\hline English Proficiency Score & $76 \%$ & ------ & $65 \%$ \\
\hline
\end{tabular}

Are the results of the think-aloud protocol congruent with other data in this report? Do the findings support the profile of Enya as a writer that has been drawn so far? How do the findings of this case study relate to the body of research in the field? The last chapter discusses these questions. 


\section{CHAPTER VII}

\section{CONCLUSION}

Getting to know Enya, both as a student and as an individual, provided a unique opportunity to develop the kinds of insight and perspective which might not be available in traditional methods of classroom research. The project had two primary goals. First, the study attempted to present a writing profile based on the interplay of culture, writing experiences past and present, and learning strategies. Another focus of this research was the writing process itself, and how one East European student learned to write in English.

The study explored various aspects of Enya's background, including her early history, her experiences as an adult, her language learning and intellectual abilities, and contextual background.

\section{FAMILY BACKGROUND}

Several themes emerge from Enya's childhood which influenced her character development as an adult:

Early Family Influences

1. Her father's longing for creative freedom

2. Her family's strong anti-communist ideology and distrust of authority

3. Her aunt's experience with different cultures

4. Her aunt's commitment to a way of life free from prejudice 


\section{ADULT PERSONAL HISTORY}

At the time the research for this paper was collected, Enya's role as working wife, mother, and student was complex and stressful, but conventional. She returned to the university because of a strong desire for higher education, in spite of the resulting financial hardship on the family. She lived by the feminist principle that she, as a woman, had as much right to an education as did her husband, who was also a student at the time.

Enya took on more responsibility than she could handle comfortably. Besides the struggle to piece together academics, loans, part-time jobs, and work-study, the main burden of child care fell on Enya. Neither she nor the children were very healthy, and she was often absent due to the illnesses of one or the other. Among other problems, the practical difficulties of surviving in a new culture put additional strain on the marriage, and the couple's relationship began to founder.

In 1992, her husband Marek took their ten-year-old son, and spent a year in Europe with him. Enya and their six-year-old daughter remained at home, and Enya continued working and studying. She found during that year of separation that she liked her independence, and decided to transfer to a university in Hawaii. When Marek and their son returned, she took both children to Hawaii, where they resided until summer, 1993. Although the couple is living apart, there has been no legal separation or divorce.

Several psycho-social and socio-political themes were suggested by the research data. They are identified as follows:

1. Enya married a man who was an artist like her father. As a couple, they felt constrained by the Communist system. They reached maturity during the 
idealistic 1960's and '70's, when young people were seeking alternative lifestyles. They experimented with the counter-culture in order to separate from the past and to chart a new course for the future, a future which hopefully included artistic and economic freedom.

2. Enya hated the political bureaucracy which humiliated her (See Chapter IV) and was responsible for the feud between her father and his relatives. She is very reluctant to relinquish personal power, a theme poignantly expressed in her think-aloud protocol (see Chapter VI). She has a strong, independent nature, and needs to feel that she is in charge of a situation. She is willing to take risks and to make mistakes, but she needs to determine her own path.

3. Enya has experienced living among several different cultures. She began a pattern of pulling up stakes and moving on, when, as a teenager, she left her parents' home, and moved from Krakow to Warsaw. The trend continued in subsequent moves to Germany, the continental United States, and then to Hawaii, where she resided until summer, 1993.

4. Enya has strong convictions about the evils of prejudice, and in her words and deeds, is committed to principles of racial equality and justice. During her years in the United States, she lived in a mixed neighborhood, and cultivated friendly relationships with people of various racial and religious backgrounds. When she suspected that her son might be limited in meeting children of other races, she transferred him from a private school and enrolled him in an integrated neighborhood school instead. 


\section{LANGUAGE BACKGROUND}

Enya's ability as a language learner is noteworthy. In spite of her rejection of Communist ideology, she became an expert student of the Russian language. In addition to expertise in Russian, she has some knowledge of German, and communicates well in English. Her husband, Marek, explained that study of language appeals to her because she is, by nature, systematic. However, that explanation seems too simplistic.

Enya grew up in a monolingual society, in which a second language, Russian, was considered an irritating imposition by most students. At some level, she understood that multiculturalism can best be achieved through multilingualism. She could break out of her narrow world if she could enter a new world through language. Language offered her a vehicle for change.

In each language, her oral/aural skills surpass her literacy skills. A combination of cultural, and educational factors elucidate this inequity. Enya described Polish people as talkers who have less interest in reading and writing than in speaking. First language skill strongly influences later language learning ability, and Enya's early literacy experiences in her native language reveal that she was a satisfactory, but not a superior student of Polish.

Learners who are skilled in more than one language have less trouble acquiring additional languages. By the time Enya arrived in the United States, she was fluent in two languages, Polish and Russian, and had experience with conversational German and English. In the United States, she acquired English with relative ease through informal conversations with a tutor (see Chapter V), and spoke well enough to find employment within a year of her arrival. 
Within a few short years, Enya accumulated an impressive employment history. At first, she worked at low-level, janitorial jobs. Her English rapidly improved, and she was hired to teach Russian by a private language school. She also taught Polish in a short-term high school extracurricular program. She worked for the Refugee Early Employment Program (REEP) at the International Refugee Center of Oregon (IRCO) teaching English to Russian immigrants. Her work-study experience included two years employment at the university library.

\section{INTELLECTUAL BACKGROUND}

Enya has superior critical thinking skills, which enable her to achieve academic success in various disciplines at the university. She has the ability to analyze and integrate what she reads. Her multicultural background and broad range of experience bring atypical maturity to classroom discussions.

Her approach to academics is a deep-seated desire to learn. She has little patience with university rules and regulations and strongly opposes the traditional system of grading. She believes, in fact, that grades interfere with learning. She tolerates the status quo because of her desire to attend graduate school in History. Originally, she planned to major in Russian and later changed to Slavic Linguistics. Presently, her undergraduate major is History.

Academically, Enya burdens herself by taking on heavy course loads, and is driven to complete her Bachelor's degree as soon as possible due to heavy financial burdens. Therefore, she often registers for twenty or more credits, then finds herself overextended, and drops several classes. 


\section{RESEARCH QUESTIONS}

This study attempts to answer four guiding questions:

1. What is the nature of writing?

2. What strategies does a writer use in composing?

3. What is the frequency, relative importance and place of specific writing behaviors for this particular individual?

4. How skilled is the subject in monitoring her own work?

This section attempts to compare the answers to the above questions according to the Review of the Literature (Chapter II), with the answers suggested by the study.

1. What is the nature of writing?

The results of this research support the contention of Perl (1979), Raimes (1985, 1987), Zamel (1987), and other scholars, that writing is a process of discovery. This study concurs with the findings of Emig (1971) and Pianko (1979) that prewriting is a very brief activity, and that planning takes place during composing. There is ample evidence in the protocol to support Perl's (1979) concepts of retrospective structuring and discovery in the writing process.

2. What strategies does a writer use in composing?

How well does Enya understand her own writing process? In 1992, using the instrument, "Case Study of Yourself As a Writer," Enya estimated the sequential steps in her composing process. (See Chapter V). I attempted to assess her accuracy by examining two 3-minute sequences, one during the first half, and one during the second half of the think-aloud protocol. I decided not to select either the first five minutes or the last few minutes, because of special non-representative strategies which 
took place during these periods. I arbitrarily chose minutes 6-9 and 28-31. (See Appendix J).

It is significant to note that the think-aloud preceded the self-evaluation by two years, which may affect the validity of this comparison. However, writing strategies are deeply embedded, and may remain fairly constant within the individual. Since Enya's description of her writing processes was based on her own categories, I adapted the coding scheme I used in the think-aloud to correspond with her own terminology. Into Enya's category, "think," I telescoped "plan," "rehearse," "comment," and "pause." I grouped "revise" and "edit" with her classification, "correct."

During the 6-9 minute interval, actual writing episodes occurred only half as frequently as Enya predicted ( $22 \%$ vs. $43 \%$ ). Much more time was utilized thinking and correcting in actuality (68\%), than in her estimate (43\%). However, during minutes 28-31, her estimated number of steps closely approximated the actual steps in nearly every category. For a comparison between Enya's estimated and actual performance, see Table XVIII.

\section{TABLE XVIII}

ENYA'S ESTIMATED VS. ACTUAL WRITING PROCESS DURING TWO 3 MINUTE PERIODS OF THINK-ALOUD

\begin{tabular}{|l|c|c|c|}
\hline & Estimate & $\begin{array}{c}\text { Actual } \\
(6-9 \text { minutes })\end{array}$ & $\begin{array}{c}\text { Actual } \\
(28-31 \text { minutes })\end{array}$ \\
\hline Think & $2 / 7(29 \%)$ & $8 / 19(42 \%)$ & $4 / 14(29 \%)$ \\
\hline Write & $3 / 7(43 \%)$ & $4 / 19(22 \%)$ & $5 / 14(36 \%)$ \\
\hline Correct & $1 / 7(14 \%)$ & $5 / 19(26 \%)$ & $2 / 14(14 \%)$ \\
\hline Reread & $1 / 7(14 \%)$ & $2 / 19(10 \%)$ & $3 / 14(22 \%)$ \\
\hline
\end{tabular}


Two inferences can be made from this data. The first is that as the composing process progressed, Enya became more efficient. The second is that Enya seems to be very much aware of her writing processes.

3. What is the frequency, relative importance, and place of specific writing behaviors for this particular individual?

Coding systems were developed by Perl (1979), for first language writers, and by Raimes (1985), for ESL writers, as a means of systematizing and recording data of real-time writing research. Adapting their think-aloud techniques, this research identified composing strategies according to when they appeared in the protocol. Protocol analysis revealed three stages from beginning to end, including: Simple Early Patterns, Patterns Used Throughout, and Complex Later Patterns.

a. Simple Early Patterns included fillers, silences, and spelling. These strategies helped the writer get started. During this stage, the linear, narrative structure of the essay was evident.

b. Patterns Used Throughout included repetition of Write-Rehearse-Pause sequences. This strategy seemed deeply embedded and automatic. Although Enya's first language strategies were not subjected to protocol analysis, it seems likely that she uses similar patterns when writing in Polish. This well-established pattern may represent her unique approach to a composing task in either $\mathrm{L}_{1}$ or $\mathrm{L}_{2}$. Different students would demonstrate different patterns.

c. Complex Later Patterns consisted of higher frequency of rereading and crossing out, and generally increased complexity of operations. During this stage, Enya shifted from her earlier linear time-frame to describing her personal reactions to the topic. She spent more time brainstorming aloud 
and gesturing, but less time actually transcribing. Data about writing instruction in Polish offers a possible explanation as to why Enya abandoned the narrative rhetorical form at the end of her essay. Polish writing instructors encourage students to give their personal response to a topic. What matters in a Polish essay is not so much the presentation of information, but what you present of yourself. In closing, Enya applied a deeply embedded first language rhetorical pattern.

4. How skilled is the subject in monitoring her own work?

According to the "novice vs. expert" categories discussed in $\mathrm{L}_{1}$ literature, student writers have difficulties in revising their own work. Perl (1979) contends that the egocentric mental state of novice writers leads to "selective perception." Flower and Hayes (1980) assert that novices produce "writer based prose," which fails to take into account a reader's perspective. Shaughnessy's "Basic Writers" use a form of language which is related more to spoken than written English. Sommers (1980) states that student writers use revision as a "mop up" activity, and adds that they revise on a surface rather than a substantive level.

In $L_{2}$ research, Krashen (1987) describes students as "monitor overusers" or "underusers." Although his work deals primarily with $\mathrm{L}_{2}$ speakers, it may be extended to $L_{2}$ writers as well. Brooks (1985) agrees with Sommers (1980) that student writers' overconcern with correctness results in only surface type revisions. Raimes (1985), on the other hand, says that students are not preoccupied with errors at the expense of ideas.

Enya's real-time writing task, the think-aloud protocol, did not elicit any global errors, which seems to support Raimes' view. However, even after numerous attempts 
at editing, 2.8 local errors per sentence remained, and only one short, 4 word sentence was totally error free. These errors remained in spite of 61 attempts to revise within sentences, and 32 attempts between sentences. The subject made an intensive effort to correct her essay during the last five minutes of the session, but the large number of uncorrected errors suggests that she was unskilled at identifying mistakes in her own work.

\section{FOCUS OF RESEARCH}

The research focused intently on a single individual, Enya. The rationale was to examine one student's learning strategies and writing processes in the hopes of adding to the body of existing knowledge. The student's background- consisting of native culture, past and present life experiences, and academic experiences-provided a broad lens through which Enya's literacy skills were examined. Since the context of learning was assumed to be of utmost importance to the project, it was necessary to build rapport with the subject, beyond a student-teacher relationship.

Through many shared conversations and social activities, aspects of Enya's personality and character came to light which further impacted the results of this project. I discovered that although she is skeptical about new people and situations, she courageously tackles uncharted territory. She often overcomes obstacles by fierce tenacity and hard work. With respect to authority, she is sometimes oppositional and rejecting. She is quick to judge people and is strongly opinionated. When she sets herself a goal, she pursues it with determination, but not always with discipline. She sometimes lets her emotions get the best of her, and tends towards self criticism. Enya is aware of her academic strengths and weaknesses, but often gets discouraged. In the last few years she has become more adept at setting realistic goals, and is less self 
deprecating. She has a better sense of humor about herself, as she is becoming more secure in her adopted culture.

Her learning style is strongly influenced by her early education in her native culture. Her previous experience with Polish, German and Russian provided her with the necessary technical knowledge for handling yet another foreign language. She has an artistic nature, gravitating to music, art, nature, natural foods, home remedies, and philosophy. Basically she is a kinesthetic, aural/oral learner with superior critical thinking and analytical skills. When she speaks, and even when she writes, Enya uses broad gestures. As a learner, her cognitive style seems more reflective than impulsive, which is consistent with her reflective, meditative personality. Her approach is to analyze a problem, think it through systematically, and after thoughtful consideration, to move towards a solution.

Among Enya's learning strategies are asking questions, seeking out people for conversation, reading, and notetaking. She thinks in the target language and rarely uses a dictionary, preferring to search for meaning on her own. She has a strong desire to communicate, is an avid learner, and seems to do best in discussion and interaction with a teacher or her peers. Enya is a good listener, as well as a good talker, and has the ability to monitor her own speech during informal conversations with native speakers of English. Yet, she often does not take well to criticism from others. She is uninhibited and outgoing in her approach to the target language.

\section{AREAS FOR FURTHER STUDY}

A video recording provides abundant naturalistic data for analysis. An area which would be possible to study but was not, is that of nonverbal communication. At 
a future date the videotape could be analyzed for gestures, posture, eye movement, and other nonverbal features.

The potential use of the computer as a diagnostic tool in writing research is significant. In order to observe computer sessions scientifically, modifications in the method of this study would have been necessary. Bridwell et al (1984) describe procedures which allow study of exact behaviors while using the word processor. Two features of a computer program would be necessary, a recording mechanism and a playback mechanism. The recording feature would register all keystrokes in one second intervals. Using frequency counts, it would be possible to determine additions, deletions, rereading, and movement. The playback feature would enable the researcher to watch the text evolve. The authors suggest that this would provide a more accurate representation than think-aloud protocol analysis.

The results of this research suggest that think-aloud is an effective tool in exploring the interplay of mental processes that occur while composing. While not exposing cognitive processes directly, a think-aloud protocol strongly hints at the underlying patterns a writer uses. The evidence for an individual's particular composing patterns, may be strengthened by cross-checking with additional units of analysis. In this study, congruence was found between the subject's self evaluation and the data found in the protocol analysis. This may or may not be true for other subjects.

Another interesting question relates to the effect of topic on writing process. The topic assigned for the think-aloud was a narrative. What would the effects have been had Enya written in a different rhetorical form? Would the composing patterns remain the same? Further research could compare the patterns of a student writing in different forms. 
A question remains as to whether think-aloud analysis has potential as an instructional technique. In the process of doing research for this study, the nature of think-aloud training, collection, and analysis was found to be a time consuming, intense, precise, and delicate operation. These characteristics suggest that a thinkaloud technique may not be practical for the classroom teacher. However, it may be useful in teacher training, since it offers unique insights into composing processes.

\section{LIMITATIONS}

Although the procedures outlined in Chapter III can be repeated, a drawback to this study is that much of it is not replicable. As a case study, it describes a unique situation, and its results are not generalizable. The usefulness of this investigation may be in adding its findings to the existing body of knowledge in the area of composing processes research. Its findings may also contribute to the field of ethnographic studies.

\section{Think Aloud}

A reliability check was not made on the coding of the think-aloud protocol. The videotape could be viewed and coded by another investigator, replicating the coding scheme to see if similar results are obtained. One drawback to the coding of the think-aloud was that it was done unilaterally. A pair, or team of researchers, scoring independently, is more reliable than the findings of a single investigator.

Furthermore, this study was limited by the researcher's lack of experience in training, administering, and coding a think-aloud protocol. Fortunately, the subject of this research was very skillful at following directions for collecting the think-aloud 
protocol. However, for different students, a longer, more intensive training period is recommended.

Another recommendation is for an investigator to play back the videotape as an immediate follow up to the video taping session. This would enable the subject to answer questions and to provide immediate feedback on the mental processes taking place during composing. The self observation of language behavior could be checked against the coding data at a later date.

Since the think-aloud technique may not be as effective with beginning speakers of English as it is with advanced students, selection of appropriate subjects is suggested. Think-aloud seems to require an intermediate or advanced level of fluency for optimum implementation.

\section{Observations}

During classroom and computer observations, the attempt was made to describe a particular context as comprehensively as possible. However, due to the complex nature of classroom research, scientific objectivity is not an attainable goal. Although attempts were made to collect and carefully select multiple pieces of data, perceptions, omissions, and value judgments may distort the truth.

Another problem was the role of the researcher during observations. The ability to maintain a low profile in the role of non-participant observer, was often compromised. Questions were asked, and comments were made, which promoted a higher degree of involvement than desired on the part of the investigator. 
Interviews

During most of the interviews, notes were recorded immediately following the conversation. Due to human error, some important points may have been omitted. The study was hampered by a limited number of native speakers of Polish, including only two in addition to the subject.

\section{Surveys and Self-Reports}

A potential problem in this type of research is its heavy reliance on the subject's cooperation. Enya was an ideal informant, and was reliable, dependable and cooperative in all aspects of the study. The key to the success of a case study such as this is the commitment, dedication, and willing participation of the subject.

In the course of the study, the subject was requested to submit numerous selfassessments, an essay in Polish, and several historical interviews. She was also asked to record literacy events, to classify data and tally printed materials in her home. In using instruments such as surveys and self reports, the study depends on the accuracy of reporting. The expectation was that by implementing multiple sources of data, a true picture would unfold.

\section{SUGGESTIONS FOR TEACHING}

The first section below identifies ways to provide a particular student, Enya, with an effective academic learning environment. The second part suggests ways to improve the teaching of writing in general. 
Enya

The results of the interviews suggest several approaches to providing an effective classroom environment for Enya. An instructor working with Enya might find it necessary to be flexible about setting deadlines for class assignments. Penalties for tardiness or excessive absences might be counterproductive, since she manages to fulfill course requirements, although at her own pace.

Classroom environment might include a variety of opportunities for interaction, since she does well in pair, group, or whole class activities. Within the structure, it would be beneficial to provide abundant opportunities for stimulating discussion. Topics for discussion should be based on interesting readings, and should be challenging as well as thought provoking.

Grammar and vocabulary learning were often problematic for Enya in ENNR. Perhaps, an emphasis on whole language learning is only effective up to a point. Since she prefers systematic language study, clear distinctions between grammar and vocabulary instruction and other language activities might be an effective teaching approach. Another possibility would be to assign discrete point exercises for homework.

Text selection is an important factor in forming Enya's first impression of a class. A nontraditional format might be perceived as threatening, confusing and frivolous. An instructor introducing such a text would need to explain that although different, it is still "serious."

Enya requires a demanding instructor, as well as a demanding curriculum. From the outset, it would be important for the teacher to set high goals for achievement for the students. Enya is able and willing to take risks and to push herself 
when she is motivated and interested in the material. Without being overly concerned with grades, she is truly interested in learning for its own sake.

An overriding problem in Enya's writing is mechanics. After years of futile struggle, she seems to have given up. She is discouraged and self-conscious about spelling and punctuation. She finds that conferencing with peers and instructors is often frustrating. A future instructor might indicate only the most important errors, and suggest that she get help from friends and from reference books. Use of published checklists might also assist her in self-monitoring. It may be possible for Enya to put her superior analytical skills to work by doing her own form of error analysis. She could be encouraged to write an essay on the topic of mechanics in writing.

A future instructor ought to be aware of Enya's occasional academic lapses, including lack of preparedness, handwritten drafts, and difficulties in accepting feedback. The "feedback" problem could be addressed by offering opportunities for peer group evaluations, which remove the instructor from the role of arbiter. The effectiveness of peer evaluation might be influenced by the perceived maturity of the students in her group. Conferencing might best proceed in question-answer format, allowing Enya the opportunity to identify and solve problems in her writing.

\section{General Applications}

The findings of this study suggest that first language background and training figure significantly in the acquisition of $L_{2}$, or additional non-native languages. It suggests that a student 's strengths in her native language transfer to subsequent languages, and so do her weaknesses. A writing teacher, working with intermediate or upper level ESL or ENNR students might design activities to elicit historical information about first language composing experience. Additional information on 
students' preferred learning style, strategies, and formal native language training, might influence textbook selection and instructional planning.

A teacher who is aware of contrastive rhetoric may be better prepared to deal with problems of organization and coherence in student writing than one who is not. Rhetorical patterns established in the first language are deeply embedded and difficult to change. A recommendation issued with caution is that there may be a place for product-oriented instruction at certain stages of the teaching of writing. This could provide security for students by presenting step-by-step guidelines to help them make a transition from one form of rhetoric to another.

This study, along with the literature, suggests that computer technology is on the forefront of research into the mental processes employed in composing. As technology becomes increasingly available in the university setting, it will be possible to assess more accurately what happens inside the mysterious "black box," and to reveal its secrets to all those who are interested in improving the teaching of writing. 


\section{REFERENCES}

Abraham, R. \& Vann, R. J. (1987). Strategies of two language learners. In A. Wenden \& J. Rubin (Eds.). Learner Strategies in Language Learning. (pp. 90-95). Englewood Cliffs, NJ: Prentice Hall.

Baker, L. (1993, January 28), Glasnost gourmets. Willamette Week, p.24.

Barrett, M. (1980). The writer writing is not at home. College Composition \& Communication 30(4), 370-377.

Benesch, S. (1986). Word processing in English as a second language: A case study of three non-native college students. Paper presented at annual conference on College Composition \& Communication. Atlanta, GA. (ERIC Document Reproduction Service No. ED 281 383).

Berkentotter, C. (1983). Decisions \& revisions: the planning strategies of a publishing writer. College Composition \& Communication, 34(2),156-172.

Bialystok, E. (1983). Some factors in the selection and implementation of communication strategies. In C. Faerch \& G. Kasper, (Eds) Strategies in interlanguage communication. (pp 100-118). New York: Longman.

Bridwell, L. \& Beach, R. (1984). Introduction. In R. Beach \& L. Bridwell (Eds.) New dimensions in composition research. (pp.1-14) New York: The Guilford Press.

Bridwell, L. \& Beach, R. (1984). The composing process. In R. Beach \& L. Bridwell (Eds.) New Directions in Composition Research. (pp. 127-130) New York:The Guilford Press.

Brislin, R. (1981). Cross-cultural encounters: Face-to-face interaction. New York: Pergamon Press.

Brooks, E. (1985). Case studies of the composing processes of 'unskilled' English as a second language college writers. Brooklyn, New York: New York University, Department of Educational Services. (ERIC Document Reproduction Service No. ED 289 340).

Brown, H.D. (1987). Principles of language learning \& teaching. Englewood Cliffs, NJ: Prentice Hall.

Carter, R. (1986). Teaching the process approach In Poland. Richmond, IN: Indiana University East. (ERIC Document Reproduction Service No. ED 268 531).

Chapin, R. (1989). Making written comments on ESL students' writing. The ORTESOL Joumal, (10), 34-54. 
Cohen, A. (1987). Using verbal reports in research on language learning. In C. Faerch \& G. Kasper, (Eds) Introspection in Second Language Research. (pp 82-95) Philadelphia: Multilingual Matters.

Collier, R. (1983). The word processor and revision strategies. College Composition \& Communication 34(2), 149-155.

Daiute, C. (1984). Performance limits on writers. In R. Beach \& L. Bridwell (Eds). New directions in composition research (pp. 205-224) New York: Guilford Press.

Damen, L. (1987) Culture learning: The fifth dimension in the language classroom. Menlo Park, CA: Addison-Wesley.

Edelsky, C. (1982). Writing in a bilingual program: the relation of $L_{1} \& L_{2}$ texts. TESOL Quarterly, 16(2), 211-218.

Elbow, P. (1973) Writing without teachers. London: Oxford University Press.

Emig, J. (1971). The composing processes of twelfth graders. (NCTE Research Report No. 13). Urbana, IL: National Council of Teachers of English.

Ericsson, K. A., \& Simon, H.A. (1987). Verbal reports on thinking. In C. Faerch \& G. Kasper (Eds.) Introspection in second language research (pp 24-53). Philadelphia, PA: Multilingual Matters.

Ericsson, K.A. \& Simon, H.A. (1980). Verbal reports as data. Psychological Review $\underline{87}$ (need \#), 215-251.

Flower, L. \& Hayes, J. R. (1981). A cognitive process theory of writing. College Composition \& Communication, 35(12),365-387.

Flower, L. (1979). Writer-based prose: a cognitive basis for problems in writing. College English, 41(1), 19-37.

Flower, L. and Hayes, J. R. (1980). The cognition of discovery: defining a rhetorical problem. College Composition \& Communication (31), 21-32.

Freedman, S. W. (1987). Research in writing: Past, present, and future. Berkeley, CA: University of California, Center For The Study of Writing. (ERIC Document Reproduction Service No. ED 285 205).

Hall, E. (1969). The hidden dimension. Garden City, New York: Anchor Books/Doubleday.

Hayes, J. R. and Flower, L. (1983). Uncovering cognitive processes in writing: An introduction to protocol analysis. In P. Mosenthal et al (Eds) Research on writing: Principles and methods (pp 207-220) New York: Longman.

Heath, S. (1983). Ways with words; language. life \& work in communities \& classrooms. New York: Cambridge University Press. 
Hildenbrand, J. (1985). Carmen: A case study of an ESL writer. Dissertation Abstracts International, 46(12), 3637A.

Hoffman, E. (1989). Lost in translation: a life in a new language. New York: Penguin Books.

Hosenfeld, C. and Yepes, J. (1988, March). What are the cognitive processes of nonnative writers of English in revision? Paper presented at the annual convention of Teachers of English to Speakers of Other Languages, Chicago, IL.

Hunt, M. (1982). The universe within: A new science explores the human mind. New York: Simon \& Schuster.

Johns, A. (1990). $L_{1}$ composition theories: implications for developing theories of $L_{2}$ composition. In B. Kroll (Ed.), Second language writing: research insights for the classroom (pp. 24-36). New York: Cambridge University Press.

Johnson, C. (1985). The composing process of six ESL students. Dissertation Abstracts International, 46(5) 1216A

Johnson, D. (1992). Approaches to research in second language acquisition. New York: Longman.

Jones S. \& Tetroe, (1987). Composing in a second language. In A. Matsuhashi Ed.). Writing in real time: Modeling production processes (pp 34-57).

Jones, S. (1985). Problems with monitor use in second language composing. In $\mathbf{M}$. Rose (Ed) Why writers can't write. New York: Guilford Press.

Kanal, N. (1993). The Oregon refugee resettlement annual report, State of Oregon Adult \& Family Services. Salem, OR.

Knowles, A. (1978). The Polish people. The international encyclopedia of higher education. Vol. 7 (pp. 3319-3325). San Francisco: Jossey-Bass Publishers.

Kraepels, A. R. (1990). An overview of second language writing process research. In B. Kroll (Ed.), Second language writing: research insights for the classroom (pp. 37-56). New York: Cambridge University Press.

Krashen, S. (1987). Applications of psycholinguistic research to the classroom. In M. Long, \& J. Richards (Eds.). Methodology in Tesol: A book of readings. (pp. 33-44). New York: Newbury House.

Langan, J. (1988). College writing skills. New York: McGraw Hill.

Lay, N. (1982). Composing processes of adult ESL learners: a case study. TESOL Quarterly 16(3), 406.

Mandel, B.J. (1980) The writer writing is not at home. College Composition \& Communication, 30 (4), 370-377. 
Matsuhashi, A. (1982). Explorations in real time production of written discourse. In M. Nystrand (Ed) What writers know: The language, process \& structure of written discourse (pp. 269-290). New York: Academic Press.

Meade, R. \& Ellis, W. (1970) Paragraph development in the modern age of rhetoric. English Journal, V59, pp. 219-226.

Oxford, R. (1990). Strategy inventory for language learning. In Language Learning Strategies: What Every Teacher Should Know. (pp. 293-299). New York: Newbury House.

Perl, S. (1979). The composing process of unskilled college writers. Research in the Teaching of English 18(4), pp. 317-336.

Perl, S. (1980). Understanding composing. College Composition \& Communication, 31(4), 363-369

Pianko, S. (1979). Description of the composing processes of freshman writers. Research in the Teaching of English, 13(1), 5-22.

Raimes, A. (1985). What unskilled ESL Students do as they write: a classroom study of composing. TESOL Quarterly 19(2), 229-258.

Raimes, A. (1987). Language proficiency, writing ability and composing strategies: a study of ESL college student writers. Language Learning 37(3), 439-468.

Reid, J.M. \& O'Brien, M.A. (1981, March). The application of holistic grading in an ESL writing program. (ERIC Document Reproduction Service No. ED 221044). Paper presented at the annual meeting of Teachers of English to Speakers of Other Languages, Detroit, MI.

Rose, M. (1980). Rigid rules, inflexible plans, and the stifling of language. College Composition \& Communication, 31(4), 389-399.

Rose, M. (1980). Rigid rules, inflexible plans, and the stifling of language: a cognitivist analysis of writer's block. College Composition \& Communication (31), 389-399.

Scardamalia, M., Bereiter, C.and Goelman, H. (1982). The role of production factors in writing ability. In M. Nystrand (Ed) What writers know: The language, process, and structure of written discourse. (pp. 173-210). New York: Academic Press.

Schumacher, G., Klare, G., Cronin, F., and Moses, J. (1984). Cognitive activities of beginning and advanced college writers: a pausal analysis. Research in the Teaching of English 18 (2), 169-187.

Shaugnessy, M. (1977). Errors and expectations. New York: Oxford University Press.

Silva, T. (1989, March). A critical review of ESL composing process research. (Paper delivered at annual conference of Teachers of English to Speakers of Other Languages, San Antonio, TX. 
Smoke, T. (1987). A writer's workbook. an interactive writing text for ESL students. New York: St. Martin's Press.

Sommers, N. ( 1980). Revision strategies of student writers and experienced adult writers. College Composition \& Communication, 31(4), 378-388.

Spack, R. (1984). Invention strategies and the ESL college composition student. TESOL Quarterly, 18 (4), 649-670.

Statistics about Soviet arrivals since 1988. (1994, June). The Sunday Oregonian.

Stevick, E. (1989). Success with foreign languages: seven who achieved it and what worked for them. New York: Prentice Hall.

Swarts, A., Flower, L., \& Hayes, J.R. (1984). Designing protocol studies of the writing process: an introduction. In R. Beach \& L. Bridwell (Eds.) New directions in composition research (pp 53-71). New York: Guilford Press.

Taylor, Barry P. (1981). Content and written form: a two way street. TESOL Quarterly, 15 (1), 5-13.

Trimbur, J. (Case Study of Yourself as a Writer). Boston University.

Tucker, A. \& Costello, J. (1985). The Random House writing course for ESL students New York: Random House.

Urzua, C. (1987). You stopped too soon: second language children composing \& revising. TESOL Quarterly, 21(2), 279-304.

Van Lier, L. (1988) The classroom \& the language learner. London: Longman.

Vygotsky, L. S. (1978) Mind in society. M. Cole, V. John-Steiner, S. Scribner, \& E. Souberman (Trans.), Cambridge: Harvard University Press.

Watson-Gegeo, K. (1988). Ethnography in ESL: defining the essentials. TESOL Quarterly,22(4), 575-592.

Whitman, R. \& Jackson, K. (1972). The unpredictability of contrastive analysis. Language Learning Vol. 22, 29-41.

Yin, R. (1984). Case study research: design \& methods. Beverly Hills, CA: Sage Publications.

Zamel, V. (1982). Writing: the process of discovering meaning. TESOL Quarterly, 16 (2): $195-209$.

Zamel, V. (1983). The composing processes of advanced ESL students: six case studies. TESOL Quarterly, 17(2), 165-187.

Zamel, V. (1987). Recent research on writing pedagogy. TESOL Quarterly, 21(4), 697-715. 
Zamel, V. (1987).Writing: The process of discovering meaning. In M.Long, \& J.Richards (Eds) Methodology In TESOL (pp 267-277). New York: Newbury House. 
APPENDIX A

PERSONAL INFORMATION 
PERSONAL INFORMATION

NAME

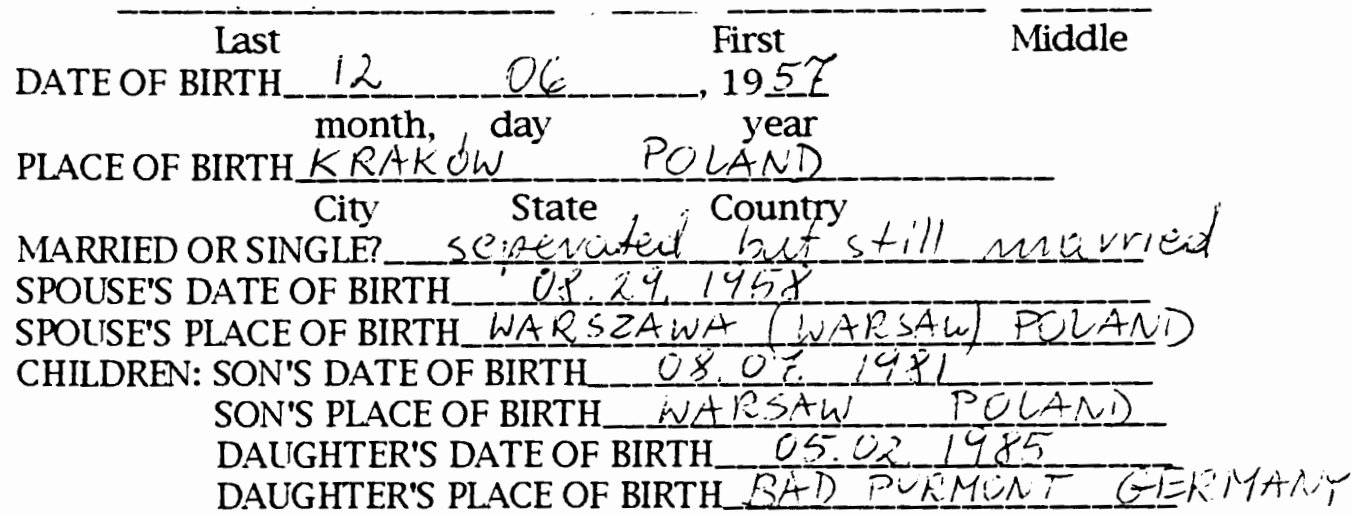

PARENT'S DATE OF BIRTH: MOTHER $03 \% 14 \%$

PARENT'S PLACE OF BIRTH: MOTHER CZERNIEC IEA EEC POLAND FATHER KeAKCW (CKACCL) PUIAN)

NUMBER OF SISTERS BROTHERSEL AGES

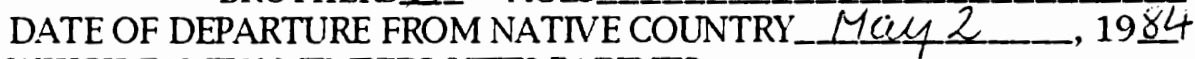

WHICH FAMILY MEMBERS IFFT? PARENTS

SISTERS AND BROTHERS___ NAwE

HUSBAND Y Y

CHILDREN

GRANDPARENTS = de dent

AUNTS, UNCLES, COUSINS

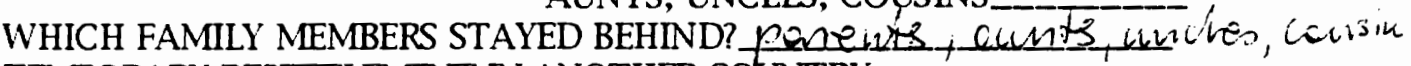
TEMPORARY RESETTLEMENT IN ANOTHER COUNTRY

(before coming to the U.S.)

Where did you stay? Juest CENMuim

How long did you stay?__L isuin?

Were you employed there?

If "YES", what kind of work did you do?

Did you study there?

If "YES", what subjects?

Where did you study?

?

How long did you study?_I im n mit sure 
APPENDIX B

FORMAL INTERVIEW: FIRST LANGUAGE 
Formai intervlew: FIRST LANGUAAGE

1. At what age did you first learn to read?

2. At what age did you first learn to write?

3. Did anyone help you with reading?
a) parents
b) teachers
c) sisters or brothers
d) friends
e) relatives

4. Did anyone help you with writing?
a) parents
b) teachers
c) sisters or brothers
d) friends
e) relatives

5. At what age did you start school?

6. How large were the classes?

7. What methods were used to teach reading and writing?

8. What difficulties did you have?

9 What kinds of reading did you do in grade school?

10. What kinds of writing did you do in grade school?

11. What kinds of reading did you do outside of school?

12. What kinds of writing did you do outside of school?

13. How much formal schooling did you have?

14. What grades did you get in reading and writing?

in grade school?

in nigh school?

in the university?

15. Do you consider yourself a good reader and writer in your first language?

16. What are your strong points in writing?

Spelling

Excellent Good Fair Poor

Punctuation

Organization

Grammar

Creativity 
17. What are your strong points in reading?

Excellent Good Fair poor

Speed

Comprenension

18. What kinds of reading do you do now in your first language?

Novels? Magazines? Newspapers? Textbooks? Bible? Other?

19. What kinds of writing do you do now in your first language? Letters? Storles? Poems? Journals? Essays?

20. How much reading and writing do you do now in your first language? 
APPENDIX C

SAMPLE- 48 HOUR DIARY 


\section{The Analysts Who Came to Dinner $1-3$,}

$$
\text { rujolicio }
$$

As any homemaker who has tried to maintain order at the dinner table knows, there is far more to a family meal than meets the palate ${ }^{\circ}$. . . . Sociologist Michael Lewis has been observing 50 families to find out just how much more. . . . The basic conclusion is . . . clear: with all that is said and done at the dinner table, food may be the least significant ingredient of the evening meal.

Lewis and his colleagues at the Educational Testing Service in Princeton, $\mathrm{N}$ J., conducted their research by videotaping the families while they ate ordinary meals in their own homes. They found that parents presiding over ${ }^{\circ}$ small families tend to converse actively with each other and their children. But as the brood ${ }^{\circ}$ gets larger, conversation gives way to the parents' efforts to control the inevitable ${ }^{\circ}$ uproar. ${ }^{\circ}$ That can have important implications ${ }^{\circ}$ for the kids. "In general, the more question-asking the parents do, the higher the children's IQ's," Lewis says. "And the more children there are, the less question-asking there is."

'Invisible': The study also offers a clue to why middle children often seem to have a harder time in life than their siblings. ${ }^{\circ}$ Lewis found that in families with three or four children, dinner conversation tends to center on the oldest child, who has the most to talk about, and the youngest, who needs the most attention. "Middle children are invisible," says Lewis. "When you see someone get up from the table and walk around during dinner, chances are it's the middle child." There is, however, one great equalizer that stops all conversation and deprives everyone of attention: "When the TV is on," Lewis says, "dinner is a non-event."

Despite the feminist movement, Lewis's study indicates that preparing dinner continues to be regarded as woman's workeven when both spouses ${ }^{\circ}$ have jobs. Some men do help out, but for most husbands dinnertime remains a relaxing hour. While the

$$
\begin{aligned}
& \text { there . . the } \\
& \text { palate: there is } \\
& \text { more than food }
\end{aligned}
$$

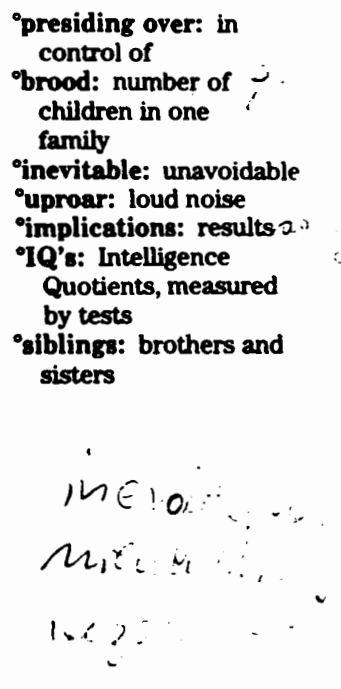

'spouses: husbands or female cooks and serves, Lewis says, "the male sits back and eats."

\section{EXPLORATIONS}

- What observations can you make from your own experience about middle children?

- What are the most common topics of conversation during mealtimes with your family?

- Do you think mealtimes are important family events? 
160

263

$2 / 23 \quad 9-10 \quad \ldots . .$.

there. the petate: there is more then food

presiding over: in coutrol at-ograini brood - mumber of childrew in ore family? grupa?

ineritable? - unevoidable?

uproas - lond noise - knyk, wates imphicetions: results - powody, shithi domysiy.

Iqs - porion inteligencii

Intelligence quotients

sibling,s: brothers and sisters rodveristwo

spouses: husbands or wives mationkonie. 


\section{APPENDIX D}

HOLISTIC EVALUATIONS: REID AND O'BRIEN 
APPENDIX A

EVALUATION SHEET

\section{ENCLISH STRUCTURE}

Excellent

Few notlceable errors in grammar, word order, punctuation and/or spelling; frequenc use of complex sentence structures.

Cood

Occasional errors In gramar, word order, punctuation and/or spelling; some use of complex sentence structures.

Average

Moderate errors in grammar, word order, punctuation and/or spelling; general use of simple sentences; occastonally an obscured meaning.

Fa1r Frequent errors in gramar, word order, punctuacion and/or spelling make comprehension difflcult; use of short baslc sentence structures.

Poor

General use of phrases and/or tragmenta; very bastc vocabulary and/or rampant misspeling.

\section{CONTENT}

Excellent

Writing to an easy task; quanticy to no oroblem; diction 1y broad and approprlace; Interesting, substantial, complex 1deas that respond directly and completely to the assignment; coplc developed fully and coherently.

Good Writing flows without much hesication; reasonable quantity; some diction errors of complex words; Interesting 1deas that are relevant to the assignment; Ideas develop the roplc with specific detall and coherence. 
Average

Fals

Poor

Cood

Average
Evidence of having stopped writing at times; somewhat l1mited vocabulary; adequate development of Ideas relevant to the assignment with some specific detall; flawed coherence.

Limited quantity; 11mited development; little specific detall; simple 1deas not necessarily related to the assignment; simple vocabulary with frequent diction errors.

Litcle writing; very simple 1deas, often not directly related to the assignment; very basic vocabulary with frequent errors.

\section{ORCANIZATION}

Excellent

Clear introduction directed in an inceresting way towards a specific audience; paragraph(s) developed linearly; topic sentence, logical support with substantial specific data; successful use of coherence devices within sentences and between sentences; clear conclusion. Obvious beginning/middle/end; division of central 1dea(s) Into smaller parts; awareness of audience; daragraph(s) llawed in development and/or logic coherence within sentences but some chopplness; conclusion often simple restatement.

Intent to develop central 1dea; some sense of beginning/ middle/end; occastonal wandering from toplc; some development of 1deas; general statements predominate; IImited use of coherence devices, especlally between sentences: conclusion simply stated or misolng. 
Fa1r

Poor
Lialted organization beyond the sentence level;

thoughts written down as they come to mind; no

Introduction or conclusion; coherence linited to

Internal sentence connectors.

No apparent organization; no lotroduction or con-

clusion; no focus; l1tele or no development; no

coherence devices. 


\section{APPENDIX B}

SCORING SHEET

SUBJECT

Evaluator

Dace

Engl1sh

Seructure

Concent

Organization

\begin{tabular}{|l|l|l|l|l|} 
Poor & Fali & Average & Good \\
\hline & & & & \\
\hline & & & & \\
\hline & & & & \\
\hline & & & & \\
\hline
\end{tabular}

\section{Overall}

Writing

Proflclency

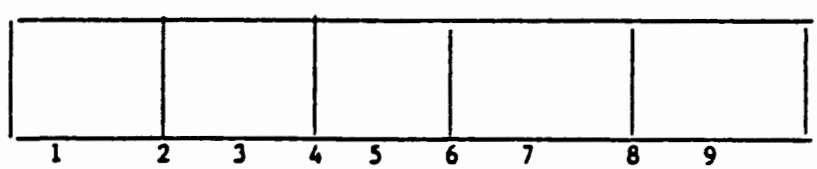

Average Score 
APPENDIX E

SAMPLE ENNR ESSAYS 
(A)

Visiting My Aunt's House

I do not remember the first time I visited my aunt, but I am sure that from the beginning I loved her big wood house in the countryside. Her house was built of wood, full of sunlight, the smell of dry apples, dry flowers and herbs.

First I always ran to the attic of the house. This was my favorite place. The smell of the old things, the reflection of the sunlight from flying dust, a secret, hidden place behind the visual world: it was enough to love the attic. - Some of the things had been stored there "for centuries," even before World war II; old watering cans, my grandfather's green and dark blue Austrian beer bottles, an old singer sewing machine with pearl decoration, old carpets

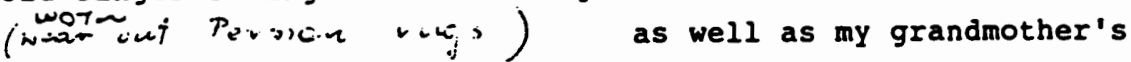
couch and her broken trunk. In the trunk was her wedding dress, ivory muslin, with a lot of lace, starting at the top and going down part of the skirt. It had pink flowers around the neck. With the dress also came a pink and white hat, with a long scarf around it and a white vail. The hat was quite big, but I often tried it on anyway.

My aunt never let me try on the dress. She was afraid that the dress would wear out. We knew she wanted to save the dress for her wedding. At this time, she was about 45 and still not married, but she had big hopes that someday she would use her mother's dress. My parents doubted that it would happen. She was not very pretty, but very picky and talked too much, they thought. 
Just a little bit less than the attic I liked the kitchen in ;, this house. A kitchen in any house is a good place to be, particularly for hungry children, or just somebody hunting for a cake or an apple. For this purpose, one sometimes might wait until midnight for a good moment when no one can disturb one in looking for delicious foodor many people, the kitchen // is the heart of the house, with its colors, fragrances and all its traditions of preparing and serving food. For my aunt, IC the kitchen was the heart of her house and her workshop of culinary art. Please imagine christmas tree ornaments made of the finest sourdough or the birthday cake with the ballerina on the top staying on her one leg and all made out of sweet cream.

In the kitchen there was a lot of dry vegatables, herbs and fruit in jars on the walls, next to the wooden kitchen accessories. The kitchen floor $h_{\text {made }}$ out of dark wood which my aunt washed regularly, kneeling on her knees with her skirt ! ! tied to her waist. She must have loved doing it because she did it even when the floor was very clean. She also liked to say: "clean floor, clean mind."

Behind the house there was a small garden with strawberry fields, which began to bear in June. I loved to stay there 12 and eat berries. But sometimes I got sick from eating too much and my aunt was very unhappy with me.

Childhood always includes a sunnier summer than now, a whiter snow than it is today, and all the memories and warm $/ \alpha$ feelings. My memory of childhood also includes feelings of simplicity, happiness and beauty of the surrounding world. Sometimes I dream about this beautiful and dear place. I know I can never go back there again. After my aunt's death my family sold the house to the city of cracow and the city built in place of my aunt's house a new highway. 
Kaffehus or Broadway Bistro.

When $I$ an on the campus and it is lunch time,first I look into my money bag and then I know where I an going to eat.If my wallet is full of money I go to eat at the Broadway Bistro and order "Fresh Pasta of the day" for $\$ 4.25$ plus Cappuccino Royale for $\$ 2.00$.If I do not have a lot of money I go to the Kaffehüs and eatnbagel with margarine for just $\$ 0.50$.

The Kaffehus is located on Broadway, across from Cramer Hall in the basement of the Campus Ministry.I both like and do not like this location.First, I never have any classes out of Neuberger Hall, so if I have just 10 minutes for $x$ lunch it is quite a long distance for me.

Second,if I do have enough time for my lunch and wish to eat the and read I feel that the Kaffehys does not have ${ }_{n}$ right lighting. When I read in light I feel fastertired and my eys start to bother me right away. I need good day light to feel comfortable with my study. The kaffehus daes aat bawe daylight tmostat ath The Broadway Bistro is located very close to the building I usually study in and I am very happy about it.But first, as I mengtioned, I am not always able to eat at this place. The Broadway Bistro has a lovely deck I realy like.Even if it is a cold day I sit there with pieasure. 
A big inconvenience in the morning for me swhen I do have money) is this, that the Broaway Bistro is open only from 11 a.m.That is surely too late for having breakfast.Then I go to the Kaffehus and have soup with a Swedish Limpa Roll. That is just fine, but next I have to drink their cofee which I do not like or buy it somewhere else, which is not very convenient.

The Kafiehus is open from $7 \mathrm{a} . \mathrm{m}$. to 3p.m., Monday thru Friday. On Monday, Wendesday and Friday I work after school, so my lunch time is at 2:50.Ten minutes for lunch is surely not enough and I usually go to the Broadway Bistro, which is open untill 4:00 p.m. I have my salad there. What, if I do not have money? Probably I have to go to Safeway to buy a bagel(I do not like to go to the Cafeteria at all), or I have to wait until I will get to my which house, is around 6:00 p.m.

Sandwiches and soup at the Kaffehus are guite inexpensive.They do not taste gourmet or homemade,but it is allright for their price.sandwiches and soup at the Eroadway Bistro taste like $T$ taste in a good restaurant and it is understand food for low price, but it does not work for restaurant owners who dream probably) about high prices for their hard work.

Both, The Kaffehus and the Broadwax Bistro are nice and friendly restaurants. They both look to me Europien and I feel at home when I am there.Sometimes I prefer cafeteria style and I am happy to serve myself instead being served.At this time Kaffehus serve me the best.But when I am really tired, than I am glad to have help in the restaurand.FOr such moments Broadway Bistro is $a$ good place for me. 
-- PAGE 3 --

I realy can not say which of these restaurants I like better.I think they are both restaurapts I like to go to.sametimes I like to ${ }^{\text {inuite }}$ my friends to them, and I can see that my friends have $a_{n}$ similarm opinion abcut them. It is possible that all students, dependett now much money is in their pockets, are choosing right place to eat cexept these who bring their own food, like Adam, the smartest). 
(C)

My cuiture and yours.

During the first year of living in America I have had a tremendous culture shock, because the American culture is very different than Polish culture. I am really amazed at how tolerant Americans are towards religion, political orientation and other ianguages.

Americans are very tolerant towards other religions.

Protestants, Buddists, Catholics, Jews, Moslems, Atheists - they

all are here. Some of them are fundamentalists, some very

liberal. I have two friends, a Catholic and a Jew. They work togetner and ofter go to iunch. I like to join them. I like to see these two people together eating, laughing, talking, joking. It realiy makes me feel good. My close nieghbors can be counted, as another example of Americans being toierant. Mr. Jorling is a Roman-Catholic. His wife is Westminster Presbyterian. They have been married for twentyeight years and during iriese years have alternately attendeo both churches. I was surprised also to find out, that their oaughter is stuoing at a private Baptist university in Maine. It seems to me, that the parents do not 


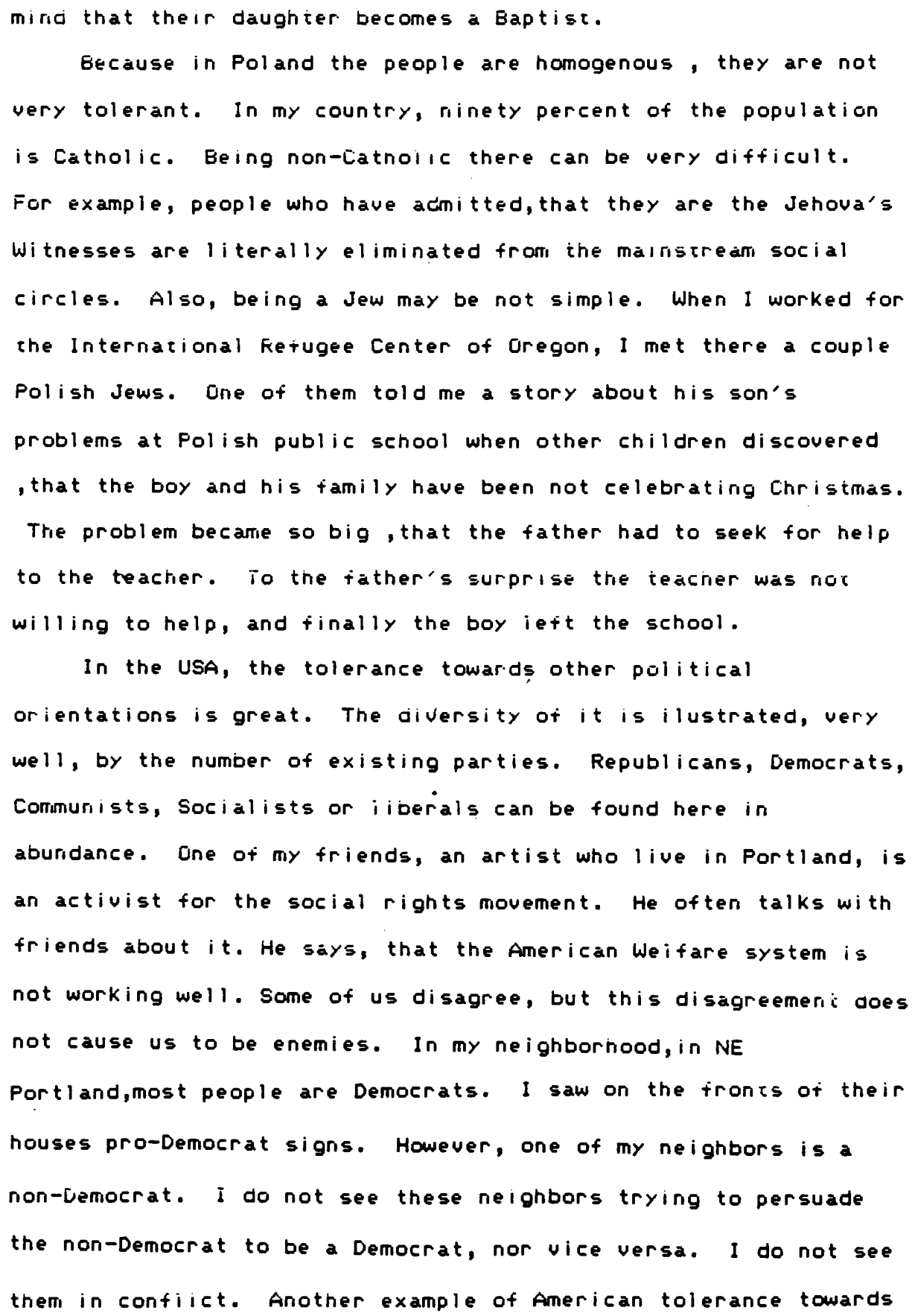




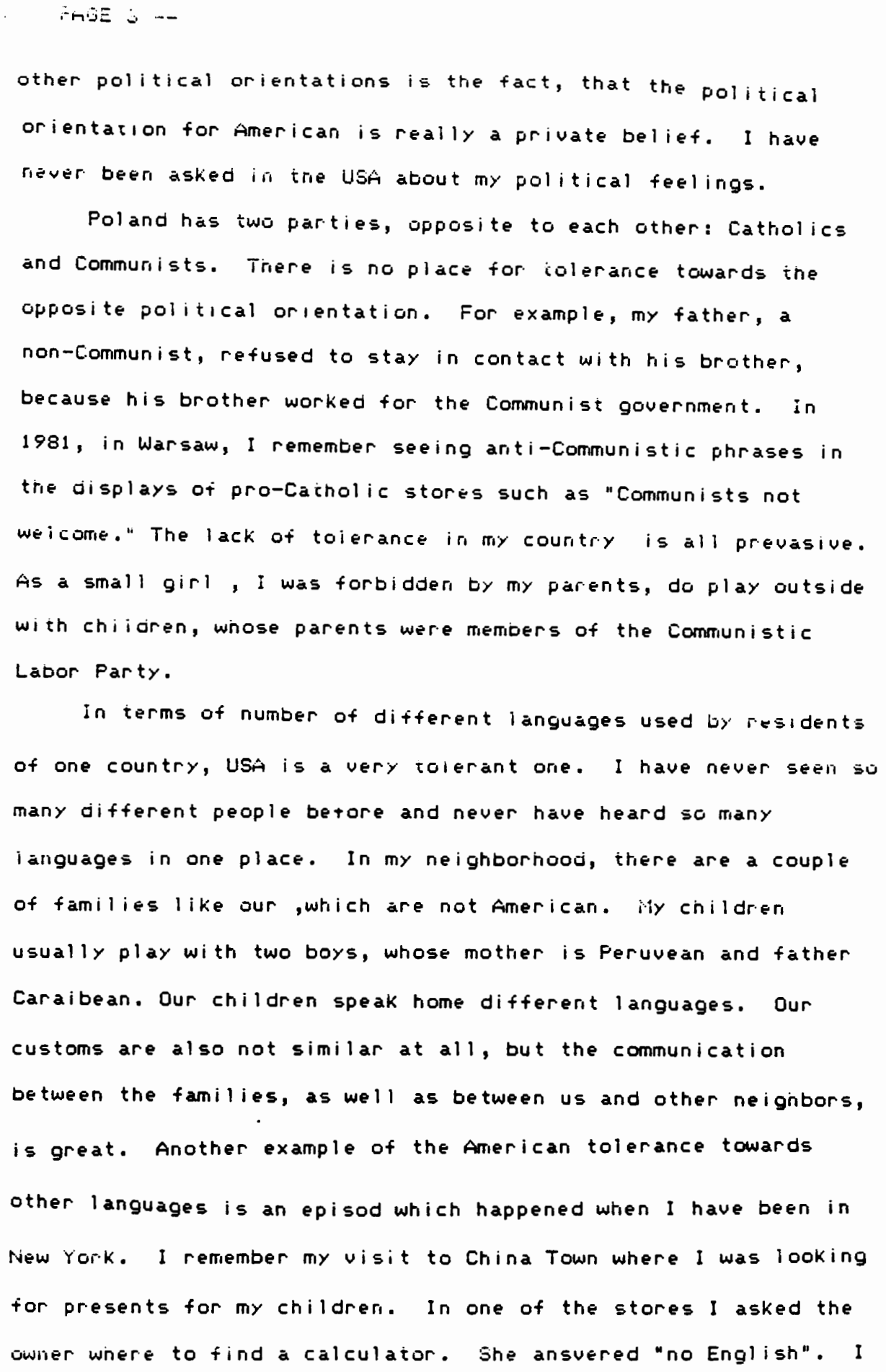




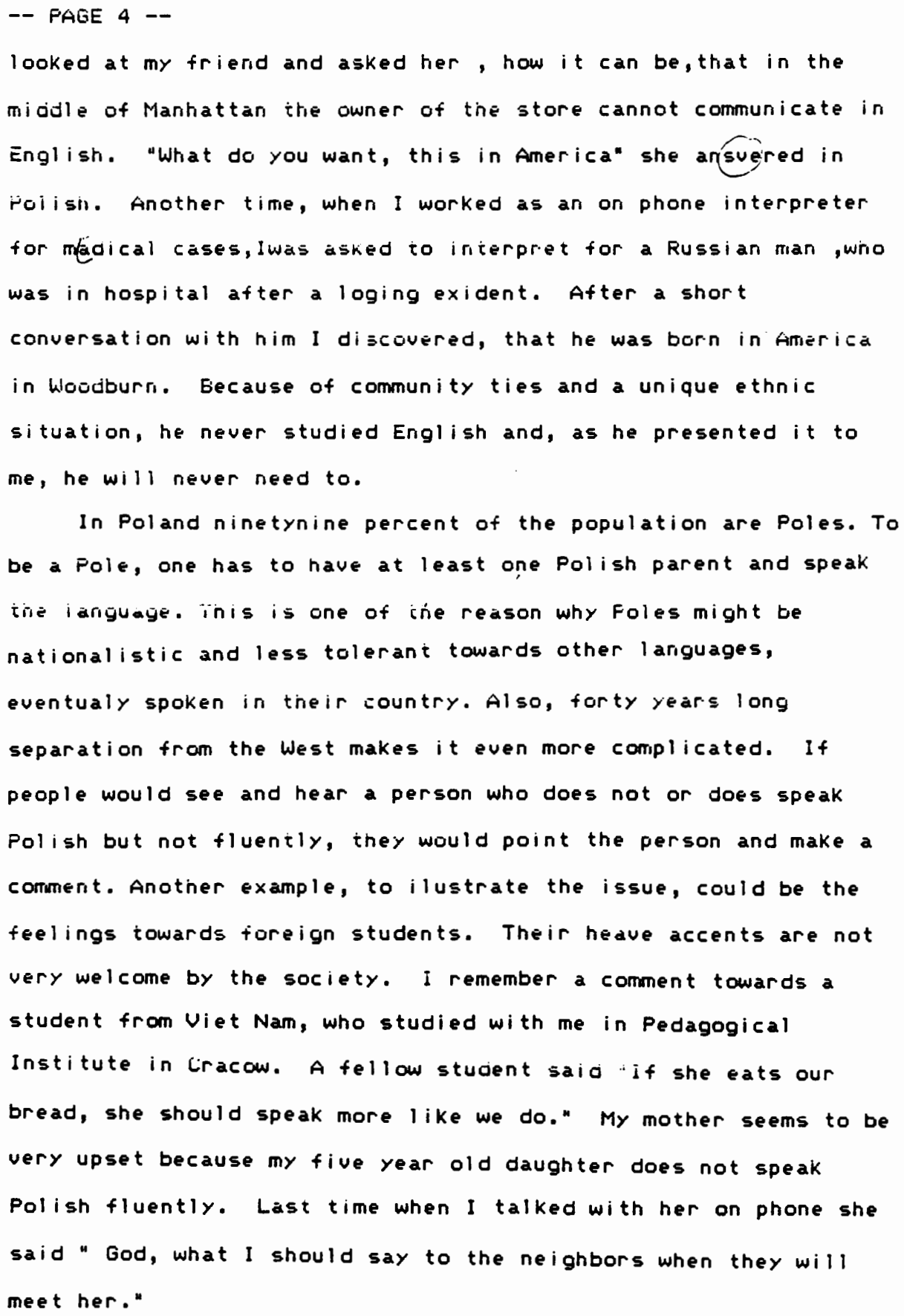


- fage 5 --

I really appreciate the diversity of the American culture, its tolerance towards different religions beliefs, political orientations and other languages. The culture can be very shocking for people coming from more traditional and conservative countries. It can be also very liberating and supportive for anyone seeking individual ism. 
APPENDIX F

FIRST LANGUAGE ESSAY 
178 baton (I hope it is enough, I didwet have imich turn

Moje powtorre spothanic 2 Brunowem Sdlulzem.

$7|23| 4$

Moje pierwsze spothanie 2 órczosciog Brunona Schulza, edy to bytam jeszize uczniem mej klasy saloty podstarsorvej "byto cstrowicie udave. feqo blepy cynamonowe" zachwycity nie bagactren jaylea i wies hieningh spojuentien na pols kos

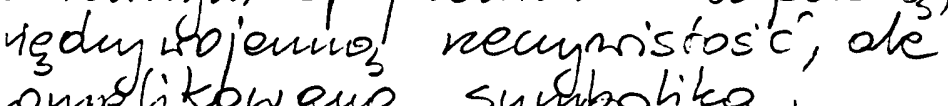
omplikbwana symbolika, istycyam , polrgburs'c kulfurowa hutza. ad tej z llo'rej wyrostam, Tyte wówcras rie w petrie mie.

Pang tygodni temu, po obejuevin

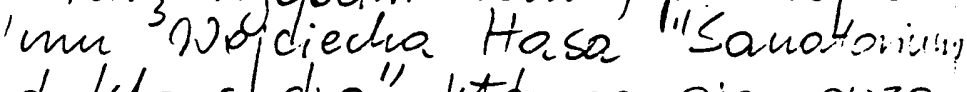
d Klepsijolios" Htórego pievirowzo$n$ by to mie coimegol a vutaśne utcowslea pwa lutam Swiadoma 30, jole boudio waino moie ic lig dla muie twórcrość teqo. inlia. Podobne do zagadleowep u reminiscencje 2 incio sellutia padty oTeboho'w moj paripc powodlowaty, ie rielobrotrie, horricie rieśriadonire moje uwag, 
179

-2-

noje skupierrie oddalato sip ool -adrajacej rumie newywistosici sowralcato do asoskich uliczele - ohobycra, jobby tam wTas'nie by To. rejsce mojego driecilistwa i resuej minodos'ci. Muiversalna nadciasara i ponadnanodowa intos'ć tworcuos'ci Bunara Scluiza navia, ip ten (zToriel, wydowato sig prowicionalny 1 zaqubiom moromiastecileonrs, ?'ycich / w swojej acy, codvierriych rapicisch, * arecie preclasta swoja epolug ym sa pisana arsioj móg by byćluwaric go bezsenisowina awangardoivego. 90 bezsensowna, tragichina sum wdiej, ie whar 2 jego oo'ejscien vicestuiona zostata niczapisana izcre cags'c ogollno'swiatorrej kultcing. Twóverośc schulra jest dla rnnie otwgm rydainiwien artysingereym: popnez falet ic pisar posiugicut ipryhiem polshim do opisavio. Hery wschoblinio - europejishich jow tym bardriej droga. the Eud.

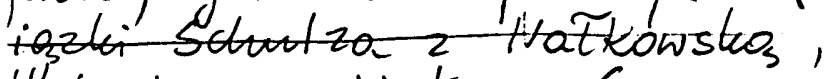
thiericiem, Watem,-Szumarien, 
APPENDIX G

CASE STUDY OF YOURSELF AS A WRITER 
CASE STUDY OF YOURSELF AS A WRITER: Adapted from John Trimbur

These questions will help you to do research on yourself as a writer. I recommend that you freewrite on each of the general issues listed below:

1. Moments: Recall important spots of time from past writing experience.

2. Stages: Intuitively divide your life as a writer into a few stages or periods; then ask yourself what characterizes each of those stages.

3. Kinds: What kinds of writing have you done in the past and what kinds of writing do you do now? Remember that there are more kinds of writing than you have done in school. Making lists is writing, and so is letterwritiing.

4. In-School vs. Out-of-School Writing: Do you go about both of these in the same way? Why or why not?

5. Audience: Who are the important people you have written for? (Not just teachers.) What effects have these different audiences had on your feelings? On your writing? Which audiences helped you most or held you back? (Don't forget "ghost" audiences or audiences we carry around in our head and unconsciouslu try to please--usually left over from experiences with past audiences.) Many people remember bad experiences more than good ones. If that's true of you, why?

6. Physical: Where do you write? When? How fast / slow? What are the effects of using pen / pencil /typewriter / word processor? How do you hold and move your body? Tell everything that could be figured out from a complete video recording of your writing from start to finish.

7. Process: Can you isolate specific ingredients in your writing process: that is, generating words and responses, revising, editing? Nonwriting counts too: sitting and thinking, talking to people. Which of these gives you the most trouble? Least? the most satisfaction? Least? Why?

8. Intervention: In what ways have others intervened in your writing: "Here, let me show you." "Do it this way." "You must start by making an outline." "You must staart by freewriting" and so forth. How has intervention affected your writing? 
9. Response and Feedback. What kinds of response and feedback have you gotten? From teachers, from peers? What effects did this feedback have on you? What do you do when you get different feedback on the same piece of writing?

10. Problems: Stuckpoints and breakthroughs. What's hardest for you or gets in the way most? How have you made or not made progress? Where have you made the greatest progress?

11. Myths: What are some of the feelings or ideas you've had about your writing (or that most people seem to have) that you now think are false? Where do these myths come from? What purpose did they serve? What effect have they had on your writing? What follows from tearing them down? 
183 (1).2) In high school first successful experiences in writing
in Polish. creative.

1984-86 - while in Germany siting letters in Polish, to my clove friends. Emotions. $1989-91$ - papers in Russian for my literature
clares. Semi-acodeunic, stiff.

last year and now - more free writing in English, papers for my taistony classes oud English, papers for my history classes and
letters to mun close friends (English, Polish).
Free, relaxed.

(3) always letter. Since 89 till present papers in Russian (stooped in, 1991) and English.

When I write papers a I feel motif, not flexible with Letters less (especially to close friends), if I write to my children I a stems it what I should be cheerful. so I ty y.

(4) In-school uniting is for more less-persomol, why? I an not sure Maybe I an less myself, still a stranger, alien, less canfortabk lest safe, feel often out eff place. Letters are more persona Iou more myself, more relaxed, more emotional.

Letters ore what I can call out-of-schod writing for me. Mo qraffitis yet.

(5) Teachers, people I hove, friends.

Teachers penalize me because Idonit want disappoint them. So some friends do. But mat close friends. Writing to them is a pleasure.

yes, I do remember bod experiences more that good once. Because I on so called soft conscious, cary get hunt. Had more bad than pood experiences (no support at lore. 
184

mon of my parents writes, except letters).

(6) I write on the table in the living room, I like it there, good light, comfortable. warm. Usually giwrite mid-slow.

Thine handwriting, hate computers etc, use pen I sit not to dore to the table so I can pithead mygnthand (which t is laying on my leg of $)$. As I am writing I move

the paper up only with my right hand Because I don't use help of ny left hand the paper usually dances on the tatoteri. but I am able to manage to write an The only problem is if the reader can read it. My writing process: start, think, write, think, write, reread, correct, write, stop, think, write, reread, change, correct stop Io a nay, start aga 'but mot from the beginning just continue! and so on to the end of the porticut whiting session.

(7) Not really. I just sit and write till the paper or letter is finished (sometime all might or obgenevilg + might). I write what ever I renrenber on subject, what I have been proceeded in my l brainbefore.ny shod papers are always first draft (risorytory grades too). I do the best on exams, fast answers No revising ed ting. I loose my interest" pretty fast lin writing. Sounds like I our "neurotic". 
185

$-2-$

(7) contra.

do the most trouble is rewriting, revision why? I get discouraged easy. Ruth, do I understand question no 7? or om I writing mon-sente?

8. Ore of my teacher likes every paper I do and I see my-relf improving. The Other contains always about my citation - sn item (that is awful). I never tole him ougain (hisses). Why? Because I freeze inside with "every redriarfy" his pen. Yes, I am a child somewhere insole I an, and meed 'wermith and acceptation No more Intervation. No peers in valved.

(9) If I get different feedback on the san piece, I get confused, and go after the negative are as the right ore. bet discouraged.

(10) How put my brilliant ideas on paper. I seem to be so intelligent when I think, and it comes on paper is such deformed way, so primitive, sometimes foul I hare read my witting' again afterfewd and hardly could understand what I mint (post tens of mean).

Ills about my progress : I do not care any more oct spelling (this in the pest created bloch in witting. 
APPENDIX H

ORIGINAL AND REPLICATED ESSAYS 
187

ORIGINAL THINK-ALOUD ESSAY

$6-2 / 90$ Samethimp unexperted that wepipenod
to me.

I thinge I maubl mite obact the very uneprecter siptuating. which heppeued to us oud me. in the enol of Mon.

Befare May wie Hdiol wat plave to po to Poloud the neason for mothori plous like thot inas it that

Pecause me wauted at first feel more confortoke ithphs and than erentuoly qotorisit our country. Also econower fimencial situation was ond is stressed so the plan to go to Polernol was posteponix. In the mibld le of Mhoy re pot a massage from Adams fenily that his father is sich ef concer and disided, over the nipht, Heat alom will go to polatd on first weet of youne, 19,90

at first ma casled to our friend Dho probalily, ere trapth so, Ecuows 
188

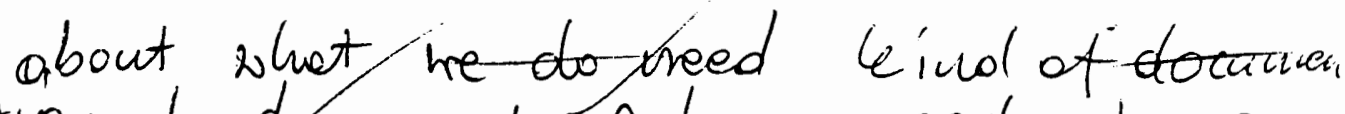
travel document Adam needs to po to Polopa!

- He called I Immigration our naturalization fer Services and got an information that me tread Allan meed apply petrel lar for a Refuge travel docuraneut.0.5 We dial not have mun time during this Another End af May

* was e rem bossy time for us. and the first dod Allow o could, apply tor the documantost Friday Jurel Iou this day Day before

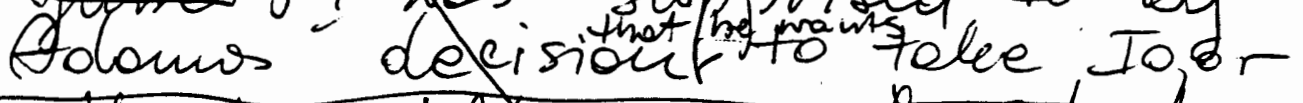
wash him. Also our final who was present of the ting we tailed thought about po ing with som him to France. Adown did not know if it will work for him.

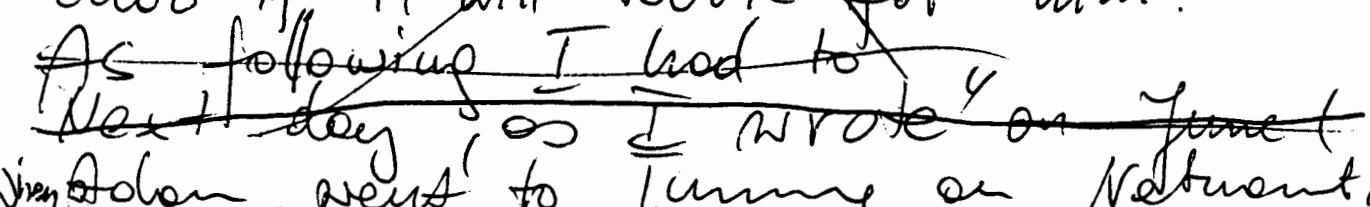

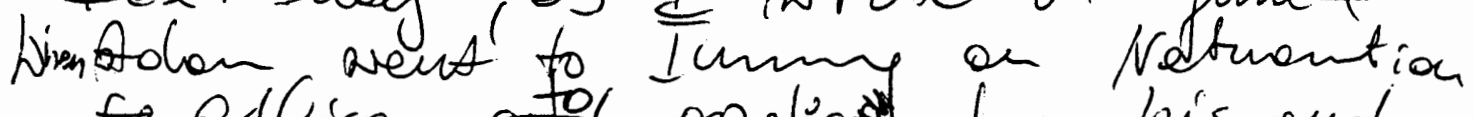
office to applied for his and 
189 The offiver there said that Aolan document. \# This facts complic ated our lifes rem" Instaed going hou, fodom hod to makp chompes in his pla Igor Defuqee tovel documents. On'Mondoy yune 4 I talked wi in Ipors teachen and sed that Ipor is coming be will be no quble to stout scliod in serptentirer 1990 becoure of the journey. The the situation was counplidated. I and the Teacizer we vere both. yey surprice bo the Adour decsion, but ofter short courversation" with ber are ageded thot

The feacher wo surprice by our obecision.tart fling so

Because of the whole situation my plous future in ctictione hone to hange Besside my financidai I. hrove to ficld andiond and orill support me and Apothe muno stays will me. It meansis that she pill inat goun har to Pots Portloud Waldorf scles l, kquare I hove to find less exponcive place for trer. 
190

(4)

Probably I nil too hare to rent fours loom to sourebady to be abl to fay mortgage.

Allan will study and 7 work full time dining coming sumner to ire can pay for ticleste to Europe. Id r trials and Spore

I alloy thouth that

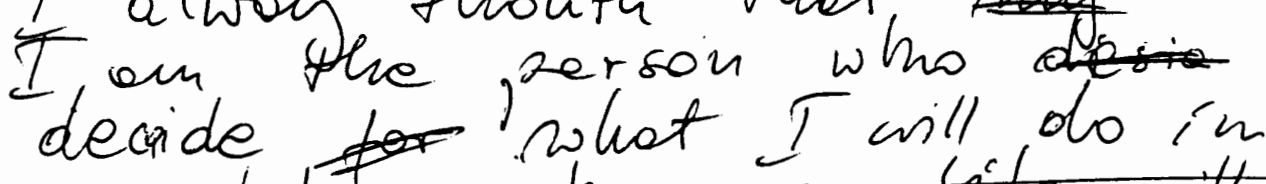
my life or how ray life will Riot olivection mon Al te will po, happened with our plows, for nest school year T plows before May I I changed my mine I changed mu attitutes towards the life. I think I con male my the hest oud this is all. 
REPLICATED THINK-ALOUD ESSAY: ENYA

Enya 6-7/90

Something unexpected that happened

to me.

I think I would write about the very

unepecter situaine . which heppened

to us and me. in the end of

May.

Before May, we th did not phone

to go to Poland,. the reason for not having

plans like that was it that

because we wanted at first feel

more confortabe i the $U \mathrm{~S}$ and then

eventualy go to visit our country. Also

our

the economical financial situation

was and is not stressed so the

plan to go to Poland was poseponed.

for maybe 10 years

In the middle of May we got a

message from Mareks family that

his father is sick of cancer

and dicided, to over the night,

that Marek will go to Poland on 
first week of June 1990

At first we called to our friend

who probably, we thougth so, knows

about what we do need kind of document

travel document Marek needs to go

to Poland.

- I Next We called Immigration

and Naturalization Of Cer Services

and got an information that

we need Marek need apply

for a Refugee travel document .

U.S.

We did not have much time during

olis this

And End of May

it was a very bussy time for

us and the first day Marek

for the document

could apply was last Friday

Friday

June 1. A on this day Day before

\section{Monday}

June I was surprised to by

that he wants

Mareks decision

to take Igor

with him.

Also our friend who

was present at the time we talked 
thought about in going with Marek

first to Poland and next take

him to France. Marek did not

know if it will work for him.

As following I had to

Next day, as I wrote on June 1

When

Marek went to Immig an Naturution

to

G Office and applied for his and

(The officer there said that we Marek

has to wait 90 days to get needed document. \#This fact complicated

our lifes very much.

Instead going now, Marek had to make de changes in his plans

Igor Refugee Travel documents.

On Monday, June 4 I talked with

Igors teacher and sed that

Igor is coming be will not be not

able to start school on $n$

September, 1990 because of the poseponed to Poland

journey

. The The situation was complicated. I

and the

teacher

we were both very surprice

by the Marek decision, but

after short conversation with her 
we agreed that

The teacher was surprice by the

our decision. but finally she

Because of the whole situation

of the

my plans and future will o change

have to change. Beside my financial aid

I have to find an additional job wich

will support me and Agathe who

mus also

stays with me. It means that

she will not go next year to

Pols Portland Waldorf school, and

because

I have to find less expensive

place for her.

Probably I will ho have to rent Mareks

room to somebody to be able to

pay morgage. Also I have to

Marek student status

Marek will study and I work full

time during coming summer so

we can pay for tickets to $y$

Europe. for himself and Igor

and

I alway thouth that my

I am the person who desio 
decide for what I will do in my life. or how my life will what direction my life will go.

Right now I am After what

happened with our plans, for next

school year and plans before May 1

I changed my mine

I changed my attitudes towards

the life. I think I can make my

the best and this is all. 
APPENDIX I

TRANSCRIPTION OF AUDIO PORTION OF THINK-ALOUD 
Something unexpected that happened to me.

Eh I think eh I would like eh write about about eh the very eh unexpected sittuation (inaudible)pected situation eh which happened to us eh and to me of course eh eh which happened (pause) to us and me in the mid- on the mid-no, on the in the end in the end of Ma- May. Eh, ya. In introduction maybe I write unh our feelings eh before eh that would happen. The story will be about eh going to Poland and eh before May eh before May we eh did not eh plan to go go to Poland. Em I think em the reason the re-reason for it - for the-- not for the reason for not having plans plans like that was un was it that No I think uh I should start different to write. So beforee May we did not plan to go to Poland because we em we wanted at first feel more comfortable in U.S. and then eventually go visit our country. Also the economic-- I-I was thinking about "material" but I think "economical economical" - no, the financial our financial situation our financial situation eh was (interruption)thank you-eh was and is not eh not may-- I also the our no we don't need (p.2) also our financial situation was and is stressed stressed so the plan to go to Poland Poland was postponed was post post postponed (inaudible). was then postponed eh yah was I already said- yah in the middle of in the middle middle of May we got a message we got a message from Adam's family that his that his that his father is sick of cancer and uh decided and dec- "c" cancer. I'm not sure is it "c" or "s" cancer and deci- decided -not "s", "c"decided and decided to over the night (end p.3) over the night. I was thinking to write "to go to Poland" but it was it was important to me to write "over the night" over the night that Adam will go to Poland 
Poland. -um- On first I think it was on first- on first week of Ju-June 1990 right now comma (inaudible) decided comma that Adam would go to Poland on first week of June, 1990. Now I'm thinking about starting new part. 3234 At first we eh call no "called" I have problem with past tense I never know what to write. At first we called to our friend who probably we we thought (end p.4) so we thought so knows about it (turns page) what what to do eh if you want go to Poland- what kind of documents we need. what kind of visa, what kind of passport, whatever-about what- what do we do need- what maybe what kind of documents what kind of documenttravel document travel- because "document" on its own doesn't make sense- "travel document" may Adam need needs- third peron, needs- needs to go to Poland. Yah. She wasn't home so we just called-eh- Im- Immigration and Na-tu-ral-iz-a-tion (syllabification) so so actually, take it out (turns back a page, crosses out). We at first, no-no- (turns back) next to we called Immigration and Na-tural -iz-a-tion (syllabification) Office (end p, 6) Ser-vi-ces (syllabification) and got -eh- infor-information (syllabification with L1 pronunciation), that we need- not "we" that Adam need apply apply for a refugee travel document travel document. Em. We did not have much time - time during this during this this- eh (crosses out) (inaudible) end-end of May. It was a very busy time-very bu-bubu time for us for us and the first day Adam could apply could c-o$\mathrm{u}$ - could apply (clears throat) was last Friday. Friday F-r- Friday JuJune first. Eh. On this day- No, I think was day before- Day before June first I was surprised surpri- surpree- surpree-zed (L1 pronunciation) surprised by Adam's Adam's dedi-deci-decision (end 
p. 7) decision d-e (L1 pronunciation) -um - to take Igor with him take Igor with him (3445). Also our friend, em, who was- was present- present- was with us was present at at the time we talked at the time t-i-m-time-"e" time at the time we we talked about about it talked talked talk-ed (L1 pronunciation)eh-talked talkedem- about invite- no he was (inaudible) he like talked about going going with Adam first to Poland first to Poland, and next taking him to France. Em. Adam did not know if it would work (inaudible) if it would w-o-r-work-k. As (a, or the) following following follow- two "l's" following-um- I (end p. 8) have to to-No (crosses out) Next dayas I wrote-as I wrote- wrote, On June first Adam went to Immigration and Naturalization Ser-ser- Office and applied applied for his and Igor's (begins new page) Igor's passports- Oh, no, norefugee refugee documents-travel documents- travel documents (inaudible) No, this is not capital " $s$ " travel documents- documents documents documents. (inaudible) On Monday- on Monday- eh- on Monday, June fourth- I-I will write that I went to the office of Igor's school and said that he not coming back next year for the for the first term- I mean for the September- in October, probably maybe November- to school. On Monday on June fourth I (end p. 9) talkedtalked with Igor's teacher- teacher and said and announced- said that Igor is not coming back-No, he's coming back- ( 3595) that Igor will not be able be able to start school on in - in September 19-in September, 1990 because the- because of the journey-jour- j-o-ur-n-e-y. Eh> The teacher was unhappy about it. No- that nyet (shakes head side to side) the situation was complic- the situation was complicated-plicated. I and the teacher-I and the teacher we were 
both both very surprised- very "surpreezed" (L1 pronunciation) by by the Adam's (long pause, ?thinking) in, um, (inaudible) by the Adam decision (3644) de-ci-sion (syllabification) (end p. 10) but em after short conversash--conver-sa-tzion (L1 pronunciation) with her we agreed a-g-e- agreed that- that--No, maybe we- I don't know how to finish this sentence. No. (rereads) "I and the teacher we were both very surprised by the Adam decision- No- (crosses out) I was surprised before the situation was complicated- the teacher was surprised (shifts subject 3 times) by the- by our decision- because actually, I decided too- by our but finally now finally (inaudible) finally-I don't (end p. 11) know how to finish this sentence. (rereads) ( 3695) The teacher was surprised by our decision but finally (crosses out) she wished (our, or us) the best- No, maybe we don't write "finally". I don't know how to finish this sentence. (Statement repeated 3X) The teacher was surprised at our decision (turns back - pages). I think I have to read it. (turns ahead) (3715) Igor's travel documents- Oh, I have to write here somewhere umThe officer there said that- say-says-says (L1 pronunciation)- nothat Adam has to wait wait ninety days to get needed document. This meant (3743) means this (end p. 12) This this fact -um- situation will be okay. This fact com-complicated our lives complicated our lives. Instead going now now Ada had to had to make decision- no, decisions (?Thinking, nods) decision has to (rereads) This fact complicate our lives. Instead of going now, comma Adam had to make change- changes in his plans (3780). (rereads) Igor-instead of Igor, okay. On Monday, June fourth I talked to Igor's teacher and said that Igor will not be able to start school in September because 
(end p.13) of the (3793) of the postponed journey the documents are not ready till (shrugs) September (Subject seems comfortable when starting sentence with time clause or adverbial) so (3800) he cannot- Adam had go now and everything just postponed (3805). The teacher was surprised at the decision. Before May we did not plan to go to Poland ( 03817$)$ because we wanted at first be more comfortable in U.S. in the U.S. (self correction) in the- and then eventually go to visit (3823) go to visit to visit our country. Also financial situation was and is stressed so (3830) in the-capitalize- in the middle of May we got a message 93834) from (end p. 14) Adam's family that his father is sick and decided over the night that Adam will go to Poland on first week of June, (3837) 1990. (turns page H. many? forward?) Next we call im- no- we call Immigration and Naturalization Service and got an information that Adam need apply for a (3844) refugee travel document before leaving (3846) leaving U.S. Without "leaving" doesn't make sense make sense. (3851) before leaving U.S. (3853) End of May, the May the end of May the- Yah- the end of May it was, without ?it was eh very busy time for us (3849). No, okay. And the first day Adam could apply (end p. 15) for (3865) the doc-for the documents was last Friday. Jine first. Day before, Monday. (3870) I was surprised by Adam decision that that he want (3877) he wants (self correction) to take Igor with him. Also, our friend who was present at the time talked talked -no- (3883) (shakes head side to side, crosses out, rereads) I was surprised by Adam's (self correction) decision to take (crosses out) Igor with him. (3887) Okay. When Adam went to Immigration and Naturalization Office and applied for- to apply (3895) to apply 
to apply ( 3 repetitions) without "ed" it's present (structure) for his em- (turns page) Igor's refugee travel (end p. 16) document the officer there said that Adam had to wait ninety days to get -the document. The fact complicated our lives very much. (3906) Instead going now Adam had make changes in his plans p-l-a-ns (3910). On Monday, June fourth I talked with Igor's teacher and said that Igor will not be able to start school in September (3919), 1990 because of the postponed journey. (inaudible) (crosses out, scratches face. shakes head side to side, turns pages back, 3928 forward) Because (3930) of the whole situation, my plans and future will change (3939) will change $\mathrm{c}-\mathrm{h}$ - change (end p. 17) (Point of view shifts to personal) c-h-a-n-g-e (3944) have to change the future have to change (rereads) my plan for future have to change (3951). I have to find a job (3954) which will support me which will support support me. No. Behind- No. What I want say is that I was going to be a student next year but the financial aid eventually if I go, it it will not eh be (3963) eh it will be not enough (changes correct to incorrect). Adam will be not here (incorrcect negation) so he cannot not help me and I have to find a job (3968). And beside beside b-e-s besid-- beside my financial (end p. 18) fi-nan-tsial (3972) I I have to find a job which will support me and Agathe (3075) who stays with me who stays--- It means means m (mmm)-ea means that she will not go next year to she will not go anymore she (3987) will not go anymore to Portland Waldorf School Po P-o Portland Waldorf (removes scarf from neck) Waldorf School (pulls scarf). (3997) Eh- I have to find find to find less expensive (4002) pensive sch-place for her for her (turns page) Probably (4010) I'm 
thinking about my house now because I will not be able to pay for it. Probably (thinks) probably (end p. 19) I will have to rent (4021) Adem's room room to somebody $(4024)$ to be able to be ahbleh (?L1 pronunciation) be able to pay rent to pay mortgage (4029) because it's not really mortgage mor gahge (?L1 pronunciation) mortgage (pause) also (4037) I have to-no (crosses out) I was writing about I want to write about eh some eh ideas I have for example cutting down my expenses like (4050) ( I observe several different kinds of thought processes, here: itemizing- do research)eh recycling things or I don't know using (4053) uh shower instead of bathtub but maybe this is not necessary. (4059) Student status I want write it because of fiunancial aid he he's supposed to start uh start em start em in September but maybe he will start in \{36 $\mathrm{min}$ \} summer so he can use Fall term for visiting Poland (4066) come back in the winter. Probably I will have to rent Adam's room to somebody to be able to pay mortgage. Adam will study and work full time (4077) during coming summer summer so he (4082) can pay for a -for flight for tickets, tickets to Europe (inaudible) pay for tickets to Europe for him-himself (4087) and Igor and study \{37 min.\} no (inaudible) (crosses out, long pause) (4095) (4097) I always alwsys thought that my life that I am the person the person who who decide (4107) (crosses out) decision decision decide (4111) decide what what I will do in my life (4118) or how \{38min\} my life will go will what direction what what direction DiRek-Tzion my life will go. Right now, now I am (4137) no maybe ... After what happened after what happened with our plans for next school year year plans before May 
\{39 min.\} After this date date (4150) what happened our plans for next year plans before May I changed my mind (4155). No, maybe (crosses out) I changed my my unh my unh attitude (4160) towards (scratches chin) the issue (4166) I mean the issue- who is the human life is not uh so simple I don't think sometimes (rereads). I changed my attitude towards the towards (4171) the life \{40 min\} life I think I can make my (inaudible) (turns back 3 pages, rereads) 
APPENDIX $\mathbf{J}$

TRANSCRIPTION OF FINAL PRODUCT 
THINK-ALOUD ESSAY: ENYA

Enya 6-7/90

Something unexpected that happened to me.

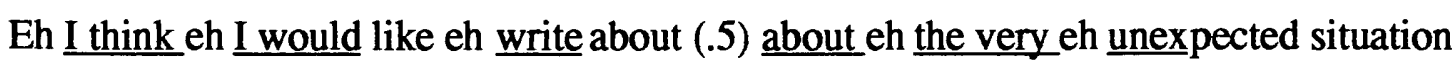
(inaudible) pected situation eh which happened to us eh and to me of course eh eh which happened (spelling) (.3) to us and me in the mid- on the mid- no, on the (.3)in the end in the end of Ma-May. $/ 1 \mathrm{~min} /$

Eh, ya. In introduction maybe I write unh our feelings eh before eh that would happen. The story will be about eh going to Poland and eh Before May eh before May we eh did not eh (.2) plan to go go to Poland.(.3) Em I think em the reason the re-reason for it - for the-- not for the reason for not having plans (.2) plans $/ 2 \mathrm{~min} /$

like that was un (.5) was it that (.3) No I think uh I should start different to write. So before May we did not plan to go to Poland because (p2) we em we wanted at first feel more comfortable (p2) in the U.S. and then eventually go visit our country Also (.2) economic-- I-I was thinking about "material" but I think "economical economical"/3 $\min /$

- no, the financial our financial situation our financial situation eh was (interruption)thank you-eh was and is not eh not maybe (.2) I also the our no we don't need also our financial situation was and is stressed stressed so the plan to go to Poland Poland was postponed was post post postponed (inaudible) $/ 4 \mathrm{~min} /$ 
was then postponed eh yah was I already said- yah in the middle of in the middle middle of May we got a message we got we got a message from Marek's family that his that his that his father is sick of cancer and uh decided and dec- "c" cancer. I'm not sure is it "c" or "s" cancer/5 min/

and deci- decided -not "s," "c"- decided and decided to (.2) over the night over the night. I was thinking to write "to go to Poland" but it was it was important to me to write "over the night" over the night that Marek will go to Poland Poland. -um- on first I think it was on first- on first week of Ju-June on first week of June, 1990 right now 16 min./

And what next? (rereads) Before May we did not plan to go to Poland because we wanted at first feel more comfortable in U.S. and then eventually go visit our country. Also our financial situation was and is stressed so the plan to go to Poland was postponed. I don't know how to write postponed. (changes third letter to "s") In the middle of May- May- capital (changes " $\mathrm{m}$ " to "M")we got a message from Marek's family that his father is sick of cancer and decided over the night (inserts comma)(inaudible) decided (inserts comma)comma that Marek would go to Poland on first week of June, 1990. Now I'm thinking about starting new part. 3234 At first we eh call no "called"/7 min/

I have problem with past tense I never know what to write. At first we called to our friend who probably we we thought so we thought so knows about it (.3) (turns page) what what to do eh if you want go to Poland- what kind of documents we need. what 
kind of visa, what kind of passport, whatever- about what- what do we do need- what maybe what kind of documents what kind of document-travel document travel-/8 min/

because "document" on its own doesn't make sense- "travel document" may Marek need needs- third peron, needs- needs to go to Poland.(.4) Yah. She wasn't home so we just called-eh- Im- Immigration and Naturalization so so actually, take it out (turns back a page, crosses out). We at first, no-no- (turns forward) next to We called (.3) Immigration $/ 9 \mathrm{~min} /$

and Na-tu-ral-ization Office Ser-vi-ces (syllabification) and got -an-infor-information that we need- not "we" that Marek need apply apply for a refugee travel document travel document. $(.5) / 10 \mathrm{~min} /$

Em. We did not have much time - time during this during this this- eh (crosses out) (inaudible) And End of May it was a very busy time-very bu-bu-b- busy time for us for us and the first day Marek could apply could c-o-u- $/ 11 \mathrm{~min} /$

could apply (clears throat) was last Friday. (.2) Friday F-r- Friday Ju- $\underline{\text { June first (.4) }}$ Eh (.2) June first. On this day-on this day No, I think was day before- Day before day before Friday ("Friday" inserted above) June first (.3) I was surprised surpri- surpreesurpree-zed surprised to $/ 12 \mathrm{~min} /$ No-by Marek's Marek's deci-deci-decision decision d-e (.4) -um - to take Igor with him (.2) take Igor with him (3445). Also our friend (.3) em (.4) who was- was presentpresent- was with us was present at the time we talked at the time $t-i-m-t i m e-" e "$ time $/ 13 \mathrm{~min} /$ 
at the time we we talked talk about it talked talked talk-ed eh- talked talked-emabout invite- no he was (inaudible) he like thought about going going with Marek first to Poland first to Poland, and next taking him to France.(p4) Em. Marek did not know if it will work (inaudible) if it will w-o-r- work-k (p3) for him. As (a, or the) following/14 $\mathrm{min} /$

following follow- two "l's" following-um- I have to to-No (crosses out "As following I had to" ") Next day-as I wrote-as I wrote- wrote (.3) On June first Marek went to Immigration and Naturalization Ser-ser- Office and applied applied for his and Igor's $115 \mathrm{~min} /$

(begins new page) Igor passports- Oh, no, no- (crosses out " $\mathrm{p}$ " for passport) refugee Refugee documents-travel documents- travel documents (inaudible) No, this is not capital "s" travel documents- documents documents documents. (inaudible) On Monday- on Monday- eh- On Monday, on June fourth I(.3) I will write that I went to the office of Igor's school and said that he not coming back next year for the for the first term/16 $\mathrm{min} /$

- I mean for the September- in October, probably maybe November- to school. On Monday on June fourth I talked- talked with Igor's teacher- teacher and said and announced-(word choice) and said that Igor is not coming back-No, he's coming back- ( 3595) that Igor will be not able be not able to start school on- in - in (crosses out "on," writes "in") September 19-- in September, 1990/17 min/ 
because the- because because of the journey- jour- j-o-u-r-n-e-y. Eh. The teacher was unhappy about it. No- that nyet (shakes head side to side) the situation was complicthe situation (.2) was complicated- plicated. I and the teacher-I and the teacher we were both both very surprised- very "surpreezed" ( $L_{1}$ pronunciation) by by the Marek $/ 18 \mathrm{~min} /$

(.4) in, um, (inaudible) by the Marek decision (3644) de-ci-sion (syllabification) but em after short conversash--conver-sa-tzion ( $\mathrm{L}_{1}$ pronunciation) with her(.3) we agreed a-g-e- agreed that (.2) that (.2)-No, maybe we- I don't know how to finish this sentence. No. (rereads) "I and the teacher we were both very surprised by the Marek decision/19 min/

No- (crosses out) I was surprised before the situation was complicated- the teacher was surprised (shifts subject) by the- by our decision- because actually, I decided too- by our but finally (.3) now finally (inaudible) finally (.4) I don't know how to finish this sentence. (rereads) ( 3695 ) The teacher was surprised by our decision but finally (crosses out) she wished our the best- No, maybe we don't write "finally"/20 $\min /$

(crosses out "but finally she") I don't know how to finish this sentence. (Statement repeated 3X) The teacher was surprised at our decision (turns back to page1). I think I have to read it (.7) (turns ahead) (3715) Igor's refugee travel documents- Oh, I have to write here somewhere um- The officer (.2) there said that- said- said -s-i-e-d (pronunciation)-that we no- that Marek has to wait $/ 21 \mathrm{~min} /$ 
wait ninety days to get needed document (.3). This this meant (3743) means this (.4) This this fact-um- situation will be okay. This fact this fact com-complicated our lives com-pli-cated our lives(.2). Instead going now now $22 \mathrm{~min} /$

Marek had to had to make (.3) decision- no, decisions (nods) decision (.3) has to (rereads) This fact complicated our lives. Instead of going now, comma Marek had to make change- changes in his plans (.3)(3780). (rereads) Igor- instead of Igor, okay. On Monday, June fourth I talked to Igor's teacher and said that Igor will not be able to start $/ 23 \mathrm{~min} /$

school in September because of the (3793) of the postponed journey the documents are not ready till (shrugs) September (Subject seems comfortable when starting sentence with time clause or adverbial) so (3800) he cannot- Marek had go now and everything just postponed (.3)(3805). The teacher was surprised by our decision. (turns back to page 1) (rereads) Before May we did not plan to go to Poland (3817) because we wanted at first be more comfortable in U.S. in the U.S. (self correction) in the U.- and then eventually go to visit (3823) go to visit to visit our country. Also financial situation our financial situation was and is stressed so (3830) the plan to go to Poland was postponed. In the -in the- capitalize- (capitalizes May) in the middle of May we got a message from Marek's family that his father is sick of cancer and decided over the night that Marek will go to Poland on first week of June, (3837) 1990. (turns ahead to page 2) Next we call im- no- we call Immigration and Naturalization Service and got an information that Marek need apply for a (3844) refugee travel document before leaving (adds "before leaving") (3846) leaving U.S. 
Without "leaving" doesn't make sense make sense. (3851) before leaving U.S. (3853) End of May, (p2)(crosses out And, inserts The) the May the end of May the- Yah- the end of May it was, without it was $\mathrm{eh} / 25 \mathrm{~min} /$

very busy time for us (p2). No, okay. And the first day Marek could apply for (3865) the doc- for the documents was last Friday, June first. Day before, Monday, (.2) I was surprised by Marek decision that that he wants(3877) he wants to take Igor with him. Also, our friend who was present at the time talked talked -no- (3883) (shakes head side to side, crosses out from "Also...for him"./26 min/

(rereads) I was surprised by Marek's (self correction) decision to take (crosses out) Igor with him. (3887) Okay.(.5) When (adds "when" to combine sentences) when Marek went to Immigration and Naturalization Office and applied for- to apply (3895) to apply to apply (3 repetitions) without "ed" it's present (structure) for his -em- (turns page) Igor's refugee travel document the officer there said that Marek has to wait ninety days to get needed document. The (misreads) fact complicated our lives very much-very much-yeh. (3906) Instead going now Marek had (misreads by omitting "to") make changes changes in his plans p-1-a-ns $/ 27 \mathrm{~min} /$

On Monday, June fourth I talked with Igor's teacher and said that Igor will not be able to start school in September (3919), 1990 because of the postponed journey. (reads "The teacher was...) (crosses out"postponed" and "to Poland") scratches face, shakes head side to side, turns pages back, forward, resumes writing) Because (3930) of the whole situation(.3) my plans and future will change (3939) will change c-h-change / $28 \mathrm{~min} /$ 
(Point of view shifts to personal) c-h-a-n-g-e (3944) have to change the future have to change (rereads) my plan for future have to change (3951). I have to find a job (3954) which will support me which will support support me. No. Behind- No. What I want say is that I was going to be a student next year but the fin- financial aid eventually if I get it it it will not eh (.3)be (3963) eh it will be not enough (changes correct to incorrect). Marek will be not here (incorrcect negation) so he cannot not help me and I have to find a job (3968). And beside Beside(changes_"Bi- to "Be-")/29 min/

b-e-besid-- beside my financial fi-nan-cial (syll) aid I I have to find an additional job which will support me and Agathe (3075) who stays with me who stays with me me. It means means $\mathrm{m}(\mathrm{mmm})$-e-a means that she will not go next year to she will not go anymore she (3987) will not go anymore to Portland Waldorf School Po P-o Portland $/ 30 \mathrm{~min} /$

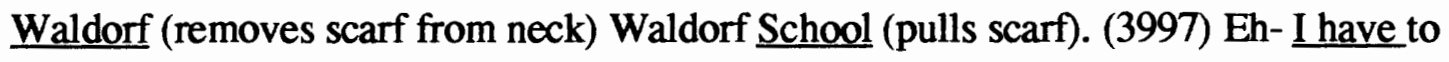
find find to find less expensive (4002) -pensive sch- (word choice)place for her for her (turns page)(p5) Probably I'm thinking about my house now because I will be not able to pay for it. Probably (.5) probably I will have to rent (4021) Marek's room $/ 31 \mathrm{~min} /$

room to somebody (4024) to be able to be able (syll.) be able to pay rent to pay mortgage (4029) because it's not really mortgage mortgage (syll) mortgage (.2) Also (4037) I have to-(.3)no (crosses out "Also...status") I was writing about I want to write about eh some eh ideas I had about for example cutting down my expenses like (4050) 
( I observe several different kinds of thought processes, here: itemizing- do research) eh recycling things $/ 32 \mathrm{~min} /$

or I don't know using (4053) uh shower instead of bathtub but maybe this is not necessary. (4059) Marek's student status sudent status I want write it because of fiunancial aid he he's supposed to start uh start em start em in September but maybe he will start in summer so he can use Fall term for visiting Poland (4066) come back in the winter. Probably I will have to rent Marek's room to somebody to be able to pay mortgage. Marek will study and ("I" is in text but not video) work full time/33 min/

(4077)and work full time during coming summer summer so he (4082) can pay for a -for flight for tickets, tickets to Europe (spells Europe)) pay for tickets to Europe for him-himself (4087) and Igor (.2)and Igor and study (.3) no (inaudible) (crosses out "for himself and Igor",p6) (4097) I always /34 min/

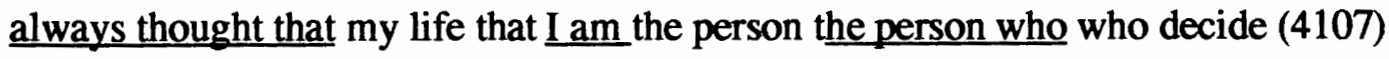
(crosses out d-e-s-i-e) decision decision decide (4111) decide what for -for decide what I will do in my life (4118) or how my life will go will what direction what what direction di-rec-tion_(syll) my life will go. $/ 35 \mathrm{~min} /$

Right now, now I am (4137) no maybe ... $\underline{\text { After that what happened after what }}$ happened with our plans for next schol year year (adds "and") plans before May, After this date date (4150) what happened with our plans for next year plans before May I changed my $\mathrm{mind} / 36 \mathrm{~min} /(4155)$. 
No, maybe (crosses out"I changed my mine") I changed my my unh my unh attitude (.2) (4160) towards (.3)(scratches chin) the issue (4166) I mean the issue- who is - the human life is not uh so simple I don't think sometimes (rereads). I changed my attitude towards the (.3) towards (4171) the (.3) towards the life (.2) life. I think I can make my the best and this is all. (turns back to page 1) $/ 37 \mathrm{~min} /$

(rereads) Before 4186 May before May we did not plan to go to Poland. 4190 because we wanted at first feel more comfortable in the U.S. and then eventually go 4195 to visit our country. Also our financial situation was and is stresssed so the plan to go to Poland was postponed 4198 for (adds "for maybe ten years ")for maybe ten years 4202 (rereads "ten years"). In the middle of May we got a message from Marek's family that his father is sick of cancer $/ 38 \mathrm{~min} /$

can-c-cer (spell change from " $s$ " to " $c$ ")and decided over the night that Marek will go to Poland on 4209 first week of June, 1990. (turns page) 4211 We called Immigration and Naturalization Service and got an information that Marek need apply 4213 for a refugee tra- eh travel document 4214 (adds "before leaving")before leaving U.S. 4215 (adds "The")The end of May was a very busy time for us 4217 and the first day Marek could apply (adds "for the documents") for the documents 4219 document was last Friday, June 1st. Day before, Monday-no- 4223 day before Friday,(crosses out "Monday")day before Friday (.6) I was surprised (crosses out "to" writes "by") by Marek's decision (adds "that he wants") that he wants to take Igor $/ 39 \mathrm{~min} /$

with him 4230. Next day-but I agreed- Yeh next day as I wrote (.2) when- no- next day- no (crosses out "Next day as I wrote on June 1")4233. When Marek - is enough. 
(adds "When") When Marek went to Immigration and Naturalization Office (crosses out "and" adds "to") to apply for his (turns page forward) and Igor's refugee travel documents the officer there 4237 said that Marek has to wait 90 days to get needed documents. This fact complicated our lives very much. 4240 Instead going now Marek had to take to make-to make (crosses out "de") changes in in his plans. On Monday, June 4th I talked with Igor's teacher and said that Igor will be not be able (Syntax) able- $140 \mathrm{~min} /$

will be not able to start school in September because of the journey 4249 to Poland to Poland or the postponed journey to Poland because maybe Poland is not needed. 4252 No.(crosses out "to Poland")Because of the whole situation my plans and future have to change (deletes "and") $4256 \mathrm{my}$ plans of the future/ $41 \mathrm{~min} /$

of the future have to ch- ( deletes "will change" writes "have to change")have to have to change. Beside my financial aid 4258 I have to find a job which will support me- an additional (syllable ) because I have already two jobs 4264 an additional job which will support me and Agathe who stays with me. in U.S. (deletes "in U.S.) /42 min./

(nod indicates No)4267 It means that she will not- for Agathe 4271- no- It means alals it means also that Agathe will not go (syntax)anymore to Portland Waldorf School and I have to and I have to find less expensive 278 because because because (deletes "and" writes "because") I have to find less expensive place for her 4282 (tums page forward) Probably I will have to rent Marek's room to somebody to be able to pay mortgage. Marek will study and (text "I" precedes "work", on video "I" is omitted) work full time Marek-during coming summer so he can pay for tickets to Europe 4285 
for him- no- for himself- to Europe. (deletes "for himself and Igor and") I always thought that I am the person who decide what I will do in my life 4290 or what decision of- of decision-or (.3) yeh maybe (crosses out "or how my life") After that (adds "that") what happened with our plans 4298 for next school year plans before May I (deleted "I changed mine")changed my attitudes towards the life./43 min/

I think - yeh- I think I can make my the best under this all... I finish Ruth./35 sec/ 


\section{APPENDIX K}

INTERVIEW QUESTIONS: MAREK 
Interview Questions: Marek : May 6, 1992

1. What was your first experience with formal education?

2. How were you taught to read and write?

3. How was public education structured? Was it influenced by the Church in any way? By Communism?

4. In the U.S. we have preschools, elementary schools, middle schools, high schools, community colleges and four year colleges. In Poland how were different grade levels separated into different schools?

5. Were standards, grades and curriculum determined by the national or local governments?

6. Were there standardized tests? If so, when.

7. Was there "tracking" into vocational or university-bound careers?

If so, when and how?

8. What was a typical composition class like in Poland? How did the teacher relate to the students? What was expected of the students?

9. What are the differences in rhetorical form between a U.S. university essay and an essay in an academic Polish class?

10. At what age did you begin to study a second language in Poland? What was it? How was it taught? How many years did you study it?

11. What was the third language you learned? Where, when, and how did you learn it?

12. How does knowing a second language influence learning additional languages?

13. Do you agree or disagree: Poland hates centralized power and prizes personal freedom. How does this statement apply to you?

14. What are the advantages and disadvantages of being a multilingual person in the U.S.? 